DOE/GO/10283-1

Field Demonstration of a $24-\mathrm{kV}$ Superconducting Cable at Detroit Edison

Final Report for the Period July 1998 - December 2003

December 2004

Nathan Kelley

Pietro Corsaro

Pirelli Power Cables \& System USA LLC

Lexington, South Carolina 29072

UNLIMITED ANNOUNCEMENT

Distribution A - Approved for public release; further dissemination unlimited 


\section{Field Demonstration of a 24-kV Superconducting Cable at Detroit Edison}

Final Report for the Period July 1998 - December 2003

Date Issued/Published December 2004

Nathan Kelley

Pietro Corsaro

PREPARED FOR THE UNITED STATES DEPARTMENT OF ENERGY OFFICE OF ENERGY EFFIECENCE AND RENEW ENERGY

Work Performed Under Contract No. DE-FC36-98GO10283 


\section{FULL LEGAL DISCLAIMER}

THIS REPORT WAS PREPARED AS AN ACCOUNT OF WORK SPONSORED BY AN AGENCY OF THE UNITED STATES GOVERNMENT. NEITHER THE UNITED STATES GOVERNMENT NOR ANY AGENCY THEREOF, NOR ANY EMPLOYEES, NOR ANY OF THEIR CONTRACTORS, SUBCONTRACTORS OR THEIR EMPLOYEES, MAKES ANY WARRANTY, EXPRESS OR IMPLIED, OR ASSUMES ANY LEGAL LIABILITY OR RESPONSIBILITY FOR THE ACCURACY, COMPLETENESS, OR ANY THIRD PARTY'S USE OR THE RESULTS OF SUCH USE OF ANY INFORMATION, APPARATUS, PRODUCT, OR PROCESS DISCLOSED, OR REPRESENTS THAT ITS USE WOULD NOT INFRINGE PRIVATELY OWNED RIGHTS. REFERENCE HEREIN TO ANY SPECIFIC COMMERCIAL PRODUCT, PROCESS, OR SERVICE BY TRADE NAME, TRADEMARK, MANUFACTURER, OR OTHERWISE, DOES NOT NECESSARILY CONSTITUTE OR IMPLY ITS ENDORSEMENT, RECOMMENDATION, OR FAVORING BY THE UNITED STATES GOVERNMENT OR ANY AGENCY THEREOF OR ITS CONTRACTORS OR SUBCONTRACTORS. THE VIEWS AND OPINIONS OF AUTHORS EXPRESSED HEREIN DO NOT NECESSARILY STATE OR REFLECT THOSE OF THE UNITED STATES GOVERNMENT OR ANY AGENCY THEREOF.

\section{AVAILABILITY STATEMENTS FOR UNCLASSIFIED, UNLIMITED STI PRODUCTS}

National Technical Information Services (NTIS):

Available for sale to the public from---

U.S. Department of Commerce

National Technical Information Service

5285 Port Royal Road

Springfield, VA 22161

Telephone: 800-553-6847

Facsimile: 703-605-6900

E-mail: orders@ntis.fedworld.gov

Online ordering: http://www.ntis.gov/ordering.htm

OSTI:

Available for a processing fee to U.S. Department of Energy and its contractors, in paper from---

U.S. Department of Energy

Office of Scientific and Technical Information

P.O. Box 62

Oak Ridge, TN 37831-0062

Telephone: (865) 576-8401

Facsimile: (865) 576-5728

E-mail: reports@adonis.osti.gov 



\section{ABSTRACT}

Customer acceptance of high temperature superconducting (HTS) cable technology requires a substantial field demonstration illustrating both the system's technical capabilities and its suitability for installation and operation within the utility environment. In this project, the world's first underground installation of an HTS cable using existing ductwork, a 120 meter demonstration cable circuit was designed and installed between the $24 \mathrm{kV}$ bus distribution bus and a $120 \mathrm{kV}-24 \mathrm{kV}$ transformer at Detroit Edison's Frisbie substation. The system incorporated cables, accessories, a refrigeration system, and control instrumentation. Although the system was never put in operation because of problems with leaks in the cryostat, the project significantly advanced the state-of-the-art in the design and implementation of Warm Dielectric cable systems in substation applications. Lesson learned in this project are already being incorporated in several ongoing demonstration projects. 


\section{PRODUCT DESCRIPTION}

Following up the successful testing of a complete 50 m, $115 \mathrm{kV}$ High Temperature Superconducting (HTS) power cable system prototype, EPRI, Pirelli Power Cables and Systems, the Department of Energy, Detroit Edison, and American Superconductor Corporation undertook a project to design, install, and operate a $24 \mathrm{kV}$ HTS power cable at Detroit Edison's Frisbie substation to serve customer load. The demonstration cable circuit ran approximately $120 \mathrm{~m}$ between the $24 \mathrm{kV}$ bus distribution bus and a $120 \mathrm{kV}-24 \mathrm{kV}$ transformer. Because of problems with leaks, the cable system was never put in continuous operation, but the lessons learned during this ambitious project significantly advanced understanding of critical technical and managerial issues and will directly impact future development efforts, some of which are already underway. This report summarizes all activities and lessons learned from this demonstration program from its inception in 1998 to December 2003.

\section{Results \& Findings}

As designed, the demonstration system incorporated cables, accessories, a refrigeration system, and control instrumentation. In the course of the project:

- 29, 000 meters of high strength superconducting tape were manufactured and tested. The mechanical characteristics of the balloon-proof tape withstood the rigors of cable manufacturing and installation. Robust tape enables optimized cable conductor designs and tight cable bending radii and is vital to practical application of HTS power cables.

- A process was developed and demonstrated for the manufacture of long-length Warm Dielectric (WD) HTS power cables. The long conductor assembly demonstrated the fabrication techniques that could eventually be used for manufacturing of commercial lengths of cable. Factory tests to applicable cable standards confirmed that the dielectric insulation had been properly extruded and that the underlying layers had kept their integrity.

- Pre-molded accessories were designed, tested and installed for WD HTS cables. One of the lessons learned in this project was that vacuum bushings are not adequately robust to enable commercial use in a WD cable design.

- A fully engineered refrigeration system was designed, fabricated, and commissioned.

- The cable and associated systems were installed, as much as possible, using personnel from Detroit Edison. The cable was installed into a rigorous route, in a pre-existing underground concrete duct bank including multiple very tight bends. 


\section{Challenges \& Objectives}

This project undertook the world's first underground installation of an HTS using existing ductwork. The objective was to make the system nearly transparent to the user, so that the evaluation could focus on proving the total system's reliability, maintainability, and operability in the crowded environment of an operating utility substation.

\section{Applications, Values \& Use}

The demonstration requirements represent very closely the performance characteristics anticipated for future cable retrofit upgrade applications, and its lessons are already being applied in other on-going projects.

\section{EPRI Perspective}

EPRI has been actively involved in the application of HTS technology to utility applications since shortly after the discovery of high temperature superconductivity in the late 1980s (EPRI reports TR-103631, TR-110891, TR-110892, and 1000160). High capacity superconducting cables can transmit two to five times more power through existing rights of way. Wires made of HTS materials have potential for use in underground transmission and distribution cables, large generators, transformers, and current limiters. In addition, end-use applications will employ powerful electric motors and power conditioning equipment involving superconducting magnetic energy storage. One especially attractive application for superconducting cables will be high power distribution. Today, to increase the power supply to an urban area, utilities have to install transmission level voltage cables and utilize transformers at new substations. Because superconducting cable will be able to transmit the same amount of power at distribution level voltages, it has the potential to eliminate the need for new substations.

\section{Approach}

The project was structured in two phases. In the first phase, the project team designed and manufactured a complete $24 \mathrm{kV} / 100$ MVA cable system including cables, accessories, refrigerator, and monitoring equipment and prepared the Frisbie substation site for installation. This phase built heavily on the experience and techniques developed during the earlier $50 \mathrm{~m}$ prototype project (EPRI report 1000160). In the second phase, the team undertook commissioning tests to verify the installation and establish a baseline for system behavior. In preparation for commissioning the system, the team conducted vacuum leak testing and discovered leaks in each of the three phases of the cryostat. After further testing, the decision was made that none of the three phases were stable enough to be energized. The team removed phases with the largest leaks and analyzed them to determine the cause of the leakage. The remaining phase was subjected to AC Loss Testing before restoring the Frisbie site to its original condition.

\section{Keywords}

Superconducting Cables

Electric Cables

Warm dielectric (WD) cable

High Temperature Superconductors

Substations

Underground Transmission Systems 


\section{CONTENTS}

1 INTRODUCTION

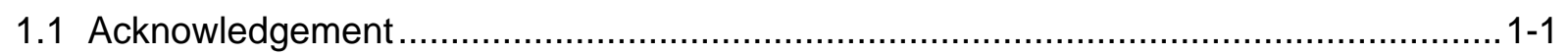

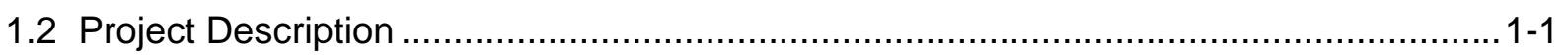

1.3 Project Partners and Activities ...........................................................................

2 SYSTEM DESIGN AND MANUFACTURE

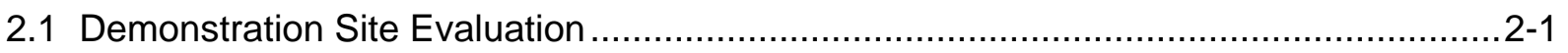

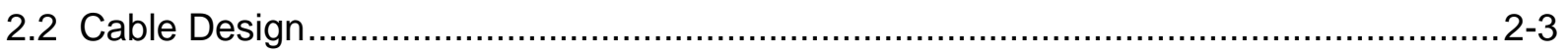

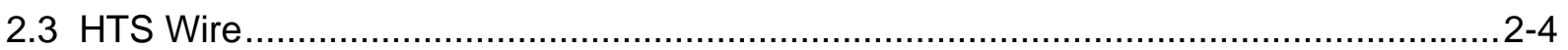

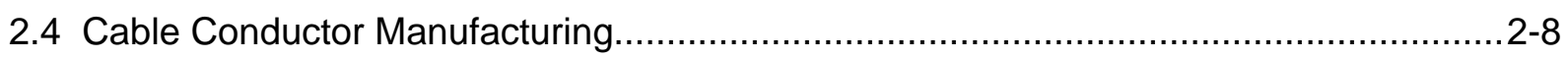

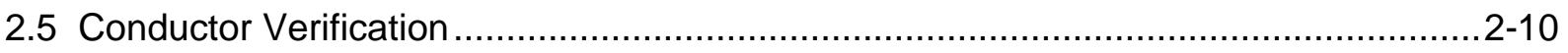

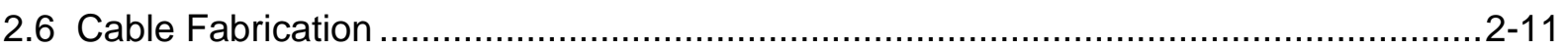

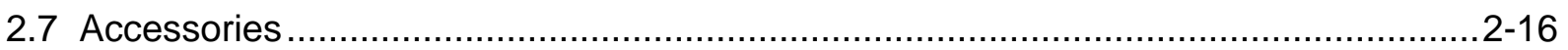

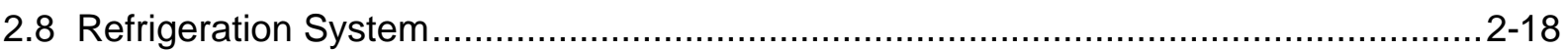

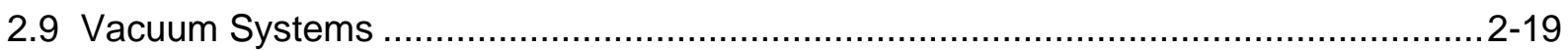

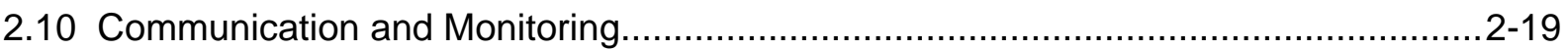

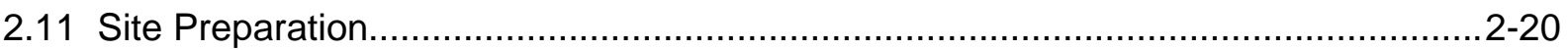

3 INSTALLATION

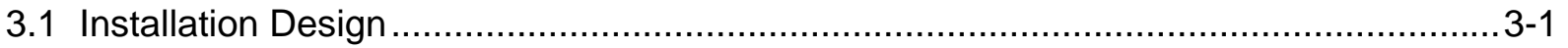

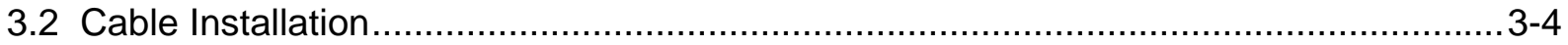

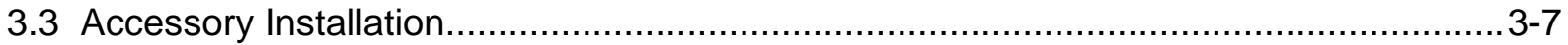

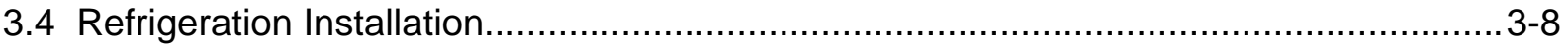

4 VACUUM LEAK DETECTION AND LOCATION

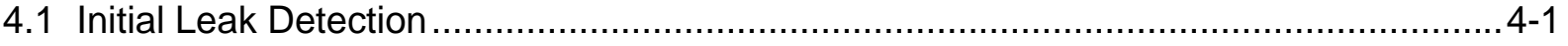

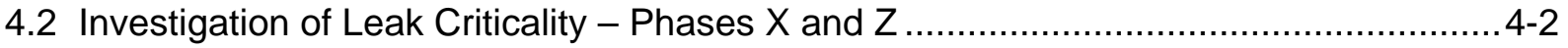

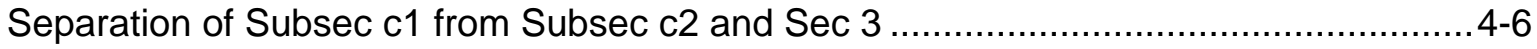

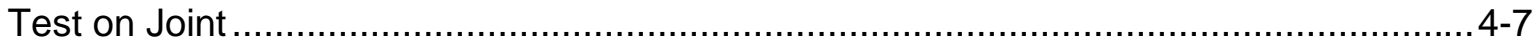




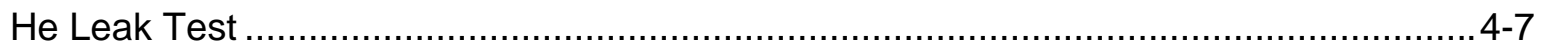

Pressure Rise in the Cryostat Gap Without Active Pumping ..................................... 4-8

Pressure Rise in Cryostat Gap with Active Pumping on Type D Test Chamber .............4-8

Nitrogen Flight Time in Cryostat Gap With LN Channel Pressurized at 4.6bar ..............4-9

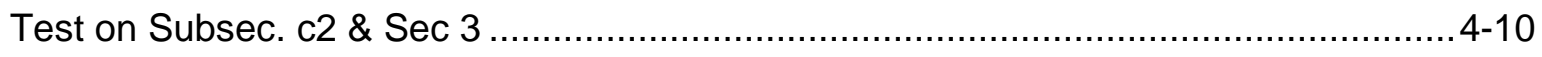

Pressure Rise in Cryostat Gap Without Active Pumping ........................................4-11

Pressure Rise in Cryostat Gap With Active Pumping ...........................................4-12

Estimation of Conductance and Size of the Leak ................................................. $4-12$

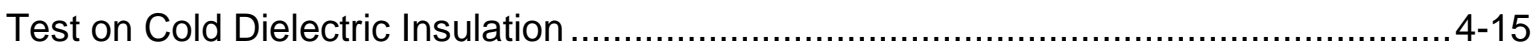

4.3 Phase Y Leak Tests ............................................................................... $4-15$

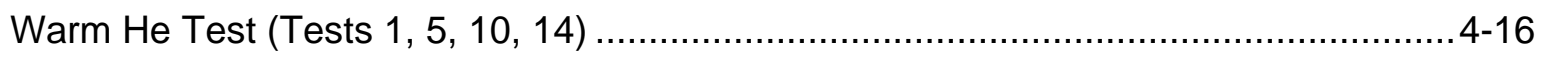

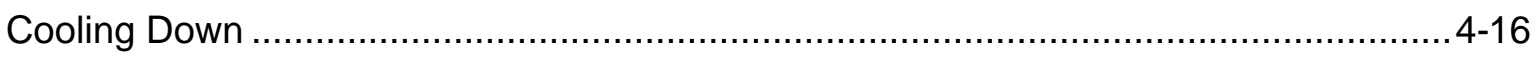

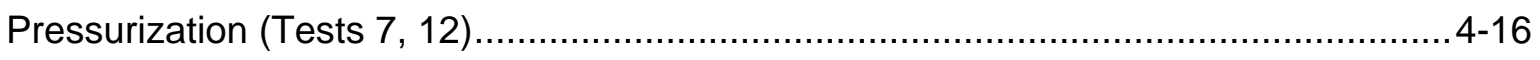

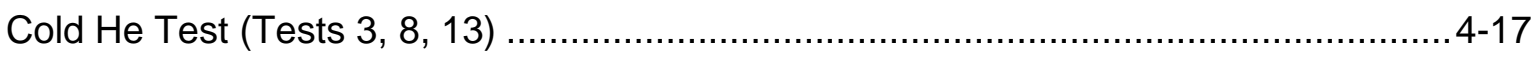

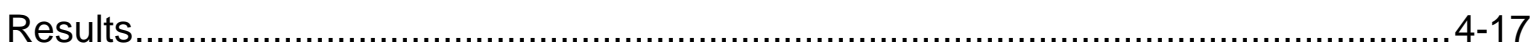

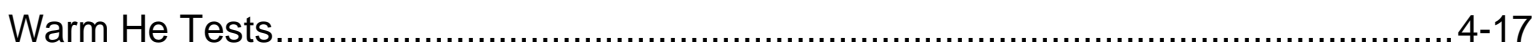

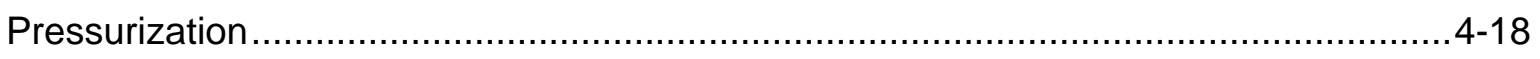

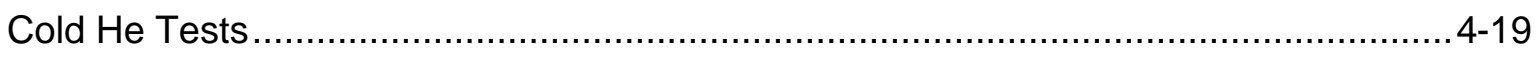

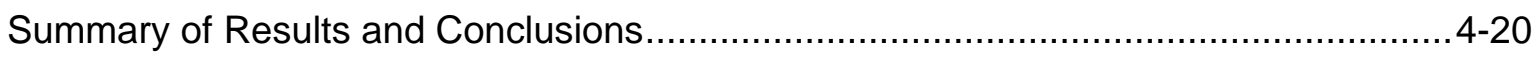

Results and Conclusions from These Tests ................................................. $4-21$

5 DISSECTION AND ANALYSIS OF PHASES X AND Z LEAKS ...................................... 5-1

5.1 Microscopic Methodologies ................................................................... $5-1$

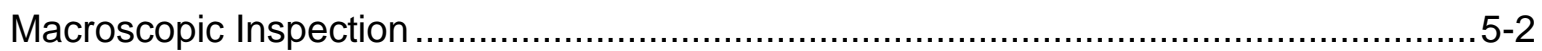

Optical Microscopic Inspection .............................................................................

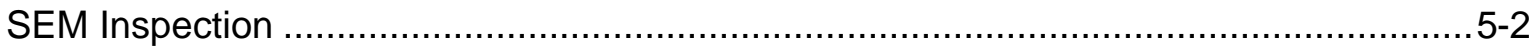

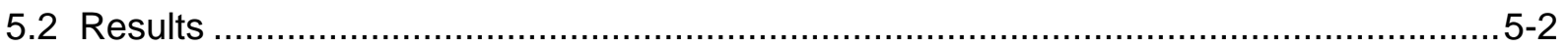

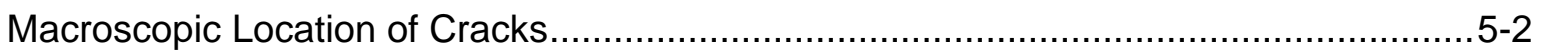

Morphology of the Cracks............................................................................

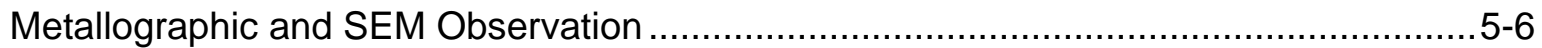

5.3 Summary and Conclusions for Leak Analysis ................................................ $5-12$

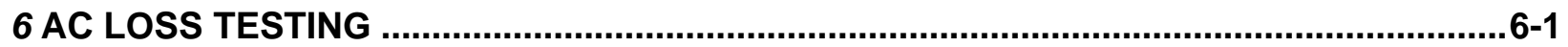

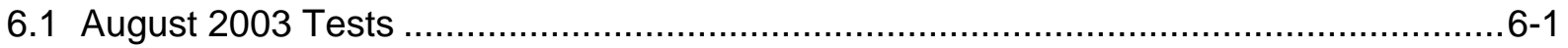

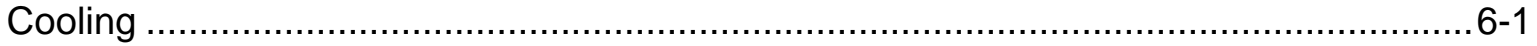




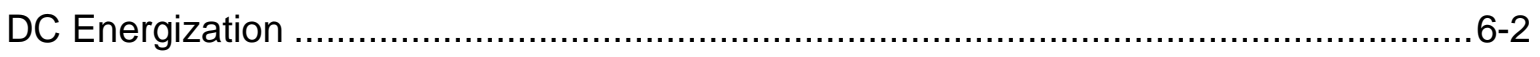

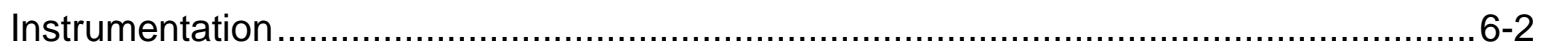

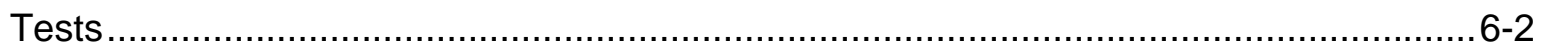

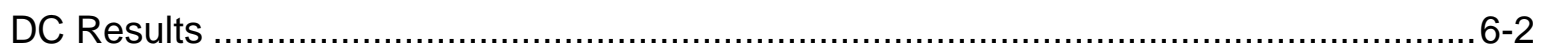

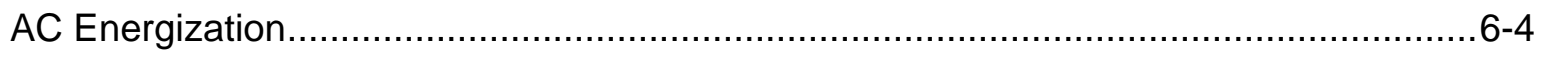

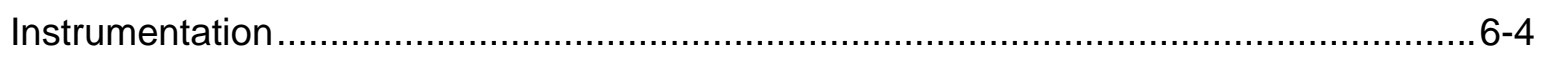

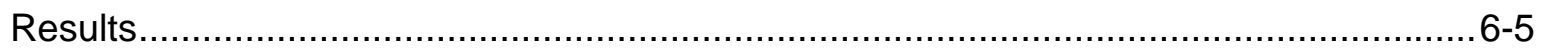

7 CONCLUSIONS FROM THE HTS CABLE DEMONSTRATION PROJECT .........................7-1

7.1 HTS Conductor........................................................................................... $7-1$

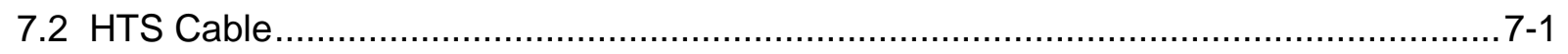

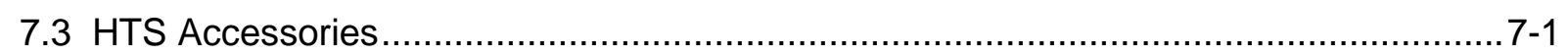

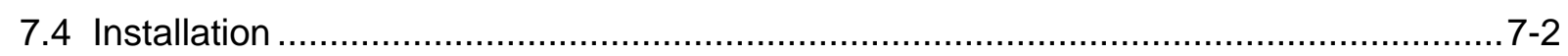

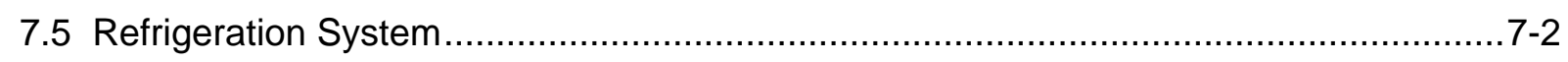

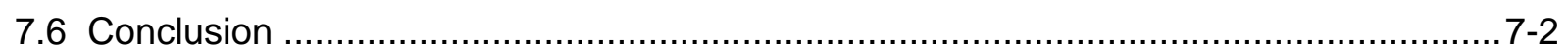





\section{LIST OF FIGURES}

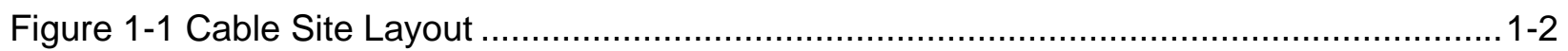

Figure 2-1 Measured Bending Radius in Sweep ........................................................... 2-2

Figure 2-2 Expanded View of HTS Tapes and Former ............................................. $2-4$

Figure 2-3 Photomicrograph of Laminated BSCCO Tape ......................................... $2-5$

Figure 2-4 Critical Current Distribution Histogram .......................................................... $2-6$

Figure 2-5 Schematic Diagram of Proof Testing Procedure .......................................... 2-7

Figure 2-6 Schematic of Mechanical Aging Test ........................................................ 2-7

Figure 2-7 Schematic of Reliability Testing Procedure ................................................... 2-8

Figure 2-8 Conductor on Pay-off Reel .................................................................

Figure 2-9 Schematic of Conductor as Stranded ........................................................... $2-10$

Figure 2-10 Cryostat During Manufacturing ................................................................

Figure 2-11 Extrusion Path for the Cable............................................................ $2-12$

Figure 2-12 Dielectric Triple Extrusion ................................................................... $2-13$

Figure 2-13 Copper Screen Application ..................................................................... 2-14

Figure 2-14 Mylar Protective Layer .................................................................. $2-14$

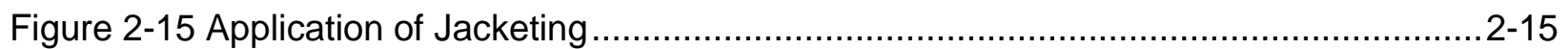

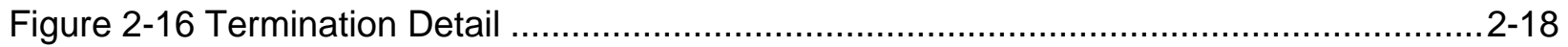

Figure 3-1 CAD Drawing of Cable Design Route ..................................................... $3-2$

Figure 3-2 Guide Structure used for Multi-Axis Support in Station Basement ......................... 3-2

Figure 3-3 Support used to Control Horizontal Bend in MH10671 ...................................3

Figure 3-4 Cable Support Structure used to Direct Cable Exiting MH13466 .........................3-3

Figure 3-5 Vacuum Enclosure for Transformer............................................................... $3-4$

Figure 3-6 Workers Guiding Cable During Installation................................................. $3-5$

Figure 3-7 Critical Current Performance after Cabling and Manufacturing ............................. 3-6

Figure 3-8 A Welder Completes the Cryostat Sleeve for the Joint .................................... 3-7

Figure 3-9 Moving the Cold Box into the Refrigeration Building …................................... 3-8

Figure 3-10 Inside of Refrigeration Building ........................................................... 3-9

Figure 4-1 Inner Cryostat Exiting Cryostat Fabrication Tool ................................................. 4-1

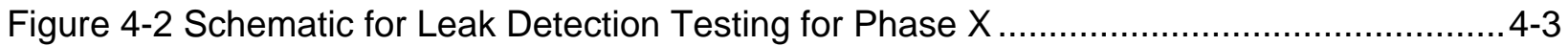

Figure 4-3 Diagram of Temporary Support for Termination (T1) .....................................4-4

Figure 4-4 Photograph of Lower Portion of Indoor Termination Cut to Accommodate Test Chambers. 
Figure 4-5 Comparison of He Flight Times in Phase X Data for Late December 2001 and

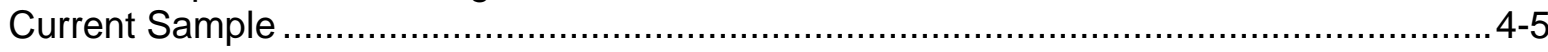

Figure 4-6 Dielectric Splice and Outer Wall of Cryostat Joint ....................................... 4-6

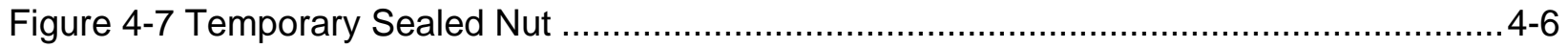

Figure 4-8 He Leak Test with Mass-Spectrometer Connected to Type D and Joint Test

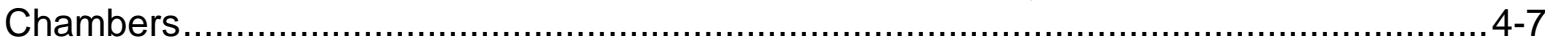

Figure 4-9 Pressure Rise in Cryostat Gap Without Active Pumping and LN Channel Pressurized

Figure 4-10 Pressure Rise in Cryostat Gap With Active Pumping and LN Channel Pressurized

Figure 4-11 Nitrogen Flight Time in Cryostat With Pump and 4.6 bar Pressurized LN Channel....

Figure 4-12 He Leak Test With Mass-Spectrometer Connected to Joint Test Chambers .......4-11

Figure 4-13 Pressure Rise Without Pumps and 5.0 bar Pressurized LN Channel................. 4-12

Figure 4-14 Pressure Rise With Pumps and 5.0 bar Pressurized LN Channel......................4-13

Figure 4-15 Illustration of Estimated Leak Position Near Splice .......................................... 4-14

Figure 4-16 Illustration of Estimated Leak Position Near Indoor Termination.......................4-14

Figure 4-17 He Leak Rate Versus Thermal and Pressure Cycles ..................................... 4-18

Figure 4-18 Cryostat Residual Pressure During Last Two Pressurization Cycles ..................4-19

Figure 4-19 Leak Rate at About LN Temperature ..................................................... 4-19

Figure $5-1$ Sample Locations ............................................................................ $5-1$

Figure 5-2 Tube Sample 4, Crack Along the Welding ................................................. $5-3$

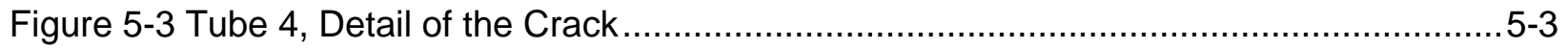

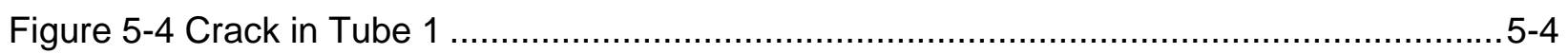

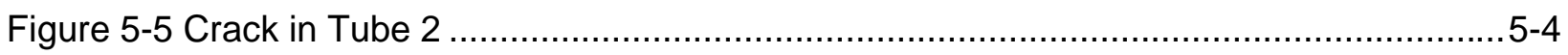

Figure 5-6 Crack 3-1 in Tube 3, Outer Surface ............................................................ 5-5

Figure 5-7 Crack 3-1 in Tube, Inner Surface (Right) .............................................. 5-5

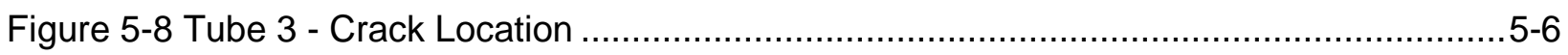

Figure 5-9 Tube 3 - Few Millimeters from Crack........................................................

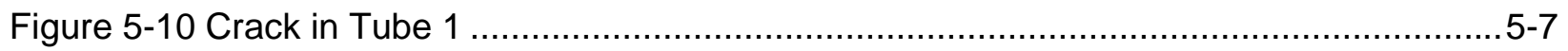

Figure 5-11 Tube 1- Detail of Crack on Outer Surface ................................................ 5-7

Figure 5-12 Tube 1 - Detail of Crack on Inner Surface ................................................. 5-8

Figure 5-13 Tube 1 - Detail of Crack on Inner Surface .................................................... 5-8

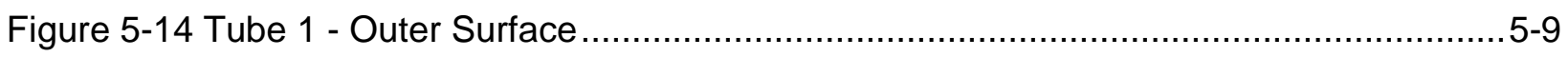

Figure 5-15 Tube 1 - Detail of Crack Shown in Figure 5-12 ........................................ 5-9

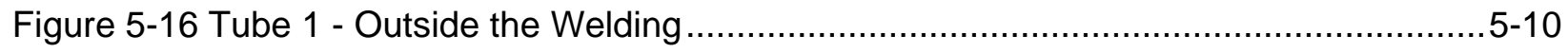

Figure 5-17 Tube 1 - Detail of the Defect in Figure 60............................................... 5-11

Figure 5-18 SEM Pictures of Defects in tube 1 - Outside the Welding ................................5-11

Figure 5-19 SEM Pictures of Defects in tube 1 - Outside the Corrugation Groove................5-12

Figure 6 -1 Tube 1: Outside the Welding .................................................................. $6-2$ 


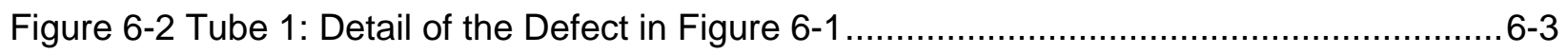

Figure 6-3 SEM Picture of Defect in Tube 1; Outside the Welding .......................................6-4

Figure 6-4 SEM Picture of Defect in Tube 1; Outside the Corrugation Groove ......................6-6

Figure 7-1 Sample of Frisbee Station HTS Cable -24 kV ................................................ 



\section{LIST OF TABLES}

Table 2-1 Comparison between HTS and Cu Tapes

2-10

Table 2-2 Dimensional Verification of Extrusion Process

2-15

Table 2-3 Factory Testing per AEIC CS6

2-16

Table 4-1 Leak Detection Test Summary for Phase $X$

4-13 



\section{1 \\ INTRODUCTION}

A project sponsored by EPRI, Pirelli Power Cables and Systems, the Department of Energy, Detroit Edison, and American Superconductor Corporation was initiated in 1998 to install and operate a $24 \mathrm{kV}$ HTS power cable in a Detroit Edison substation to serve customer load. A prior cooperation between Pirelli Power Cables and Systems and EPRI had resulted in the successful testing of a complete 50 m, 115 kV High Temperature Superconducting (HTS) power cable system prototype. This collaboration was planned to move the laboratory success into the field.

Customer acceptance of HTS cable technology requires a substantial field demonstration illustrating both the system's technical capabilities and its suitability for installation and operation within the utility environment. To resolve the outstanding questions of HTS cable's suitability for utility operation, a demonstration project supported by EPRI and the US DOE Superconducting Partnership was initiated which had the goal of the fabrication, installation and operation of a $24 \mathrm{kV} / 100$ MVA HTS cable system in a load-serving substation owned and operated by Detroit Edison Company.

The cornerstone of this demonstration lies in the field application of HTS cable technology. The scope of this project was planned to result in the world's first underground installation of a HTS cable system using an existing duct network. Furthermore, the project involves installing the necessary accessories on the project site within the constraints of a crowded distribution station.

This Final Report summarizes all activities and the lessons learned from this demonstration program between the dates of 1 December 1998 and 1 December 2003.

\subsection{Acknowledgement}

The authors would like to acknowledge the accomplishment of this work through its partnership with the Department of Energy's Office of Power Technologies supported under cooperative agreement number DE-FC36-98GO10283. This support does not constitute an endorsement of the views expressed in this paper.

\subsection{Project Description}

The demonstration cable circuit ran approximately $120 \mathrm{~m}$ between the $24 \mathrm{kV}$ bus distribution bus and a $120 \mathrm{kV}-24 \mathrm{kV}$ transformer. This location for the demonstration site was selected because it combined performance specifications suitable for the application of an HTS cable circuit and several practical advantages. Though the route is not as long as is anticipated for commercial applications and completely contained within Detroit Edison's property, it offered many of the 
challenges that will be faced in other field installations. Figure 1-1 shows the station layout and the installation route.

Frisbie station has a design capacity of 100 MVA, or 2400 Arms at 24-kV. This full capacity can served through either of two parallel cable circuits, and so typical loading on the demonstration circuit is about half of the station load. The site has an available fault current of $15 \mathrm{kA}$ for approximately $100 \mathrm{~ms}$.

The demonstration requirements represent very closely the performance characteristics anticipated for future cable retrofit upgrade applications. Based on earlier work sponsored by EPRI, the Warm Dielectric (WD) cable was identified as most suitable for retrofitting the existing power delivery infrastructure for performance upgrades. Retrofitting with HTS cables can provide the opportunity to increase by up to three times the delivered power through existing duct or pipe. The ability to maximize the investment existing rights-of-way, particularly where new construction is prohibited can help to allow sustained growth in areas that have saturated their existing power delivery infrastructure.

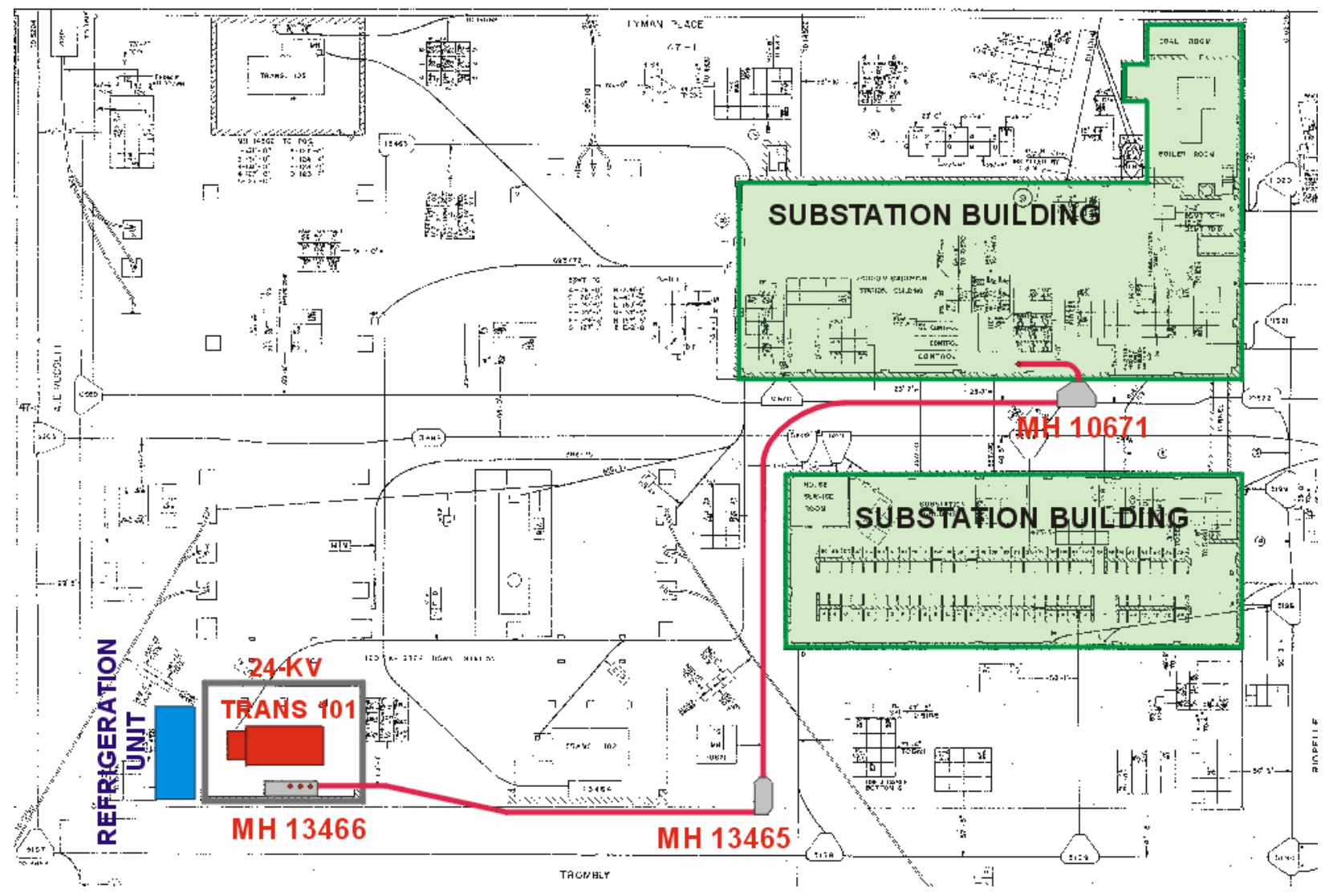

Figure 1-1

Cable Site Layout

The project was structured in two phases. The objectives of the first phase were the design and manufacture of the complete cable system (cables, accessories, refrigerator, and monitoring 
equipment), as well as the preparation of the substation site for installation. This phase built heavily on the experience and techniques developed during the earlier $50 \mathrm{~m}$ prototype project.

The second phase of the project had the goal of demonstrating HTS cable systems in the utility environment. The cable and accessories designed and manufactured in the earlier phase were installed at Frisbie substation. The complete cable system was to undergo commissioning tests for a period of time to verify the installation and establish a baseline for system behavior.

Once fully commissioned, the plan established by the partners called for a basic operating period of two years. Two years was recognized as the minimum time needed to begin to appreciate the long-term behavior and reliability of the system.

In preparation of commissioning the system, vacuum leak testing was conducted; and leaks were discovered in each of the three phases. After further testing, the decision was made that none of the three phases were stable enough to be energized. The phases with the largest leaks were removed and analyzed for cause of the leaks. The remaining phase was subjected to AC Loss Testing before restoring the Frisbie site to its original condition.

This report summarizes all activities in both phases of the project and reports on the lessons learned in the demonstration project.

\subsection{Project Partners and Activities}

An HTS cable system requires a fully engineered integration of three core technologies; HTS wire, power cable manufacturing, and cryogenic systems. The project team has been formulated to provide expertise in all of the various aspects and components of HTS systems and their application to the electric power network.

- Pirelli Cables and Systems, the world's largest power cable manufacturer, is the project leader, as well as specified all subcontracted material and designed and manufactured the cable and accessories;

- American Superconductor Corporation provided the highest quality and performance BSCCO-2223 wire available;

- Detroit Edison provides the demonstration site as well as their perspective and expertise as an electric utility with significant Transmission and Distribution cable systems. Detroit Edison field personnel also worked on the installation and commissioning of the systems;

- EPRI contributes their overall industry perspective and experience introducing new technologies to the utility industry;

- Los Alamos National Laboratory provides experimental evaluation of AC losses in conductor assemblies; and

- Lotepro Corporation engineered and manufactured the cryogenic refrigeration system.

The work is supported under Phase Two of the Department of Energy Office of Energy Technology’s Superconducting Partnership Initiative. 



\section{SYSTEM DESIGN AND MANUFACTURE}

Developing the system specification involves an optimization between the cable properties and the application constraints. Obviously, the performance specification for the cable must be met; however, it is the installation requirements that impose the greatest challenges to the cable designer. Particularly, the tight bending radii and small duct diameter require a very compact cable with excellent flexibility and strain tolerance. Conforming to the application specification goes beyond meeting the physical requirements for power rating or installation. The demonstration system was also designed to integrate with the existing infrastructural and institutional framework of the utility, which is an unquestionable requirement for commercial systems. The objective was to make the system nearly transparent to the user, so that the evaluation can focus on proving the total system's reliability, maintainability, and operability.

\subsection{Demonstration Site Evaluation}

As this was to be the world's first installation of an underground HTS cable, particular attention was been paid to the installation site. Surveys of the manholes, ducts, and pothead mounting locations were conducted to ensure that there were no unforeseen obstacles for the installation of the cable system.

Particular attention was paid to the installation behavior of the cable. The duct network to be used was installed approximately 50 years ago, and so an evaluation of the ducts was performed to confirm their condition. Also, it was decided to experimentally verify the minimum-bending radius that the cable will experience. A primary concern was that if a duct buckled or two adjacent ducts moved slightly off-line, the available space for passing the cable would be reduced.

The first activity was to analyze the conventional cables as they were removed. The soft lead sheathing would show scoring or deformation due to being pulled through a constricted or damaged zone. No damage was observed on the removed cables. The original cables, however, have a smaller diameter than that anticipated for the HTS circuit, so further evaluations were performed.

The next step was to video the duct interior to verify further their condition. Neither gross deterioration of the ducts nor any misalignment was seen. A significant observation was that the duct bends viewed in the video were not consistent with the site drawings. In the drawings, it

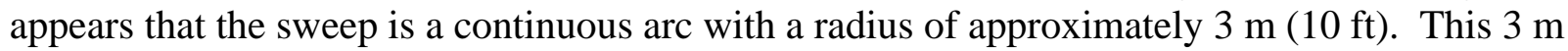

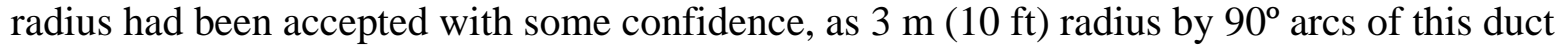
material were part of the catalog of materials used by Detroit Edison at that time. Not only were the two separate arcs obvious from the video, but also the bend radii looked noticeably smaller 
than $3 \mathrm{~m}$ (10 ft). This point was significant, because preliminary cable designs were based on a

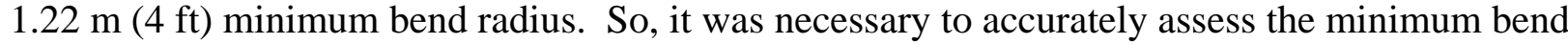
radius before the cable design could be finalized.

A measurement fixture, designed and fabricated by Pirelli for difficult installations, was used to map the bend radius along the duct route. The measurements revealed that the duct bend was

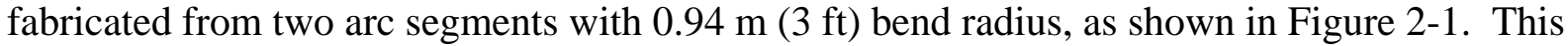
radius was the lowest measured at any point along the route, and so became the limiting design value for the cable.

Bending Radii Measurement at Frisbie Substation

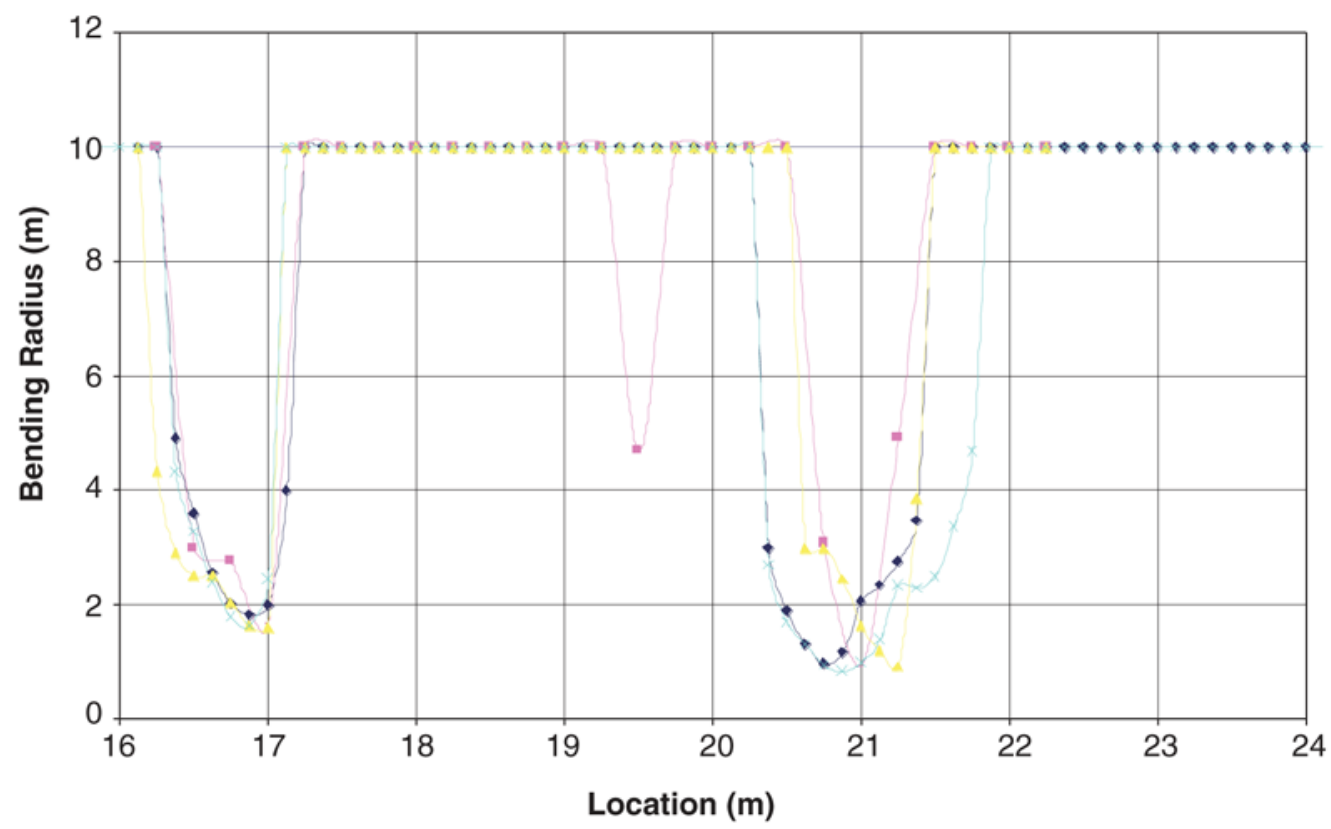

Figure 2-1

Measured Bending Radius in Sweep

Further tests were conducted, however, as a flaw not evident from the video could still impede the installation due to the limited clearance between the cable diameter and the nominal duct diameter. To further ensure that there would be no clearance problems along the duct route, a mandrel with a diameter of 3.7 in (greater than that of the HTS cable) was pulled through the ducts. The successful passing of this mandrel confirmed that no restrictions exist which could block the HTS cable's pull.

A final test was performed to verify the coefficient of friction between the polyethylene cable jacket and the fiber-bitumen wall. A conventional copper cable, $300 \mathrm{ft}$ long, with similar outer diameter as that anticipated for the demonstration cables was lubricated with duct lubricant. A load cell, installed at the pulling eye, measured the pulling force required as the cable was pulled into the duct. An analysis of the measured data revealed that the coefficient for the duct run would be approximately $0.25-0.3$, which is consistent with the predictions from the lubricant manufacturer. 


\subsection{Cable Design}

The cable is designed by co-optimizing the available diametrical dimensions. The outer diameter of the cable is determined by the available duct diameter and the clearance necessary for installation.

Pirelli has established the ability to design and manufacture long-length conductors in the earlier $50 \mathrm{~m}$ prototype program and through separate internal development activities. The focus for the design for the conductor became to minimize electrical transport losses and to endure the mechanical effects of handling, installation, and operation.

The conductor assembly has four layers of Ag-sheated $\mathrm{Bi}_{2} \mathrm{Ca}_{2} \mathrm{Sr}_{2} \mathrm{Cu}_{3} \mathrm{O}_{\mathrm{x}}$ tapes wound around a flexible former. The tapes will have a minimum critical current $\mathrm{I}_{\mathrm{C}, \mathrm{DC}} \sim 110 \mathrm{~A}$, measured over the total length of the tape at $77 \mathrm{~K}$ and in self-field. The calculated critical current for the conductor at $77 \mathrm{~K}$ is approximately 5500 Adc. This value is actually lower than the expected operational critical current, as the operating temperature for the system should be close to $70 \mathrm{~K}$. The winding angles of the different layers have a considerable impact on the cable performance and are selected to meet several requirements, such as:

- limiting the strain experienced by the HTS tapes due to thermal contraction and cable bending, so that the electric performance of the tapes is not affected;

- the current distribution among the HTS layers should be as uniform as possible, to provide the most efficient use of the superconducting materials, particularly in the high current range;

- the magnetic field acting on a single tape in the cable configuration should be minimized to increase the cable critical current and to reduce the AC losses.

To meet these requirements, the winding pattern of the HTS layers was selected to optimize the overall performance of the cable. Some layers were wound with an opposite angle to provide a mitigating influence to the axial magnetic fields.

As seen in Figure 3, the HTS wires are wound over a hollow former. The former serves many purposes over the life of the cable. Fundamentally, it provides:

- Thermal mass to stabilize the conductor temperature rise due to short-circuits and maintain it within acceptable values;

- A reinforcing surface to support the HTS wires;

- A smooth channel for the $\mathrm{LN}_{2}$ flow to limit the pressure drop. 


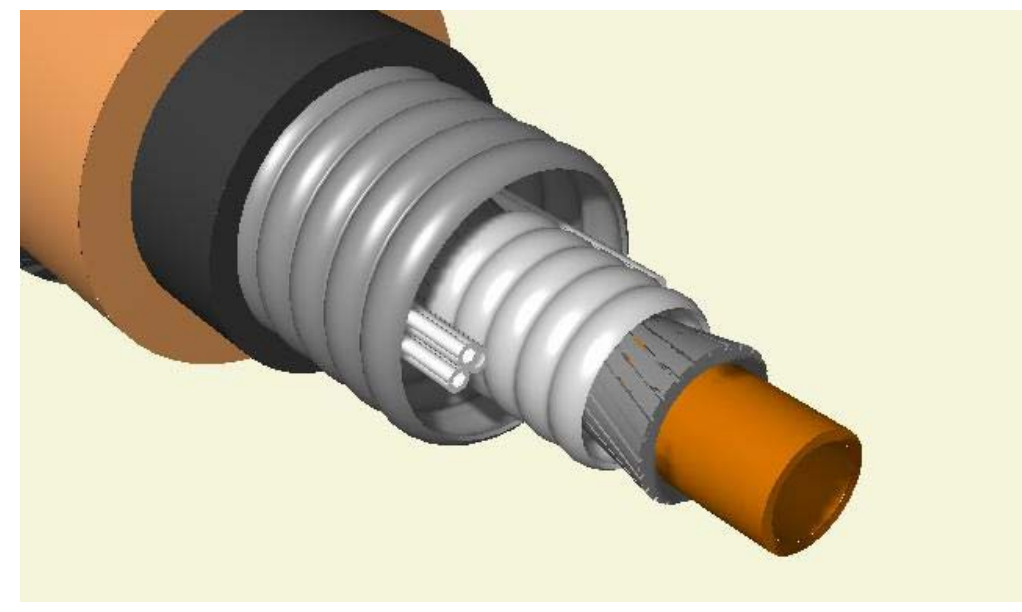

Figure 2-2

Expanded View of HTS Tapes and Former

The selection and design of the former must consider its role in cable manufacturing and installation, too. To meet these requirements, it must have sufficient stiffness for the manufacturing phases (i.e. HTS tapes and insulation application), while remaining flexible and light to facilitate the installation procedure.

The cryostat provides thermal insulation for the cable. Two parallel-corrugated stainless steel tubes are used with vacuum and radiative insulation shields inside to limit the different modes of heat transfer. The basic configuration was developed based on liquid nitrogen transfer line technology, and the efficacy of the approach was proven with the $50 \mathrm{~m}$ prototype system.

Also, the cryostat design considers the installation and handling requirements of the application. The cable will need to pass through several tight $90^{\circ}$ bends between the transformer bay and the substation.

The dielectric system for a Warm Dielectric cable is applied over the outer wall of the cryostat. The demonstration system uses ethylene-propylene rubber (EPR) co-extruded with polymeric semi-conductive compounds to smooth and distribute the electrical field. Standard design principles, developed through years of use for this insulation system, determined the thickness of the insulation components. To prove the design process, extrusion trials were performed on short lengths of outer cryostat. Basic qualification tests (ac voltage withstand $-52 \mathrm{kV}$ for 30 minutes and impulse to $52 \mathrm{kV}$ ) were successfully passed.

\subsection{HTS Wire}

Operating HTS power cables in the field requires a HTS wire specification which includes, critical current, mechanical performance needed for installation and handling, and the reliability of the wire to ensure that there is no possibility of degradation due to environmental factors. 
The wire design delivered for this project was selected because of its ability to meet the strict requirements of a field deployed cable system. In the photomicrograph shown as Figure 2-3, the multi-filamentary structure can clearly be seen embedded in the silver matrix. The processing technology employed results in very high fill-factor for the superconductor in the wire and also a high degree of uniformity along the wire length.

The tape employs two mechanisms to enhance the mechanical performance of the tape; an oxidedispersion-strengthened silver alloy matrix, and a laminated wire structure. The high strength matrix is a technique developed by various companies around the world. The laminated structure for the tape imparts significantly improved wire performance. The final construction can withstand up to $300 \mathrm{MPa}$ of stress and $0.4 \%$ strain with only minimal degradation in superconducting properties.

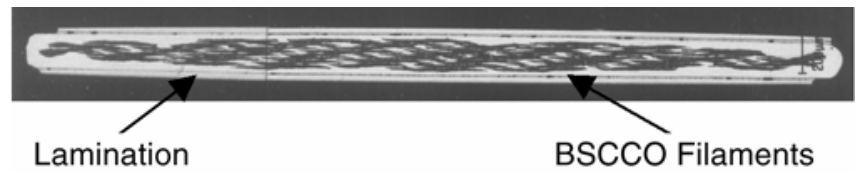

Figure 2-3

Photomicrograph of Laminated BSCCO Tape

The wire manufacturing campaign by partner American Superconductor was completed in September 2000, and resulted in the delivery of approximately 29,000 meters of wire for the demonstration project. In Figure 2-4, the results of the manufacturing run are shown in a histogram format for 187 wire piece lengths that nominally measured 155 meters. The average tape critical current (Ic) of this manufacturing run was 118 amps (77K, self-field, $1 \mu \mathrm{V} / \mathrm{cm}$ ) with a standard deviation of only $6 \%$ and a maximum performance of 134 amps $(77 \mathrm{~K}$, self-field, $1 \mu \mathrm{V} / \mathrm{cm})$.

A form of environmental degradation was observed following the $50 \mathrm{~m}$ prototype project. Blisters formed in the HTS wire at some point during the testing period. This phenomenon has since been called "Ballooning". By emulating cable-operating conditions, it was recognized that the blisters were formed due to liquid nitrogen penetration into the HTS filaments. Upon warming the cable, the nitrogen would vaporize, causing very high localized pressure and damage to the superconducting filaments. 


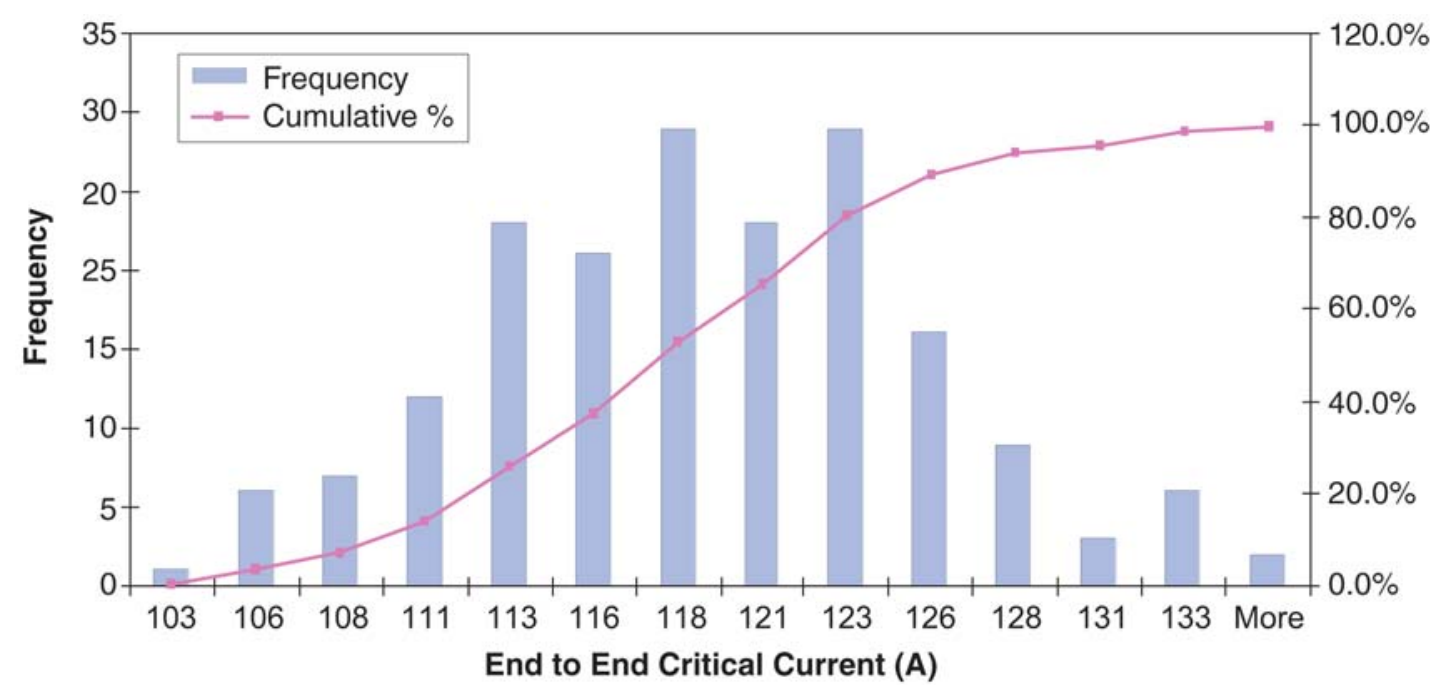

Figure 2-4 Critical Current Distribution Histogram

The modifications needed to ensure the wire would be robust against ballooning delayed the initiation of the wire manufacturing campaign for the demonstration project. The new wire and all of the processing modifications were performed separately from the demonstration project activities, as part of the BSCCO development cooperation between Pirelli and ASC.

The wire specification for the demonstration project included both performance specifications and a rigorous testing process that each batch of wire must pass before acceptance by Pirelli. The proof testing procedure ensures that every tape delivered for the demonstration cable meets the stringent requirements for a cable system. These requirements include (1) physical dimensions, (2) critical current, and (3) resistance to liquid cryogen penetration. This testing procedure, illustrated in Figure 6, utilizes a 100\% end-to-end testing approach comprising three testing steps. The steps are (1) complete testing of thickness and width along the entire length of the tape, (2) complete testing of critical current along the entire length of the tape, and (3) exposure of the entire tape length to pressurized liquid nitrogen to ensure that no defects are present that would allow penetration of liquid cryogen into the HTS filaments. This test was used to qualify every one of the 187 pieces delivered to Pirelli for this project.

The tests illustrated in Figure 2-5 are designed to ensure that the tapes are of good quality (i.e. free from flaws) when they are delivered to Pirelli. However, these tests do not detect flaws that might arise during the fabrication, testing, or installation of the cable. To anticipate flaws that may be generated during conductor stranding, Pirelli and American Superconductor have designed and implemented a new mechanical aging test intended to simulate the mechanical forces that occur during the conductor stranding operation. This test, shown schematically in Figure 2-6, simulates the bending, twisting, and tensile forces experienced by the HTS tapes during conductor stranding. This test, which is a continuous test from pay-off to take-up, is run on 50-meter samples of tape cut from the ends of the tapes delivered to Pirelli. 


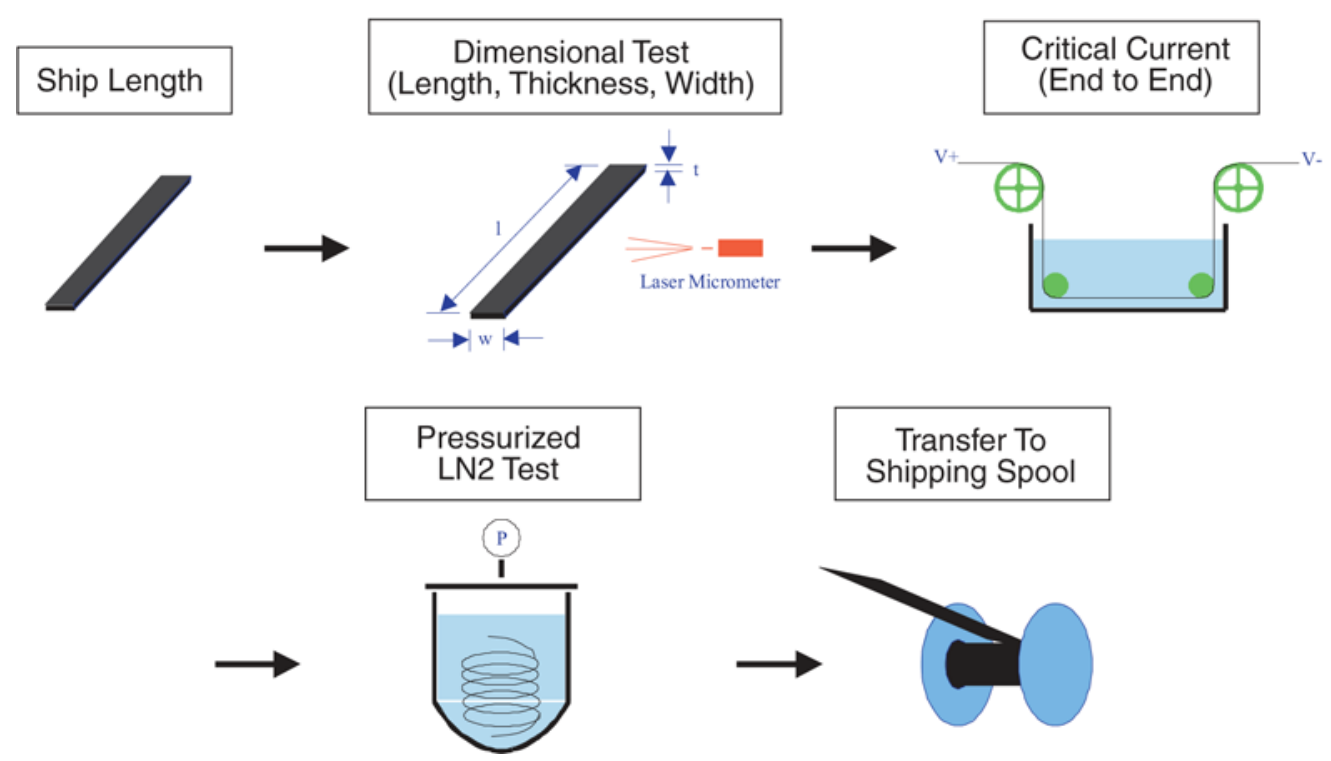

Figure 2-5

Schematic Diagram of Proof Testing Procedure

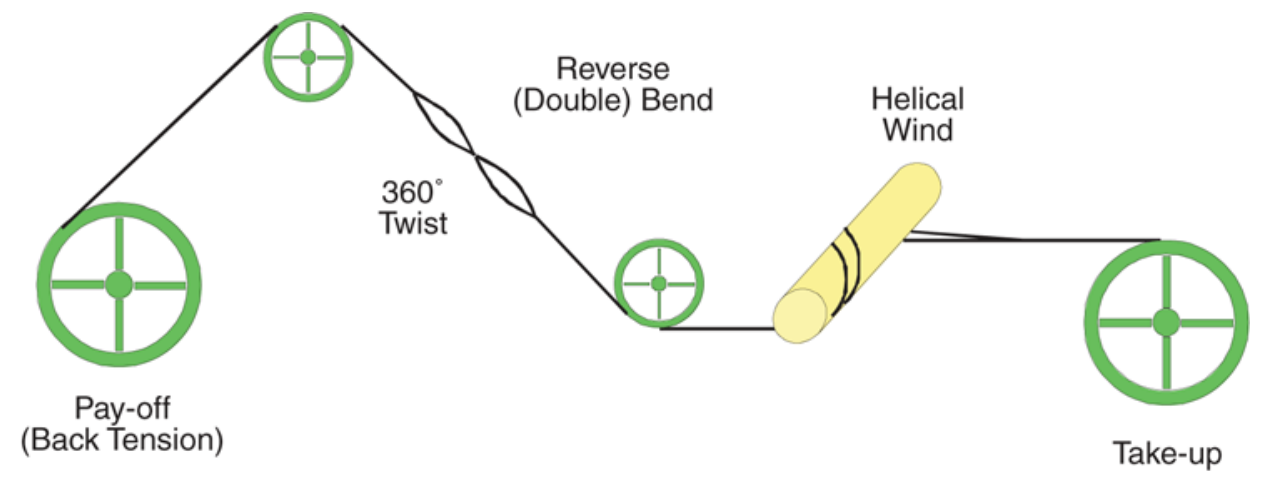

\section{Figure 2-6}

Schematic of Mechanical Aging Test

The mechanical aging test illustrated in Figure 2-6 is designed to accelerate the formation of flaws due to the stranding operation, however this test does not address the formation of flaws that might result from the thermal excursions experienced by the BSCCO tapes prior to being put into service. To anticipate these thermally induced flaws, two additional tests were developed and inserted into the reliability testing protocol. One test, referred to as thermal aging, exposes the tapes to an elevated temperature for an extended period of time to simulate the curing cycle that is used during the process of applying Pirelli's standard extruded dielectric. The other test, thermal cycling, exposes the tapes to ten thermal cycles from room temperature to $77 \mathrm{~K}$ to simulate the various tests that will be performed on the cable during start-up and commissioning. These two tests, plus the mechanical aging test, have been combined into a suite of tests that we refer to as reliability testing and are illustrated schematically in Figure 2-7. 
Over 150 BSCCO tape samples were processed through the test shown in Figure 2-7 to ensure that the tapes would be robust and reliable enough for this cable project. The reliability test comprises seven testing stations: (1) end-to-end critical current test to establish the tape's performance baseline; (2) pressurized LN2 test to ensure resistance to liquid cryogen penetration; (3) the mechanical aging test illustrated in Figure 2-6; (4) exposure to elevated temperature for an extended period of time to simulate the thermal curing cycle of the dielectric cable insulation; (5) another end-to-end critical current test to ensure that no performance degradation has occurred; (6) thermal cycling between room temperature and liquid nitrogen temperature to simulate the operational temperature cycling of the cable; and (7) a final pressurized LN2 test to ensure that none of the previous tests have affected the resistance to liquid cryogen penetration. Of the over 150 tape samples tested, only one showed an unacceptable degradation in critical current, and none showed penetration of liquid cryogen into the HTS filaments.

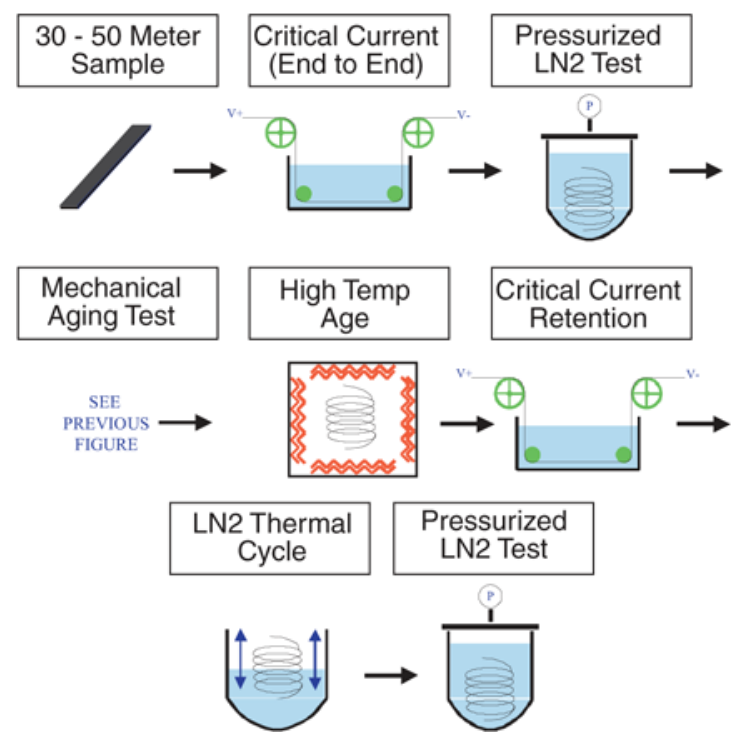

Figure 2-7

Schematic of Reliability Testing Procedure

\subsection{Cable Conductor Manufacturing}

The conductor assembly includes four layers of HTS wires, a layer of instrumentation wiring, and cable instrumentation. The multi-strand cable conductor was manufactured at Pirelli's dedicated facility near Milan, Italy between September and October 2000. Figure 2-8 shows the stranded conductor being wound onto the take up reel during the application of the third layer of HTS tapes. 


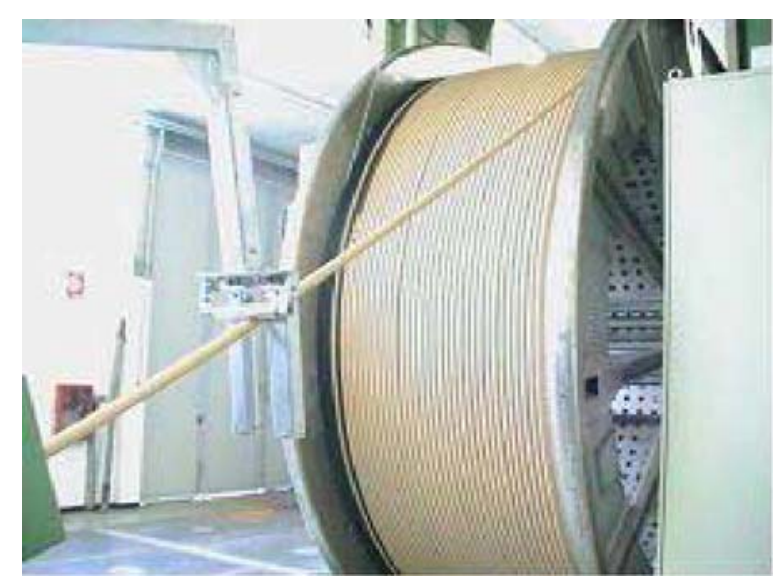

\section{Figure 2-8}

Conductor on Pay-off Reel

The three phases of the conductor were manufactured into one continuous length, having copper leaders between each phase. The leaders were included so that parts of the conductor which might be damaged during handling or installation are not populated with superconductors.

The four layers of the cable and instrumentation wire were stranded separately. Though the stranding process is performed by a stranding machine, more stranding stations will be required for concurrent stranding of multiple layers.

The order for stranding was as follows:

1. Copper leader

2. HTS tape for the first phase

3. Copper leader

4. HTS tape for the second phase

5. Copper leader

6. HTS tape for the third phase

7. Copper leader

The cable was replaced onto the payoff reel, and the process continued for the second, third, and fourth layers. After all of the HTS layers had been applied, the instrumentation layer was added.

Figure 2-9 shows a schematic of the demonstration conductor as manufactured. 


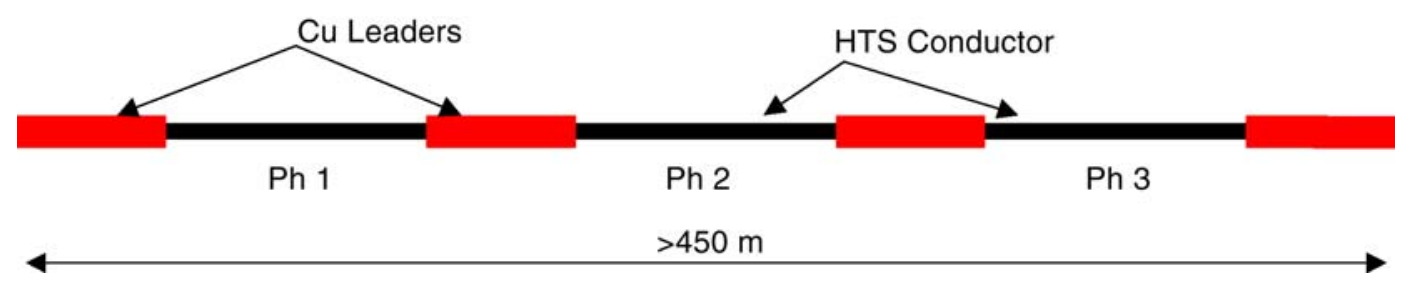

Figure 2-9

Schematic of Conductor as Stranded

Because the demonstration system will be the first underground HTS cable installed in a network, the cable has been instrumented to measure temperature and voltage losses. This instrumentation will be used for commissioning verification and benchmarking tests, as well as real-time performance monitoring of temperature profiles and ac transport losses.

\subsection{Conductor Verification}

Samples of the conductor design were manufactured using the "dummy" approach. This approach is Pirelli's standard method for evaluating mechanical performance of conductor designs, substituting copper tapes for most of the HTS tapes and leaving a few HTS tapes in each layer. All HTS tapes are continuously characterized as part of the acceptance/proof test (discussed in Section 2.3), and these values are used to provide a performance baseline. The "dummy" conductor, then, is subjected to various mechanical tests, and the performance of the HTS tapes re-measured to identify any degradation due to the mechanical loading conditions. A similar technique is also used to establish machine and equipment settings for the remaining cabling processes.

The $\mathrm{Cu}$ tapes were chosen having the same dimensions and very similar thermo-mechanical properties as the superconducting tapes, as shown in Table 2-1. The Cu tapes were annealed to obtain a similar modulus and yielding point.

Table 2-1

Comparison between HTS and Cu Tapes

\begin{tabular}{lcc}
\hline \hline & HTS tape & Cu tape \\
\hline Density $(\mathrm{kg} / \mathrm{m} 3)$ & 7980 & 8980 \\
CTE $(1 / \mathrm{K})$ & $13.510-6$ & $1410-6$ \\
Weight $(\mathrm{gr} / \mathrm{m})$ & 12 & 13.5 \\
Modulus at RT (GPa) & 70 & 85 \\
\hline
\end{tabular}

The initial "standard" length for the dummy conductor is $100 \mathrm{~m}$, which is progressively cut after certain steps of cable manufacturing to obtain measurement specimens. Sections cut $5 \mathrm{~m}$ to $10 \mathrm{~m}$ long are divided into parts. The first one is inspected visually and the Ic measured; the second one is stored for future analysis. The collections of these samples provide a "trace" of the process. Inspected sections are opened, and every layer carefully examined. The HTS tapes 
present in each conductor layer are removed individually, and a critical current measurement is carried out on each.

When the dummy cable is complete, tens of meters from the initial $100 \mathrm{~m}$ are still available for further testing, such as multiple bending, axial tension, cooling, thermal cycling, etc.

Furthermore, it's possible to simulate the installation, termination and joint assembly processes for the cable system.

Tests on the dummy conductor for the demonstration system were used to verify the analytical methods employed in the conductor design process. The tests conducted to date include multiple bending and lateral pressure tests. Cool-down with constrained ends and critical current tests will be performed on fully populated samples later.

The multiple bending test consists of wrapping the dummy conductor around drums of various diameters and applying a back tension sufficient to conform the conductor to the desired diameter. Two types of this test were conducted, 10x single bending and 10x single bending + $3 \mathrm{x}$ reverse bending. The drum diameters selected were $1.2 \mathrm{~m}, 1.5 \mathrm{~m}$, and $3.0 \mathrm{~m}$. The minimumbending diameter expected for installation of the demonstration application is $1.80 \mathrm{~m}$.

Lateral pressure tests are designed to evaluate the effect of the inner cryostat corrugation peaks in contact with the HTS conductor. As the actual local pressure and stress profile for the tape is impossible to predict, empirical tests are the best technique to evaluate possible degradation of performance.

The test is conducted using a dummy conductor is slipped inside of a finished cryostat tube, and a steel rope is pulled through the duct channel. The assembly is bent around a drum having a diameter of $1.5 \mathrm{~m}$. By applying varying loads to the rope, forces are generated between the conductor tapes and the cryostat. At $1000 \mathrm{~kg}$ of loading, approximately $2 \%$ degradation was measured.

\subsection{Cable Fabrication}

Over the conductor, a cryostat was applied. The cryostat is composed of two concentric, corrugated, longitudinally welded, non-magnetic stainless steel tubes, between which is placed radiative shields. The longitudinal weld was done using a T.I.G. process, i.e., arc welding in inert atmosphere, without any filling material. When a high level of vacuum is created between the tubes, a high thermal efficiency can be obtained through the reduction of convective, conductive, and radiative heat transfer modes.

First, the inner layer of the cryostat is applied over the conductor in a continuous operation. The design of the inner cryostat is dictated by mechanical requirements, as it must minimize forces due to high thermal contraction, as well as contain hydraulic loading due to the flowing $\mathrm{LN}_{2}$ coolant. Figure 2-10 shows the inner cryostat exiting from the cryostat fabrication tool. 


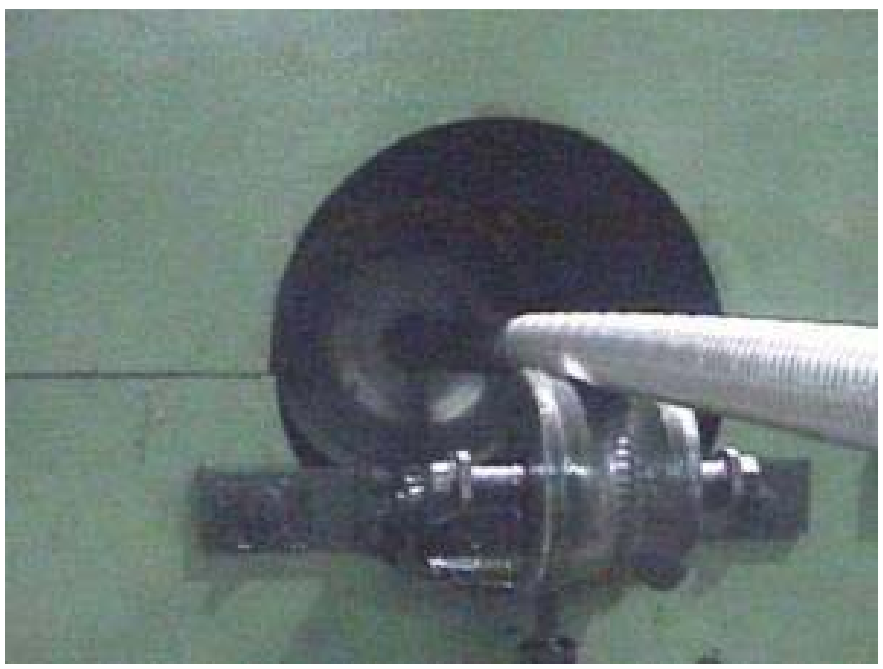

Figure 2-10

Cryostat During Manufacturing

Inside of the cryostat, components are included to provide mechanical and thermal isolation between the inner and outer tubes, as well as the radiative insulation discussed earlier. The distance between the inner and outer tubes must be kept very small to ensure a compact cable.

The outer tube of the cryostat is applied over the radiative layers in the same fashion that the inner tube was applied over the conductor. The design of the outer tube was designed considering manufacturing loading, as well as installation and operation forces. Several dummy cryostats of different lengths were manufactured for warm and cold testing before the final manufacturing phase.

After the application of the inner and outer tubes, a helium leak check was conducted over the entire length of the cryostat to verify the longitudinal welding process.

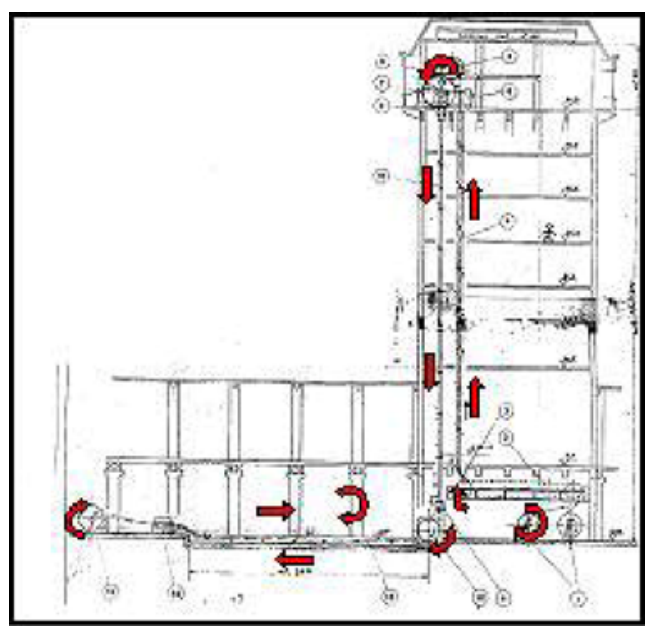

Figure 2-11

Extrusion Path for the Cable 
In the WD cable configuration, the dielectric system is applied directly over the outer cryostat tube. For the demonstration cable system, an extruded dielectric (EPR) was selected. The extrusion introduced an additional technical element into the fabrication of the system, as no long length HTS cable had been fabricated in this manner.

A high degree of process control during the extrusion onto the cryostat was critical for both the quality of the insulation and to protect the conductor core from the high temperatures reached during extrusion. The dielectric system was applied using a triple extrusion process performed at a factory having a vertical extrusion line, see Figure 2-11. The extrusion line uses superheated steam and was modified for extrusion over the cryostat and to keep the temperature rise in the HTS tapes at an acceptable level. The red arrows show the cable paths.

There were two main challenges that have been successfully won during the triple extrusion process:

1. To ensure high quality extrusion standard on a not uniform surface like the outer cryostat tube is because of the helicoidal corrugation.

2. To compensate the high mechanical stress on the corrugated tube due to the pressure of overheated stem and the several reverse bending experienced by the cable during the extrusion.

Figure 2-12 shows a detail of the bottom part of the extrusion head, just before closing the vulcanisation pipe. After the vulcanisation the cable has been moved to another Pirelli factory to lap the copper screen and the protective layer and to extrude the graphite coated polyethylene jacket (see Figures 2-14 and 2-15). Following these final manufacturing stages, factory tests as specified in AEIC CS6 were performed.

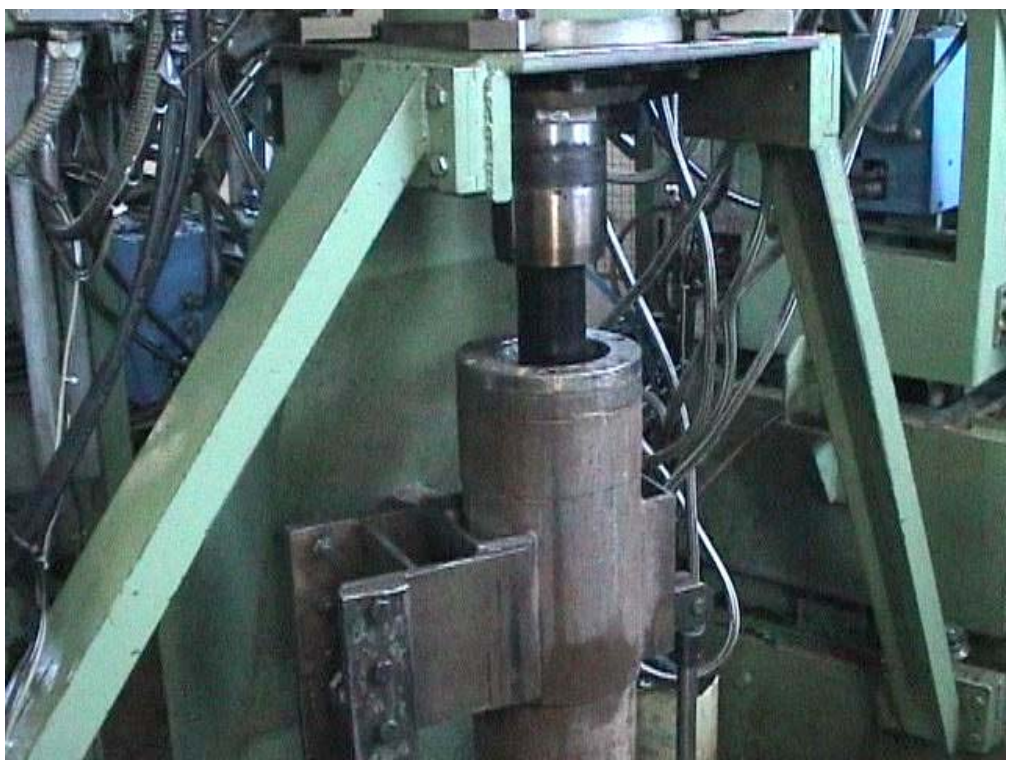

Figure 2-12

Dielectric Triple Extrusion 


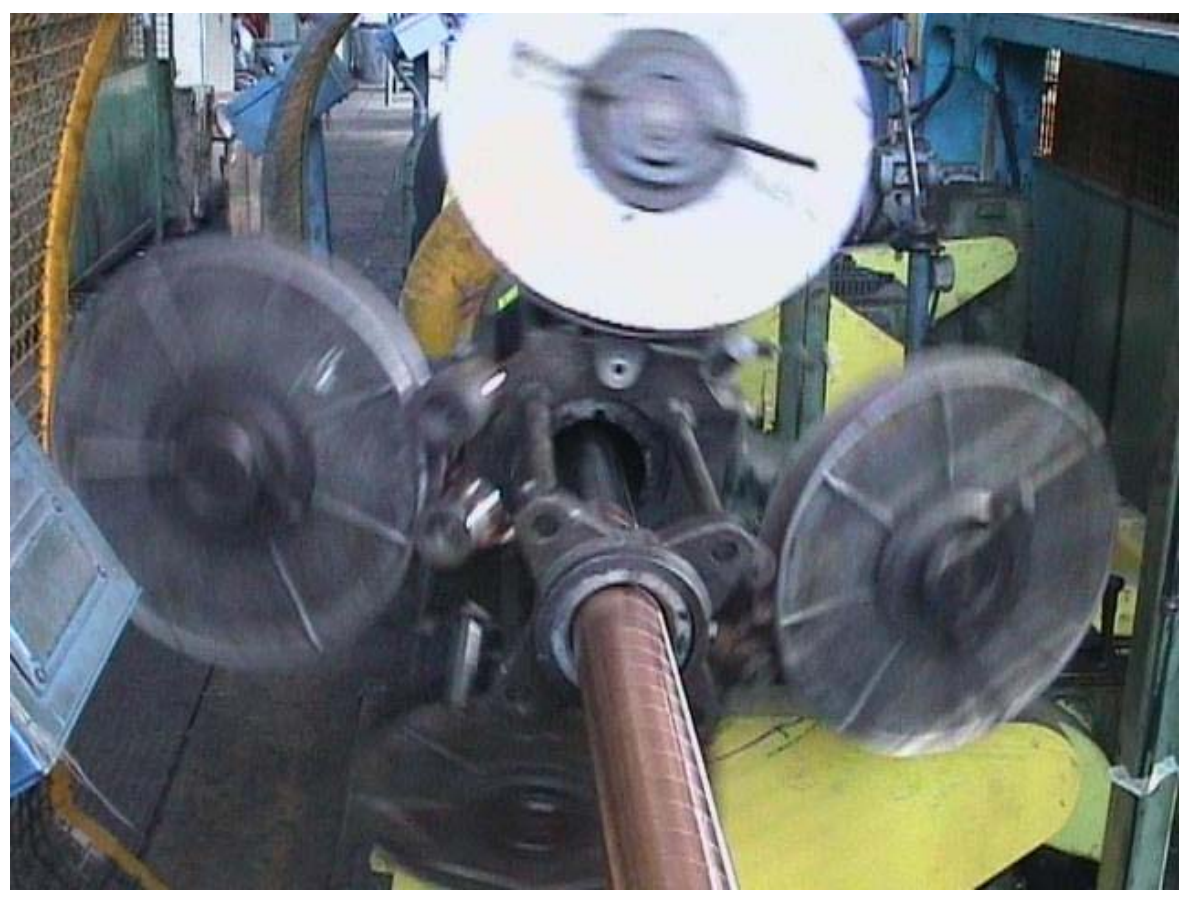

Figure 2-13

Copper Screen Application

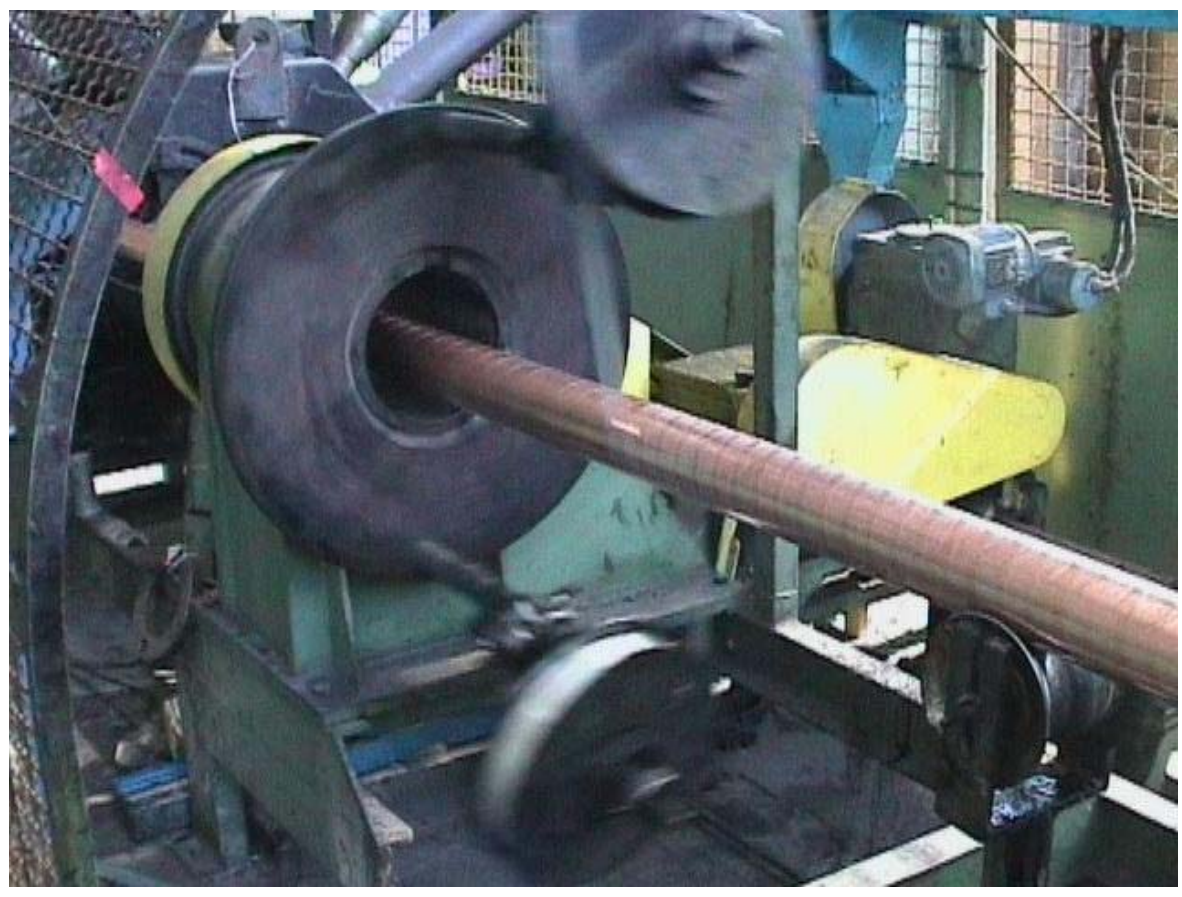

Figure 2-14

Mylar Protective Layer 


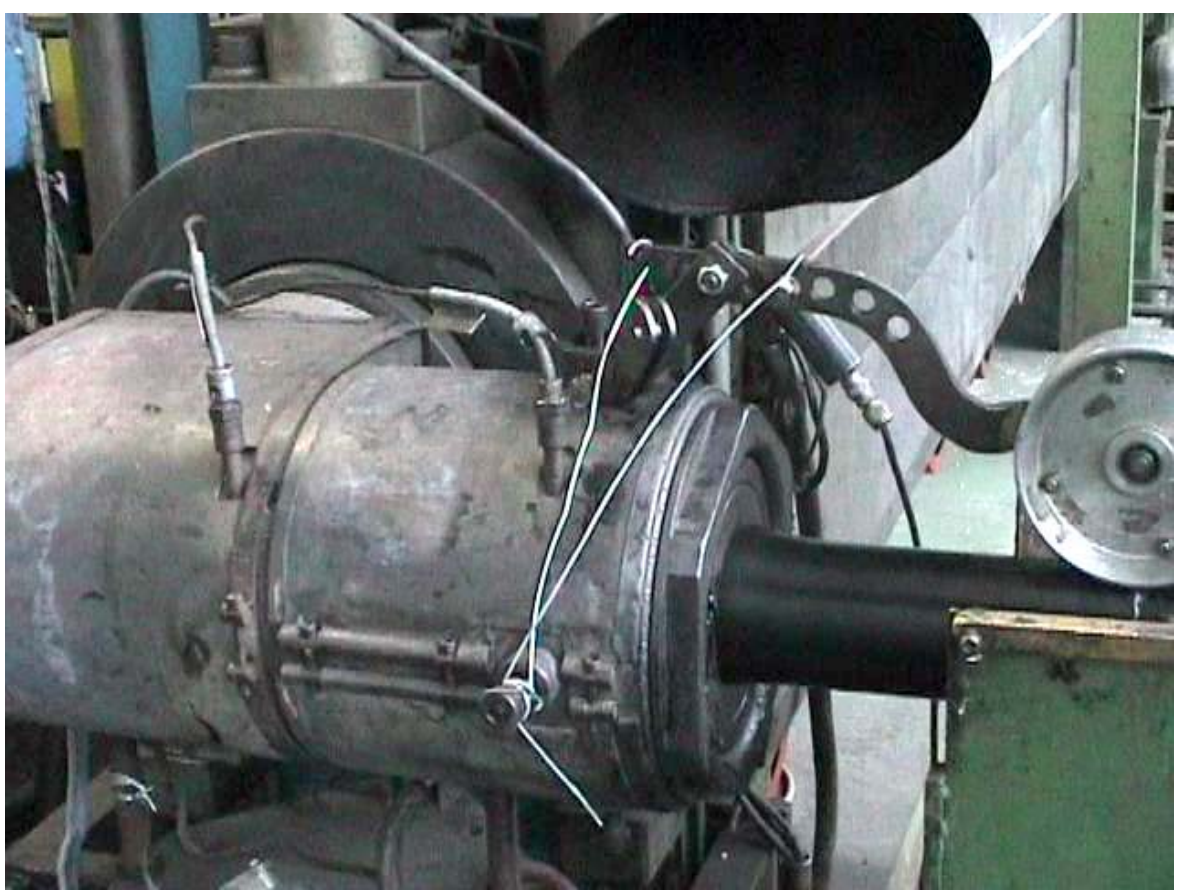

Figure 2-15

Application of Jacketing

A dimensional check confirmed the conformance to AEIC CS6 standards.

Table 2-2

Dimensional Verification of Extrusion Process

\begin{tabular}{lcc}
\hline \hline & $\begin{array}{c}\text { Specification } \\
\text { Criteria }\end{array}$ & Results \\
\hline Min Ave Insulation Thickness & $6.6 \mathrm{~mm}$ & $6.6 \mathrm{~mm}$ \\
Max Eccentricity & $1.02 \mathrm{~mm}$ & $0.53 \mathrm{~mm}$ \\
\hline
\end{tabular}

To ensure the dielectric system design and application, factory test in agreement with AEIC CS6 standards were performed as far as applicable on the three phases before their shipment to Detroit. The results of these tests confirmed that the dielectric insulation had been properly extruded, as shown by conformance with the applicable cable standards.

Following the manufacturing process, the cable was factory tested as specified in AEIC CS6, as described in Table 2-3. 


\section{Table 2-3}

Factory Testing per AEIC CS6

\begin{tabular}{lcc}
\hline \hline & Test Criteria & Results \\
\hline Voltage Withstand & $85 \mathrm{kV} / 30 \mathrm{~min}$ & Pass \\
Partial Discharge & $<5 \mathrm{pc} @ 52 \mathrm{kV}$ & $<3 \mathrm{pc}$ \\
Jacket Withstand & $22 \mathrm{kV} / 1 \mathrm{~min}$ & Pass \\
\hline
\end{tabular}

\subsection{Accessories}

The accessories for a Warm Dielectric HTS cable system follow the same design philosophy used for the cable; separating the thermal and electrical insulation requirements. This approach enables the use of dielectric control techniques derived from conventional accessories. Thermal control techniques, liquid nitrogen, and vacuum system requirements comprise the novel portion of the accessories.

The demonstration system includes three outdoor terminations, three indoor terminations, and an installation joint on one phase and a repair joint on one phase. (Though the original cable circuits had joints in each phase, the low weight and high flexibility of the HTS cable will enable a pull-through design. The joints were included to complete the field-assembled accessories, which would be needed for a commercial cable system.) The accessories were installed on-site.

The electrical stress control of the accessories uses pre-molded slip-on type electrical stress control. As with the cable, the electric insulation system operates outside of the cryogenic environment. So, conventional techniques and design rules have been applied. Silicon accessory bodies are used because of the simplified mold design requirements. Because the pre-molded components are specially manufactured, expansion tests to evaluate the recovery and interface pressure characteristics of the silicon body.

The unique parts of an HTS accessory involves the need to provide thermal isolation, vacuum continuity, electrical continuity (between conventional and superconducting materials), and liquid nitrogen flow through. These novel aspects also provided the greatest challenges during installation. The vacuum of the cryostat is continuous for the entire length of each phase of cable, as well as in each cable's terminations. An insulating vacuum-tight bushing is used to permit continuous cryostat maintenance while the cable is energized.

The terminations connect the HTS cable to normally conducting equipment through a "current lead" made of conventional conducting material. The current lead is a specially designed part of the termination assembly, which connects at the cold end to the HTS cable and at the warm end to the substation bus or transformer trainer. Because of the transition between the superconductor and the normal conductor cannot be avoided, the lead should be designed to minimize the energy which enters the cryogenic environment through either conduction of heat from the ambient down the conventional current lead and through resistive losses in the lead. This problem is common to low temperature electrical systems, such as superconducting magnets. The technique for solving the appropriate lead dimensions involves minimizing the 
heat transfer due to a lead operating between cryogenic and ambient temperatures at full current loading.

A challenge in the project has been to design a compact current lead that will fit into the space vacated by the original termination assemblies, as the electrical termination requires the same space as the conventional system. The current lead has been designed to occupy a minimum amount of space and to integrate with the termination structure to provide the necessary dielectric clearance and creepage distance.

The terminations must also allow liquid nitrogen to flow from the ground potential of the refrigerator plant into the cable operating at $24 \mathrm{kV}$. Typically, thermally insulated transfer lines are fabricated of concentric pipes of stainless steel (like the cryostat for the cable). The metallic transfer lines must be interrupted using a bushing, which also thermally insulates the liquid nitrogen flow. This component is unique to the Warm Dielectric HTS cable and is called a "Feed through Bushing" or FTB. The dielectric design of the bushing is consistent with the 24 $\mathrm{kV}$ insulation requirements of the conventional termination. The FTB operates between the phase and ground. For the terminations inside the station building, the liquid nitrogen flows into a manifold connection. The flow exits one cable and returns through the others. The outside terminations are each connected to the refrigeration plant through transfer piping.

The terminations were fabricated using pre-molded silicon dielectric control sleeves. The silicon-molded technique was selected to reduce mold fabrication cost and time. In a WD cable design, the thermal control, $\mathrm{LN}_{2}$ transfer, and vacuum transfer must all be conducted at high voltage. The thermal control was accomplished using an optimally designed current lead. Current lead optimization techniques for low temperature applications have been thoroughly documented in EPRI report 1000160, "Superconducting Cable Construction and Testing.”

The termination structure is shown in Figure 2-16. The key elements visible in this photograph are (a) the current lead, (b) the normal insulator, and (c) the $\mathrm{LN}_{2}$ and vacuum pass through insulator. Additionally, (d) the vacuum jacketed piping to transfer the $\mathrm{LN}_{2}$ between the refrigerator and the cables can be seen.

The terminations also considered the requirements for cable system testing. As this system represented a unique opportunity to analyze the performance of HTS cables in the utility network, sensors were added to the cable construction to enable the measurement of temperature and real voltage losses along the cable length. These sensors, which are placed in the cryogenic space, must be connected to instruments located at ambient temperature. So, the terminations include wiring pass through plugs for these tests. A special power supply that uses a current transformer and suitable electronics to generate a dc voltage to operate the instrumentation from the line current in the cable.

Two styles of joints were employed for the project. The first joint was installed as an installation joint. This joint used the same premolded silicone body as the terminations. The joint was installed between the ends of the X Phase that had been cut in the factory to the required lengths. The joint was installed in MH13465. The joint creates continuity of the HTS conductor, the vacuum space of the cryostat and the dielectric system. 
A second joint was installed on the Z Phase after cable installation. The phase was cut in MH13465 to demonstrate a repair jointing procedure. This joint differs from the installation joint, as it cannot use a premolded sleeve. Rather the dielectric system is reconstituted using taping methods.

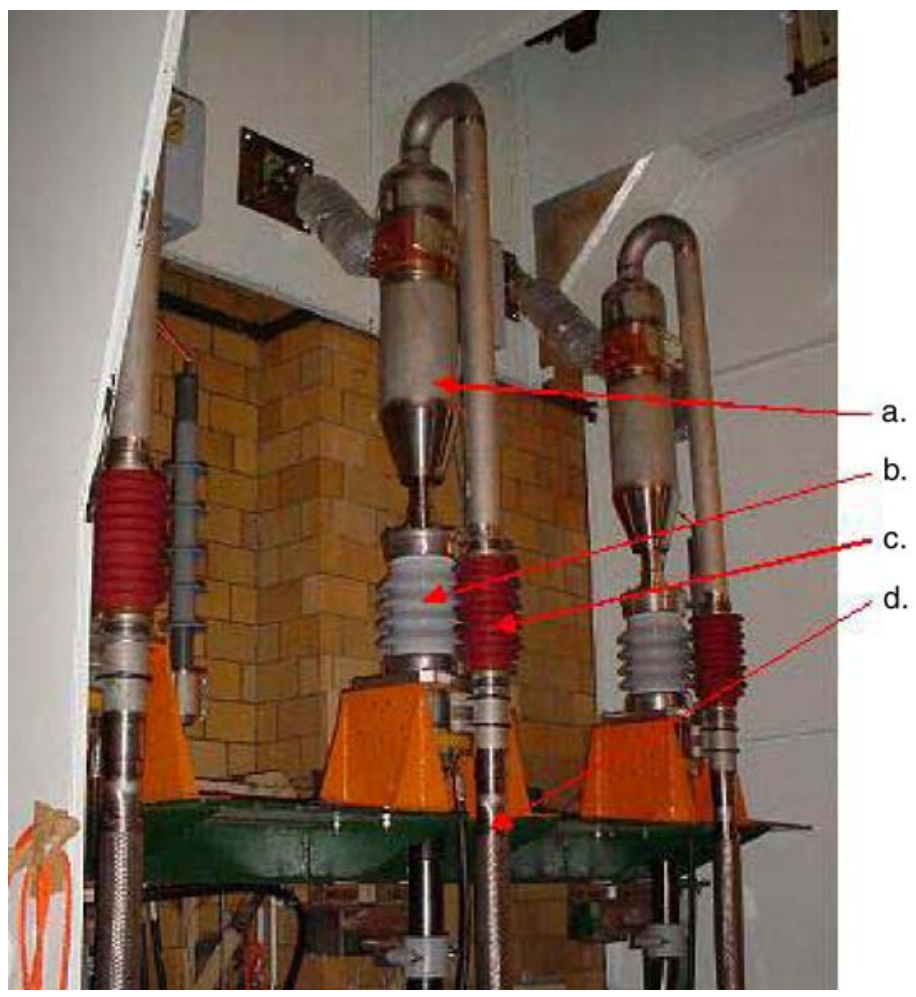

Figure 2-16

Termination Detail

\subsection{Refrigeration System}

Maintaining the HTS cable circuit at the necessary temperature requires the use of specialized refrigeration techniques. For this project, several types of cryogenic refrigerator were considered. In the context of the demonstration project, the specific characteristics sought in the refrigerator were reliability, operability, and scalability. The demonstration project objective is to prove the technical and logistical feasibility of HTS cables in the utility environment.

The cryogenic system must perform with absolute reliability over the length of the program, operating continuously even during contingencies, such as maintenance, power failure, and component failure. The utility partner, Detroit Edison, expressed their desire to have a refrigeration plant that would be fully self-contained, requiring no periodic (or at worst minimal) observation and action by the operators. Finally, scalability of the refrigeration plant was added to weight concepts that could be representative of systems cooling long length cable systems.

The final refrigerator concept uses a reverse-Brayton cycle refrigerator with helium as the coolant to remove heat from the liquid nitrogen loop that flows through the cable system. The 
system is designed to cool the $\mathrm{LN}_{2}$ flowing through the cable and maintains it at less than $67 \mathrm{~K}$ by removing up to $4300 \mathrm{~W}$ of energy. In case of the helium system's unavailability, a backup refrigerator has been added. This configuration provides a very high level of reliability and flexibility to the system operation.

Reverse-Brayton refrigeration systems have been used in hundreds of helium liquification plants around the world. They have demonstrated reliability and design techniques and provided a very high confidence in the system specification. Helium refrigerators can have cooling capacities much higher than foreseen for even the longest cable application. This combination of reliability, technical maturity, and scalability directed the selection of the final refrigeration configuration.

The backup refrigerator uses an evaporative bath of nitrogen to provide refrigeration. In order to produce refrigeration at low temperatures (below the atmospheric boiling point of nitrogen, 77 $\mathrm{K})$, a vacuum system reduces the boiling pressure and so the saturation temperature. The control logic has been designed to automatically engage the backup system in the event of a primary system outage. Also, the logic permits parallel operation of the primary system and backup system in order to provide additional refrigeration capacity in case of transient events causing heating in the cable.

Installing the refrigeration plant into the Frisbie substation required particular care in the equipment layout. The station had a small area available to the west of Transformer 101. The refrigeration equipment and enclosure were designed to fit within the available space, and to maintain necessary clearances. The position of the refrigeration equipment is shown in Figure 1.

\subsection{Vacuum Systems}

To support the low temperature operation of the cable system, besides the refrigeration system described above, is a vacuum system to maintain a low gas pressure in the cryostat to provide high efficiency thermal insulation.

Vacuum systems are located at each termination position. They are composed of a separate pumping group for each cable and connected near each termination. The pumping group is somewhat standard for cryogenic vacuum applications and includes a mechanical roughing pump and a turbomolecular pump. The group uses PLC-based logic for pump control and communicates the data with the master Data Acquisition System. The vacuum pumps will operate continuously during the test program to ensure high efficiency of the thermal insulation.

\subsection{Communication and Monitoring}

Evaluation of the cable performance during the project will be primarily its ability to serve the necessary load without requiring particular maintenance or attention. However to characterize and learn from the demonstration project, the cable and refrigerator system will be instrumented to permit examination of the dynamic character of the aggregate system. 
As with conventional cables, the temperature of the cable provides the most important information on system behavior. To measure this, temperature will be monitored at discrete locations along the length of the cable, as well as past the termination in the liquid nitrogen transfer system. Discrete temperature measurements taken on the cable conductor gives the most specific detail of the system operation. These measurements required specially designed communications and power supplies, because the measurement will be taken on the conductor at line voltage. The signal will be converted to a digital signal and transmitted via fiber optic links. The measurements taken past the terminations in the liquid nitrogen transfer system are positioned at ground potential, and don't require special signal conditioning devices. These measurements will indicate the integrated behavior along the cable.

All of the key parameters for the cable and refrigerator will be transmitted to a computer-based data acquisition system. The data was analyzed automatically to detect measurements beyond the normal parameter limits. In the event of an alarm condition, prescribed operational procedures will be implemented.

Detroit Edison has requested a simple representation for the status of the cable system; three signals will indicate a problem and the level of action that will be required. The lowest level will be triggered by parameter variations past normal, but below critical levels. This will serve as a warning for the operators. A second level indicates that a parameter has exceeded the permitted operating range, and that load on the cable should be removed. This precaution is to avoid exacerbating a minor problem and possibly damaging equipment. A third, most severe, level results in the trip of both voltage and current from the cable. This level would indicate a severe problem with the system, and maintenance or physical examination of the system is necessary. Removing the voltage and current will ensure a safe operating environment for personnel responding to the alarm.

\subsection{Site Preparation}

To prepare the Frisbie substation for the HTS cable, foundations for the refrigerator were poured, the relaying scheme was updated, and the house service power feeds were reconfigured.

In addition to the traditional relaying system, an additional relaying scheme was installed to remove load on the cable for a refrigeration system failure, as discussed earlier.

The refrigeration system will be located next to Transformer 101 bay, with the liquid nitrogen storage tank and helium buffer tanks just north of the refrigeration container. Since the refrigeration system must be operating for the HTS cable to carry load, a redundant house service was planned for the refrigeration system. The primary refrigerator will be powered by a $480 \mathrm{~V}$ service from an overhead $4.8 \mathrm{kV}$ distribution circuit. The backup refrigerator, $\mathrm{LN}_{2}$ circulation pumps and control system will be powered from the station $240 \mathrm{~V}$ service, which is fully redundant. 


\section{INSTALLATION}

The components of the system were all installed on site. Wherever possible, Detroit Edison work crews participated in the activity. Their involvement included cable pulling crews for the cable installation, equipment technicians during commissioning the cable system, and electricians assisting with equipment wiring and controls.

Due to the unique nature of the cable system, extreme care has been taken during handling and installation of the cable and accessories. The cable was pulled from the substation building toward the transformer bay along the $400 \mathrm{ft}$ route. The tension along the pull was monitored at the winch position, and was consistent with calculations.

\subsection{Installation Design}

Site constraints dictated a minimum cable-bending radius of less than $1.0 \mathrm{~m}$. HTS cables are somewhat more sensitive to bending strain than the conventional alternative, so cable guides were specially designed. These guides ensured that the cable bend radius was always supported, so that points of high lateral stress were eliminated and that there was no risk of deformation of the cryostat. Also, the large number of bends (five $90^{\circ}$ bends over a $120 \mathrm{~m}$ length, could cause high pulling tensions to develop if rubbing friction developed through the bends. Figure 3-1 shows a 3-D CAD drawing of one of the cable supports. The normal route, shown earlier in Figure 1, passes the cable from the substation building to the transformer bay. Figures 3-2 - 3-4 show the cable support system at different positions along the route. The primary function was to support the cable bends whenever they would be outside the duct and to minimize the friction generated by passing the cable through these supports. 
Installation

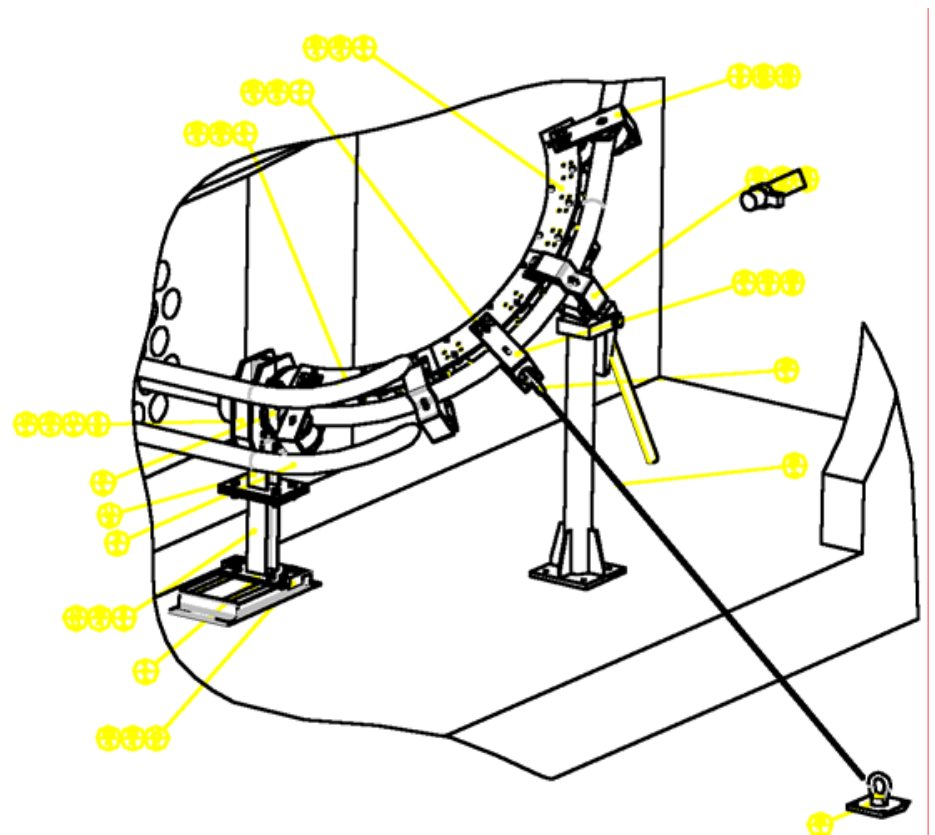

Figure 3-1

CAD Drawing of Cable Design Route

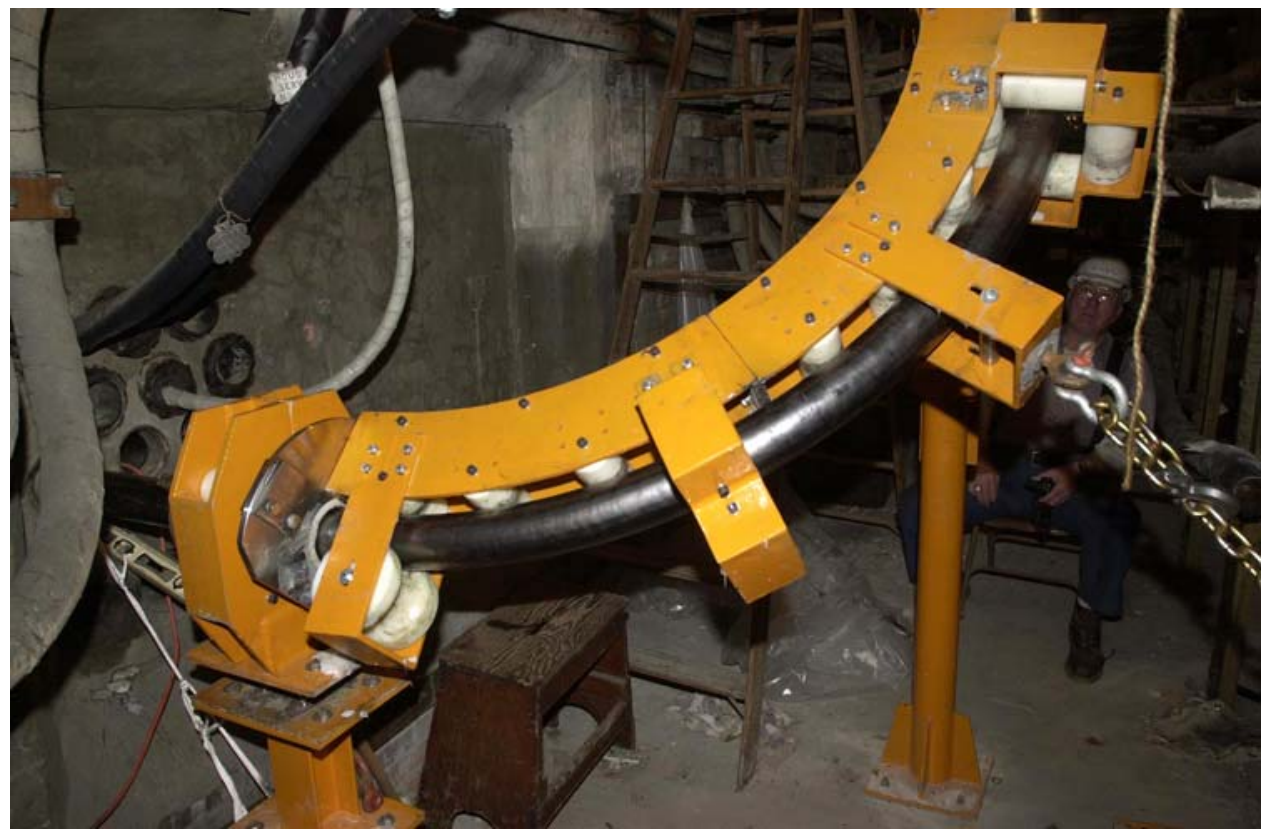

Figure 3-2

Guide Structure used for Multi-Axis Support in Station Basement 


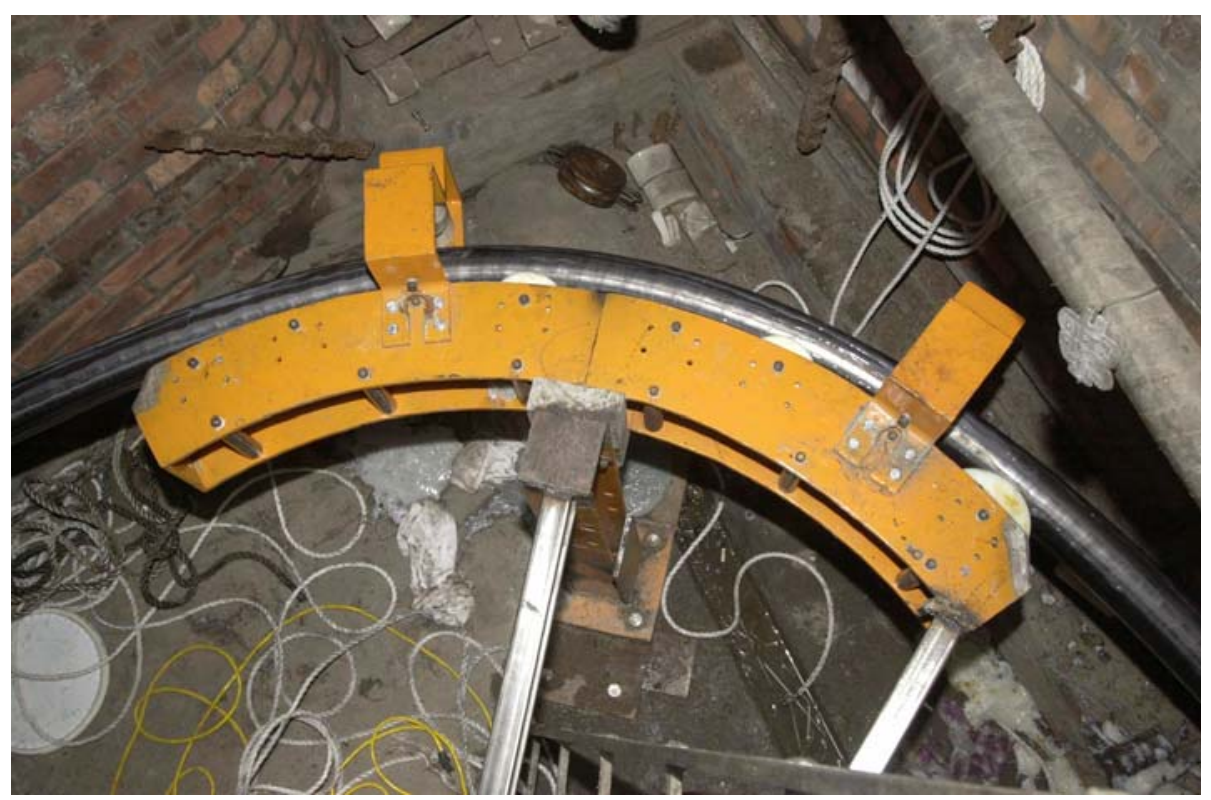

Figure 3-3

Support used to Control Horizontal Bend in MH10671

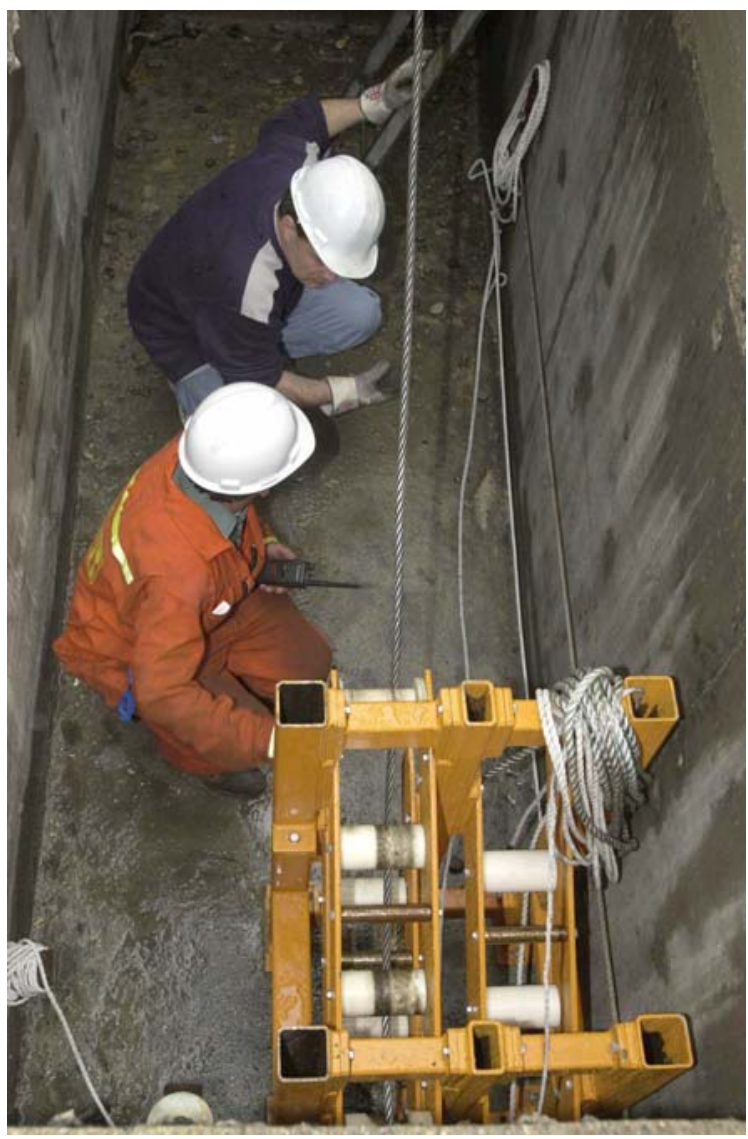

Figure 3-4

Cable Support Structure used to Direct Cable Exiting MH13466 
The cable will be installed in a "fixed-end" configuration. This configuration restrains the cable from contracting upon cool down to operating conditions. The termination support structures and configuration were reinforced to ensure adequate mechanical strength to resist this axial force.

Some of the new accessories required for the HTS cable, such as $\mathrm{LN}_{2}$ piping and vacuum systems, had to be sited near the cable system. This presented a new challenge, as the original design of the distribution substation had not considered these components. Figure 3-5 shows the placement of the vacuum system near the transformer-side terminations.

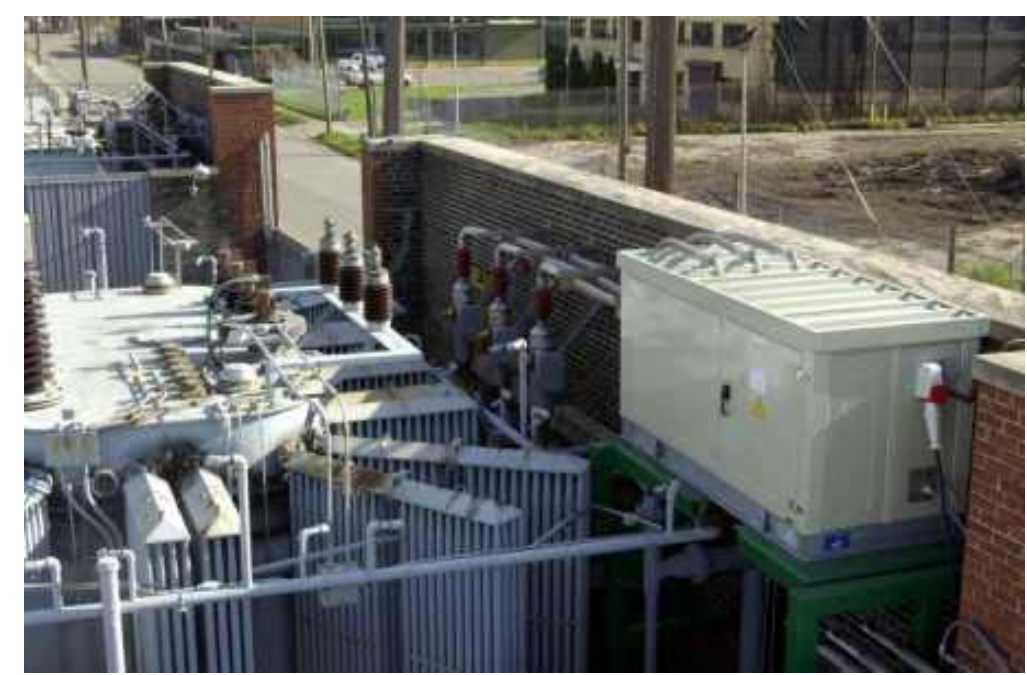

Figure 3-5

Vacuum Enclosure for Transformer

\subsection{Cable Installation}

The cable installation was accomplished by installation crews from both Pirelli's High Voltage Engineering and Construction Services Company (ESCO), and Detroit Edison's underground group. Figure 3-6 shows Detroit Edison workers guiding the cable during installation. 


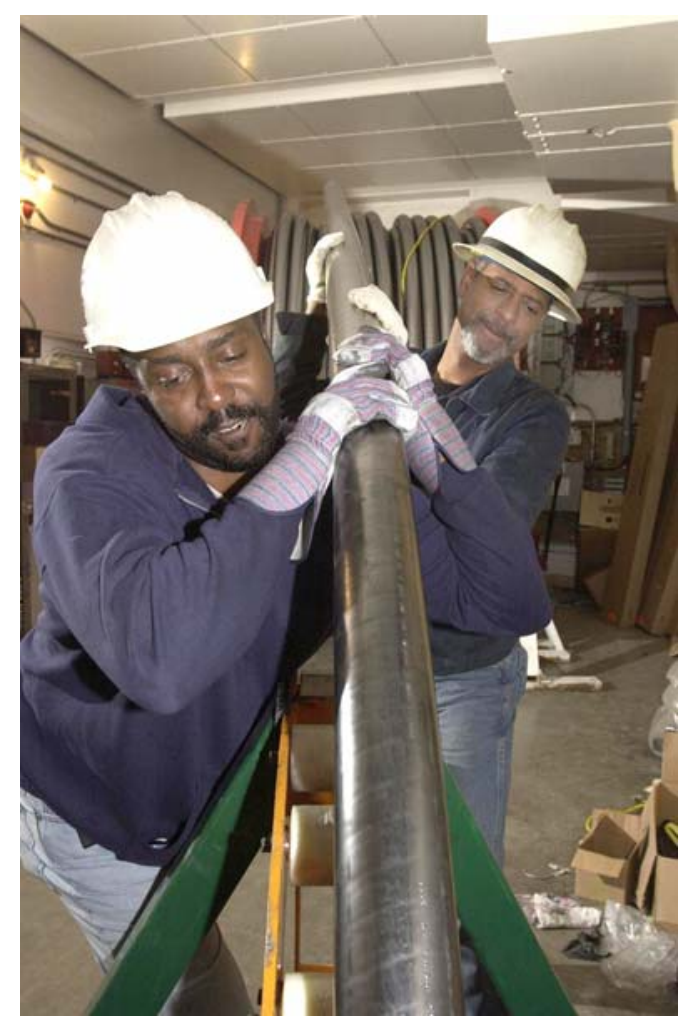

\section{Figure 3-6}

Workers Guiding Cable During Installation

The installation process involved setup of the cable support equipment, experimental pulls with mock-up cable sections, and the actual cable pulls. The process was more involved than that used for typical cable installations in order to minimize the chance of damage to the unique cable system. After installation, samples of cable conductor which had passed through the entire installation route were returned to the lab for analysis. A global measurement of the critical current capacity (a key factor in HTS conductors), as well as measurement of critical current for each of the four layers of conductors were performed. The results of the measurement for the complete conductor are shown below in Figure 3-7. 


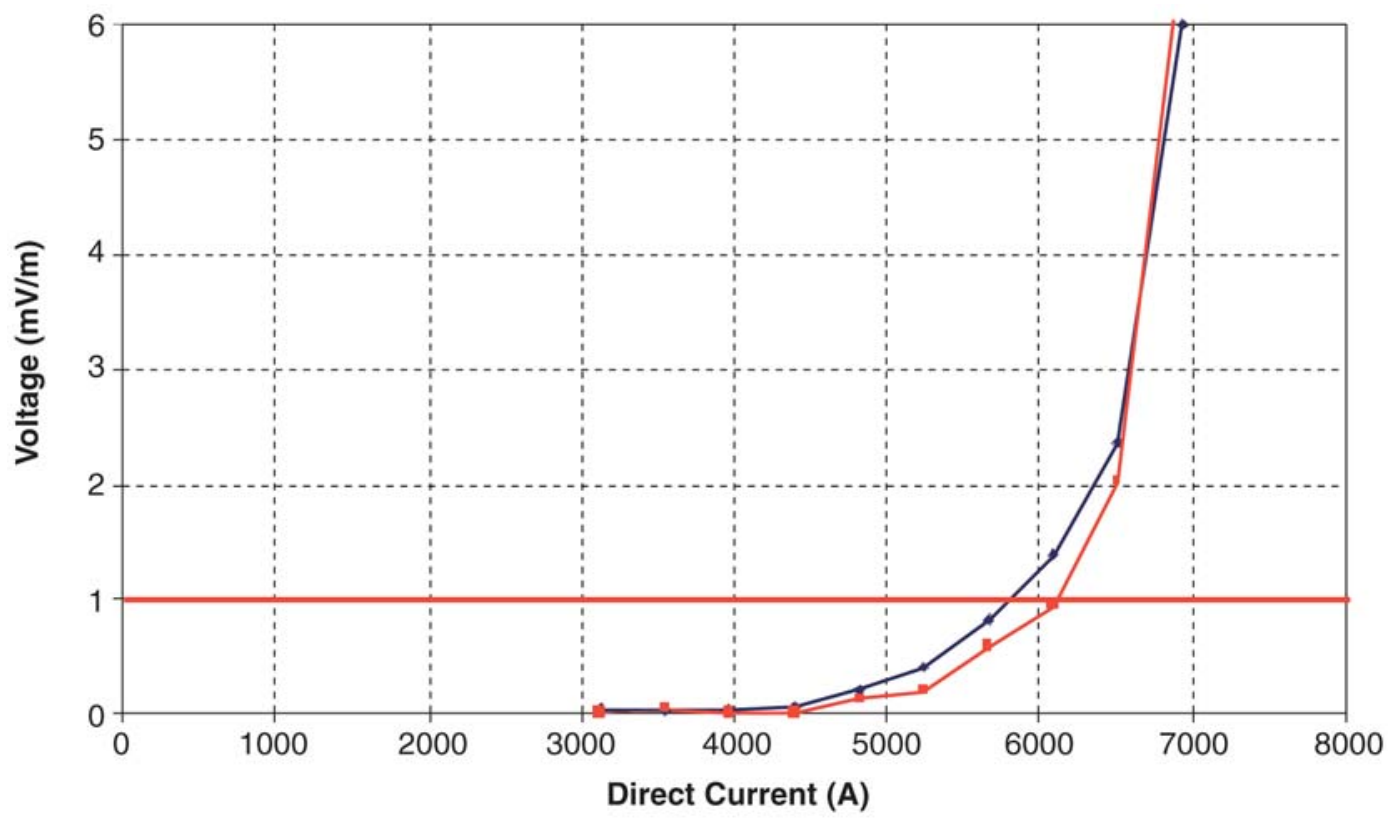

\section{Figure 3-7}

Critical Current Performance after Cabling and Manufacturing

As can be seen, the critical current for the entire cable assembly at $77 \mathrm{~K}$ remained about $6000 \mathrm{~A}$. This value is within $10 \%$ of the critical current measured immediately after conductor assembly. So, the total cable experienced less than $10 \%$ degradation of capacity due to forces during cabling and installation.

During installation of all of the cables, careful attention was paid in each of the manholes, in the station basement, and in the transformer bay as the cable exited the duct route. Workers were stationed in each position to monitor the progress of the cable and to apply lubricant continuously. The cable's stiffness required careful alignment of the support structures to limit pulling tension.

The first phase installed was Phase X. This phase was selected to include the installation joint. As the phase was to be jointed, the cable was factory prepared to the necessary lengths and pulling heads applied. First, the phase between the substation and MH13465 was installed by pulling from the transformer end. Then, the second section was installed from the transformer end to MH13465. Prior to installation of the remaining cables, the joint was installed. This activity will be discussed in a later section.

The other cables, Phase Y and Phase Z respectively were pulled completely through the route between the station building and the transformer. The pulling characteristics for this cable were exactly as anticipated by the pulling trials conducted earlier in the project; the maximum pulling force was generated by bending the cable into the entrance of the bends occurring between MH10671 and MH13465 and in MH13465. This behavior was not evidenced by Phase X, because its ends stopped in MH13465, and so were not subject to bending. 


\subsection{Accessory Installation}

All of the accessories were field installed. For the terminations, this effort involved creating the normal dielectric termination using the premolded sleeves, followed by placement and connection of the current lead and $\mathrm{LN}_{2}$ transfer piping. A conductor splicing technique was used to ensure very low electrical resistance connections.

The cable joints were installed in MH13465, as were the joints of the nine conventional cables replaced by the three HTS cables. Both joints include splicing the conductors of the ends of the two cables, as well as joining and sealing their cryostats. Following each weld on the cryostat, leak checks were performed to verify the quality of the welding. The installation joint used a premolded sleeve to perform the dielectric function, while the repair joint was hand taped. All jointing work was performed in the manhole. Figure 3-8 shows a welder sealing the cryostat of the installation joint.

Installation of the terminations proceeded similarly to the joint installation. The dielectric termination was prepared first, using the same techniques as for conventional cables. The current leads were installed in place and the current carrying connection completed. Again, welds were used to seal the cryostat. The terminations also include $\mathrm{LN}_{2}$ piping which connects the terminations at the transformer with the refrigerator and which transfers $\mathrm{LN}_{2}$ between the phases at the substation. In most cases, this piping was factory fabricated.

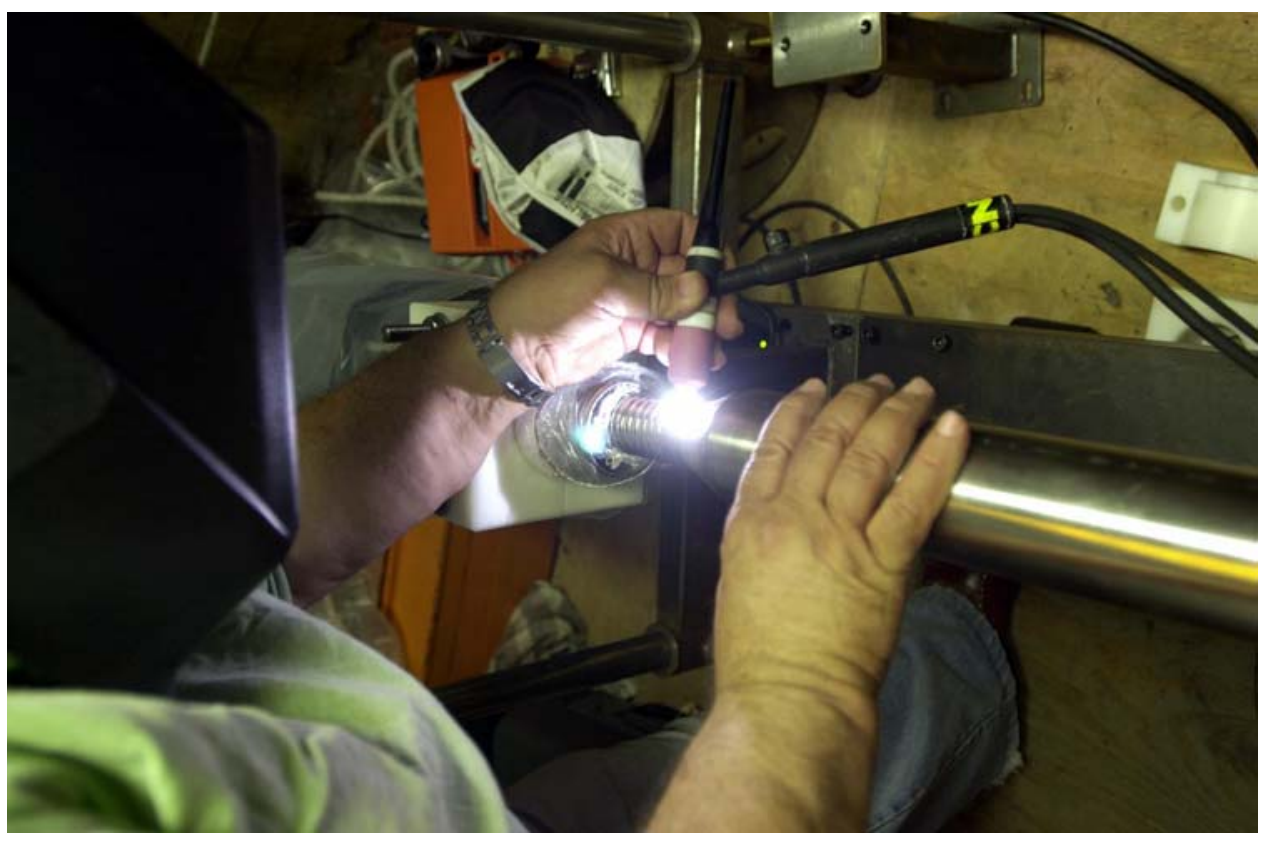

Figure 3-8

A Welder Completes the Cryostat Sleeve for the Joint 


\subsection{Refrigeration Installation}

The refrigeration unit was installed through an effort that included Linde's commissioning engineers and project managers and Detroit Edison electricians and equipment personnel. Installation of the refrigerator includes locating all of the equipment, completing field installation of the connecting piping, completing the control wiring, and making all of the electrical connections.

The refrigerator included an internal bypass loop to permit system testing and verification of load capacity and pump characteristics. Following installation, system tests were successfully conducted demonstrating that the refrigeration plant could provide greater than the design capacity at the required outlet temperature, and that the backup system would function to provide a high level of reliability for the demonstration.

Figure 3-9 shows the coldbox being positioned by Detroit Edison riggers. After the coldbox was placed, the compressor units were installed. Figure 3-10 is a photograph of the interior of the refrigeration equipment building with all equipment installed. The compressors are seen in the foreground with the coldbox in the back.

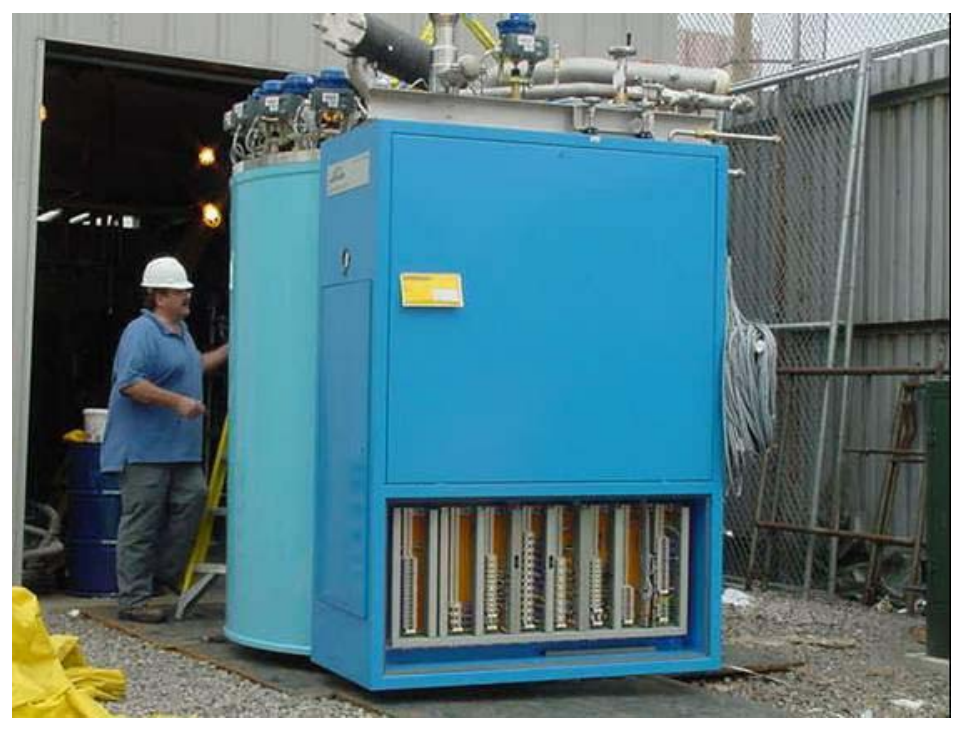

Figure 3-9

Moving the Cold Box into the Refrigeration Building 
Installation

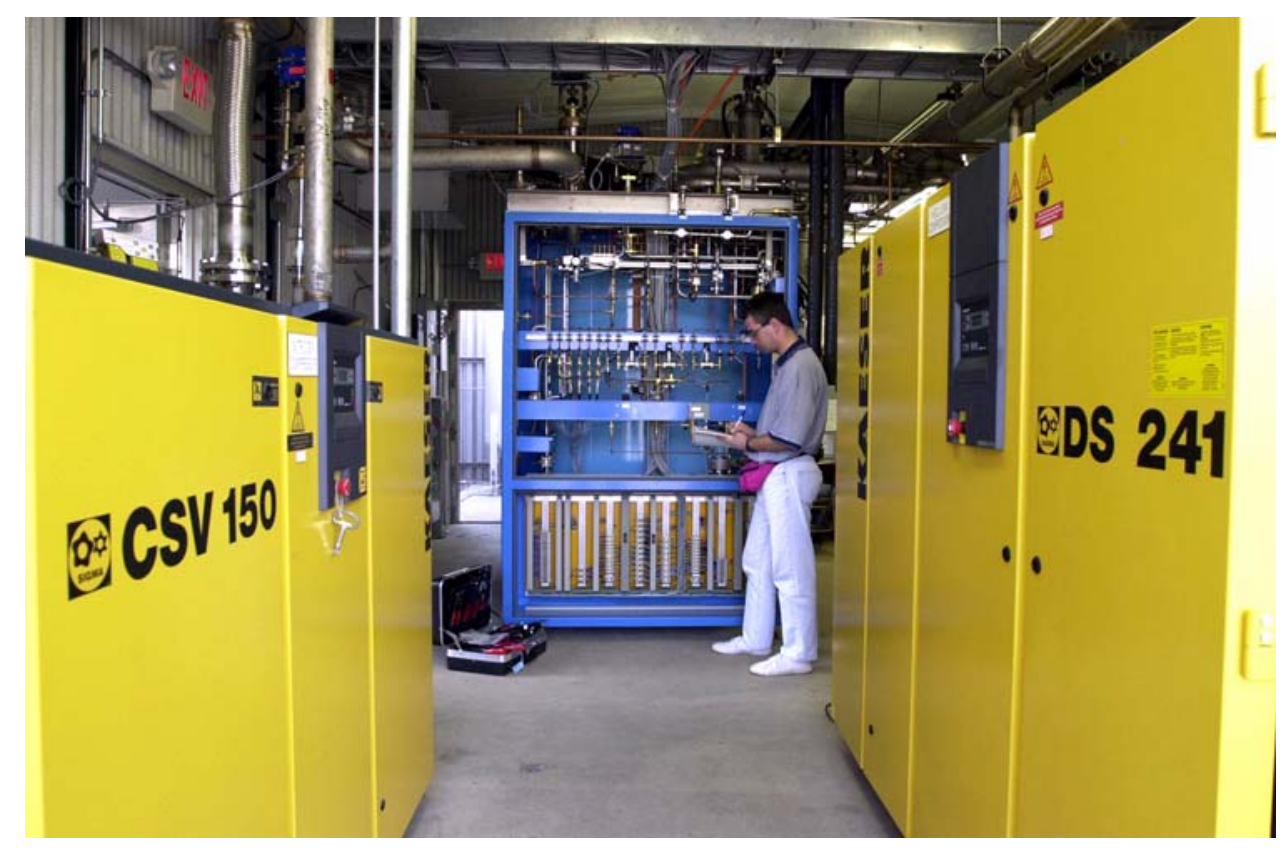

Figure 3-10

Inside of Refrigeration Building 



\section{4}

\section{VACUUM LEAK DETECTION AND LOCATION}

\subsection{Initial Leak Detection}

After installation, in late December 2001, tests were conducted to prove-in the integrity of the vacuum system in preparation for the power-up of the system. The cables' cryostats were purged with $\mathrm{CO}_{2}$ and then were connected to pumping groups. After about one month of pumping, the residual pressure was not satisfactory in any of the phases, indicating possible leaks.

Therefore, pressure variation response tests were conducted on each conductor phase. Using different pumping groups, the cryostats and conductor space inside of the inner corrugated tubes were evacuated. After evacuating the conductor space (thereby minimizing leaks between the conductor space and cryostat), an improvement in vacuum level of phases $\mathrm{X}$ and $\mathrm{Z}$ has been recorded. All the conductor spaces were pressurized with GN @ 1.6, 2.6 and 3.6 bar. An immediate vacuum pressure response was recorded on phases $\mathrm{X}$ and $\mathrm{Z}$. Before increasing pressure in the conductor space from one level to the next, the pressure in the cryostat was allowed to reach a plateau. Pressure was monitored from each end of the cryostats. See Figure 4-1 below. Note that Vacuum gauge X out was not working properly.

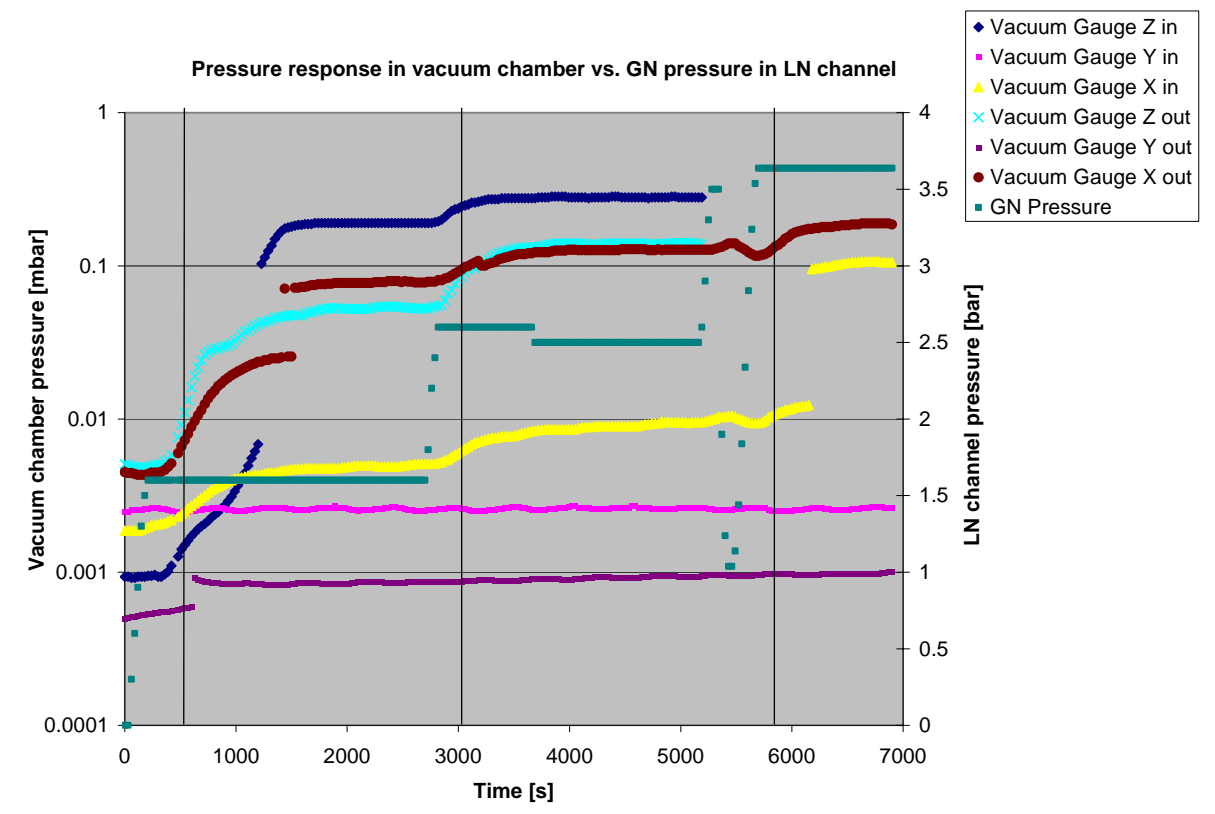

Figure 4-1 Inner Cryostat Exiting Cryostat Fabrication Tool 
From this test we concluded that:

A. Phase $X$ and $Z$ vacuum gauges response could give an indication on leak position, but their responses almost equal in time but at different level, could indicate:

- leaks of different size on both terminations;

- leak on phase $\mathrm{Z}$ in and on phase $\mathrm{X}$ out.; and

B. Phase Y didn't show any response to pressure variation.

In order to further identify the size and leak locations in Phases $\mathrm{X}$ and $\mathrm{Z}$ and to confirm there were no leaks in Phase Y, a He diffusion time test was conducted. The cryostat of each phase was evacuated, and the He background level was measured with a mass spectrometer (Pfeiffer QualyTest) connected at one end (Sec. I). Then the He leak rate and the He diffusion time was measured, pressurizing the inner corrugated tube@1 bar. The test was repeated, moving the mass spectrometer to the other end of the cryostat (Sec. 3) and then for each phase. See attached graphs.

These tests showed that both Phase $\mathrm{X}$ and Phase $\mathrm{Z}$ have probable large leaks close to the indoor termination end of the cable, and that Phase $\mathrm{Y}$ had a probable small leak close to the indoor termination end of the cable.

After evaluating the data from these tests, it was determined that at least partial disassembly of Phases $\mathrm{X}$ and $\mathrm{Z}$ was required to further investigate the criticality of the leaks and to determine if the leaks were repairable insitu. This further investigation necessitated both design of the tests and components to reassemble the cable phases after the tests were conducted and leak repaired, if possible.

\subsection{Investigation of Leak Criticality - Phases X and Z}

In particular, quality tests on the inner corrugated tube from short lengths of cable which were connected to the pulling head during the initial cable installation and subsequently cut from the cable and returned to Italy were conducted in February 2002. These short lengths had experienced the worst installation loading.

The He leak test has been performed on some samples of inner corrugated tube. These tubes have been taken from the extra length of the installed cable near the cable head. The aim of the test was to verify statistically if any damage occurred to the longitudinal weld as consequence of cables installation. All the components were tested with He sniffer and the He spray method, being both methods based on a mass spectrometer analysis. Neither the spray nor the sniffer methods have shown any detectable leak in the longitudinal weld of the inner corrugated tube. Therefore it was concluded that leaks, if existing, are lower than $1 * 10^{-8} \mathrm{mbar} / \mathrm{s}$.

Further, thermal inertia tests on the cryostat with low vacuum pressure were conducted in February/March of 2002. This test was carried out on a 3-meter long cable sample. Three holes at $120^{\circ}$ apart around the longitudinal axis of the cable were drilled in the triple insulation of the 
cable close to the two ends and in the middle of the sample. Nine thermocouples were placed in these holes to monitor EPR temperature during the cooling down. The LN channel was then filled with LN, with varying pressures in the cryostat. The goal of the test was to evaluate the cool-down time of triple extrusion inner surface; when a good residual pressure cannot be assured; that is if cryo-pumping could ensure a good residual pressure level. We found that for residual pressure higher than $10^{-3} \mathrm{mbar}$, heat conduction due to residual gas is high enough to cool EPR temperature down to $250 \mathrm{~K}$ in approximately 4 hours. This result confirmed that it would be almost impossible to safely perform electrical test on the installed cables.

All the components that would be needed to reassemble the cables were designed. Furthermore five test chambers were designed, purchased, tested with few modifications required. The chambers were designed for use in the leak detection activity in Detroit. In particular, the investigating technique consists of removing from the termination's outer jacket one piece at the time, providing separation between sections with removable seals. This technique requires cuts, temporary components and welds for the reconstruction. Care must be taken during the cut phase in order to reduce vibrations and to leave a safe and wide enough area where to work with the temporary chambers needed for the test. The cutting device and method and the test chambers were tested in Milan for efficiency, that is, providing an opportunity for a design review of the tools. In fact few modifications were necessary. Main modifications were done to obtain an easier fit of cutting tools on the terminations and a good sealing performance. Two main challenges were overcome: narrow spaces to fit temporary test chambers and seals on orthogonal faces. The test showed a sufficient fit for the chambers and a good behavior of the seals.

These components were sent to the Frisbie site and investigation was begun and completed on Phase X. Figure 4-2 is used as a reference point for the ensuing discussion of this investigation.

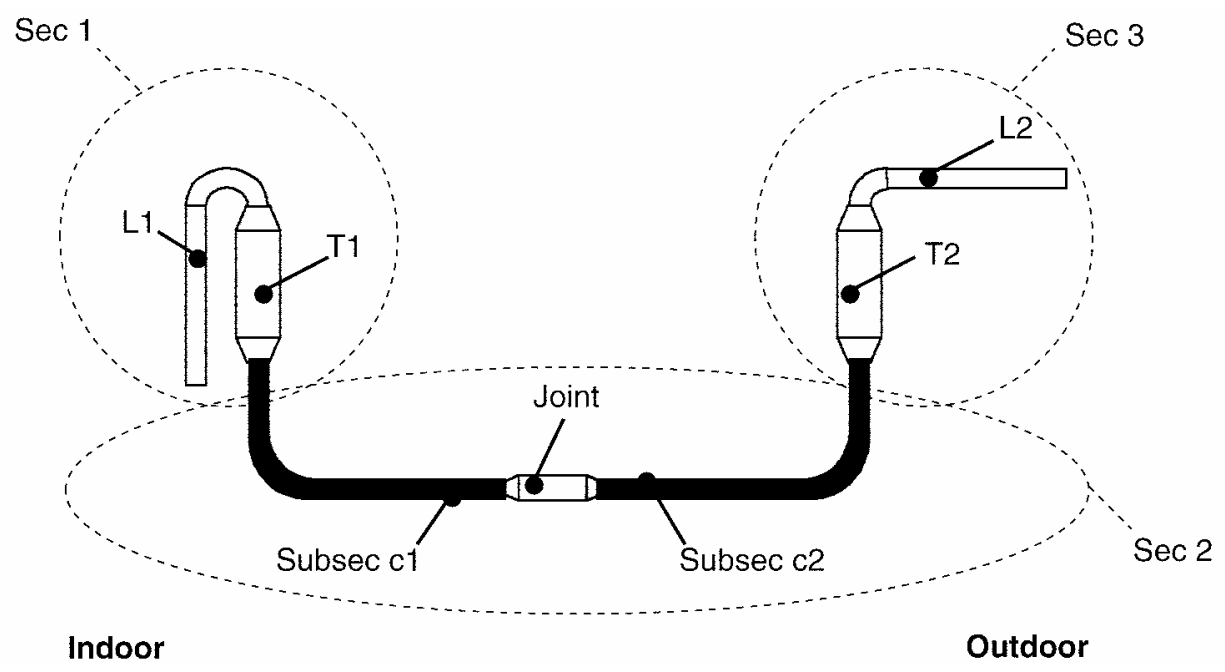

Figure 4-2

Schematic for Leak Detection Testing for Phase X 
After installing the temporary support for the termination (T1), the lower part of the indoor termination was cut away so that the type $\mathrm{C}$ and type $\mathrm{D}$ test chambers could be mounted. See Figures 4-3 and 4-4.

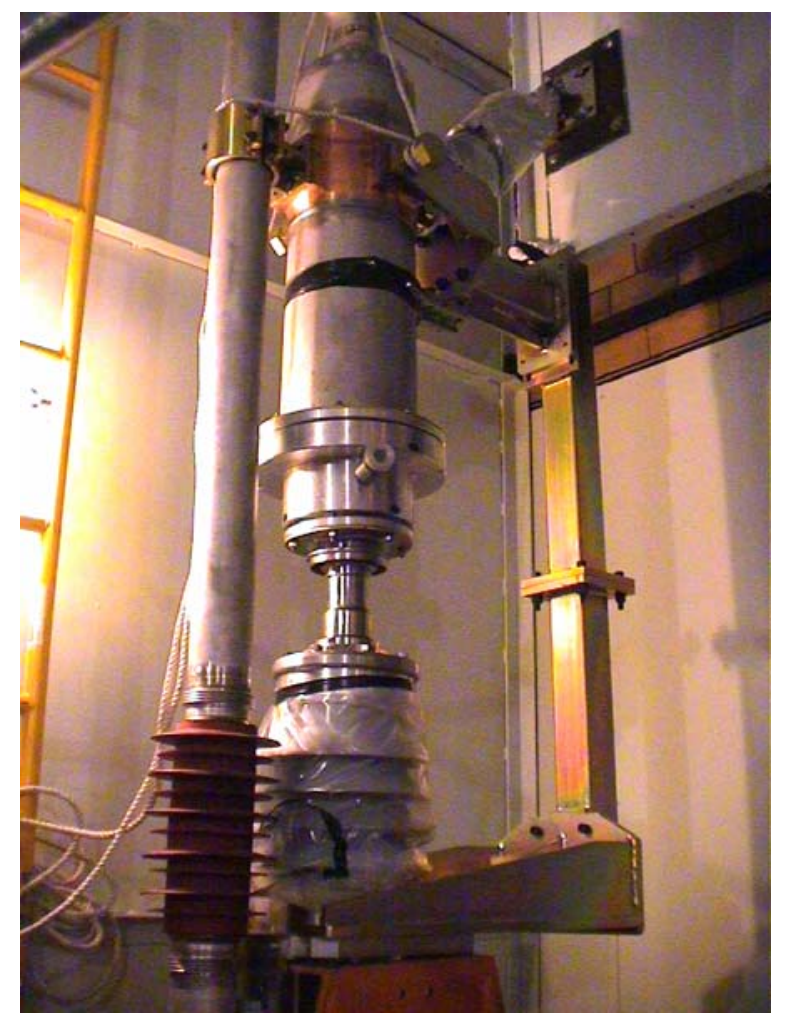

Figure 4-3

Diagram of Temporary Support for Termination (T1)

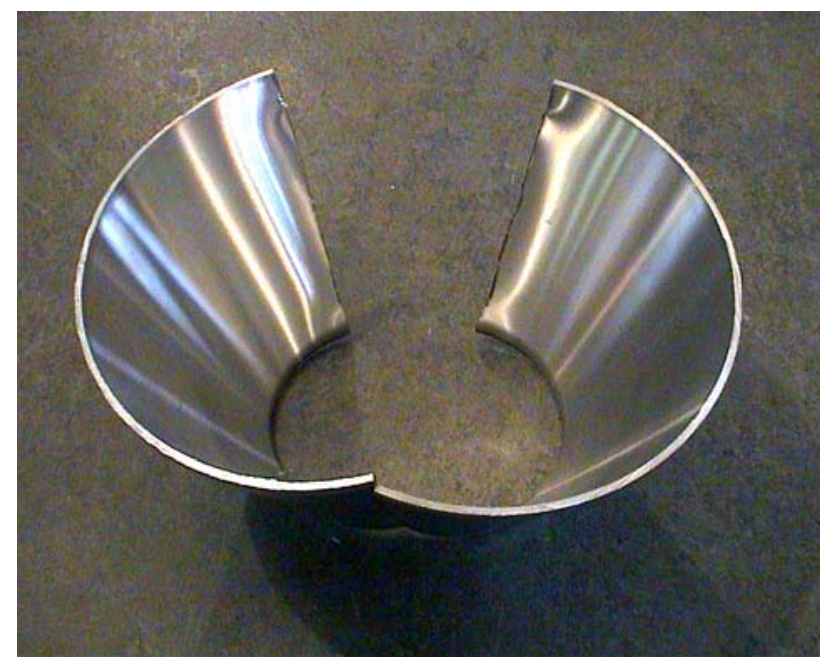

Figure 4-4

Photograph of Lower Portion of Indoor Termination Cut to Accommodate Test Chambers 
After placing in position the type $C$ test chamber, the cryostat of Sec. 1 and the whole LN channel were evacuated, and the Sec. 1 cryostat connected to a mass spectrometer. After verifying the mass-spectrometer response time with a calibrated leak (few seconds), the LN channel was filled from a port on the cold box with GHe at 15 psi. After 10 minutes with the mass spectrometer response being steady and below $1 * 10^{-8}$ standard cubic centimeter per second (sccs), the test was considered concluded, and that no leaks were present between the LN channel and the cryostat in Sec. 1.

Following the test on Sec. 1, the type $\mathrm{C}$ test chamber was removed and the type $\mathrm{D}$ test chamber installed. To reduce the He background, the LN channel and cryostat gap were flushed with GN.

A mass spectrometer was connected on each end of the section to be tested (i.e. to the vacuum port of the type D test chamber and to the vacuum port of L2). The LN channel and cryostat of Sections 2 \& 3 were evacuated. Then, the LN channel was filled with GHe at 15 psi. This test positively identified a leak. The leak was detected first by the mass spectrometer connected to the test chamber (at the indoor termination position) and then by the mass spectrometer at the outdoor termination position. The results of this test are overlaid with data from a similar test conducted in late December 2001 in Figure 4-5 below.

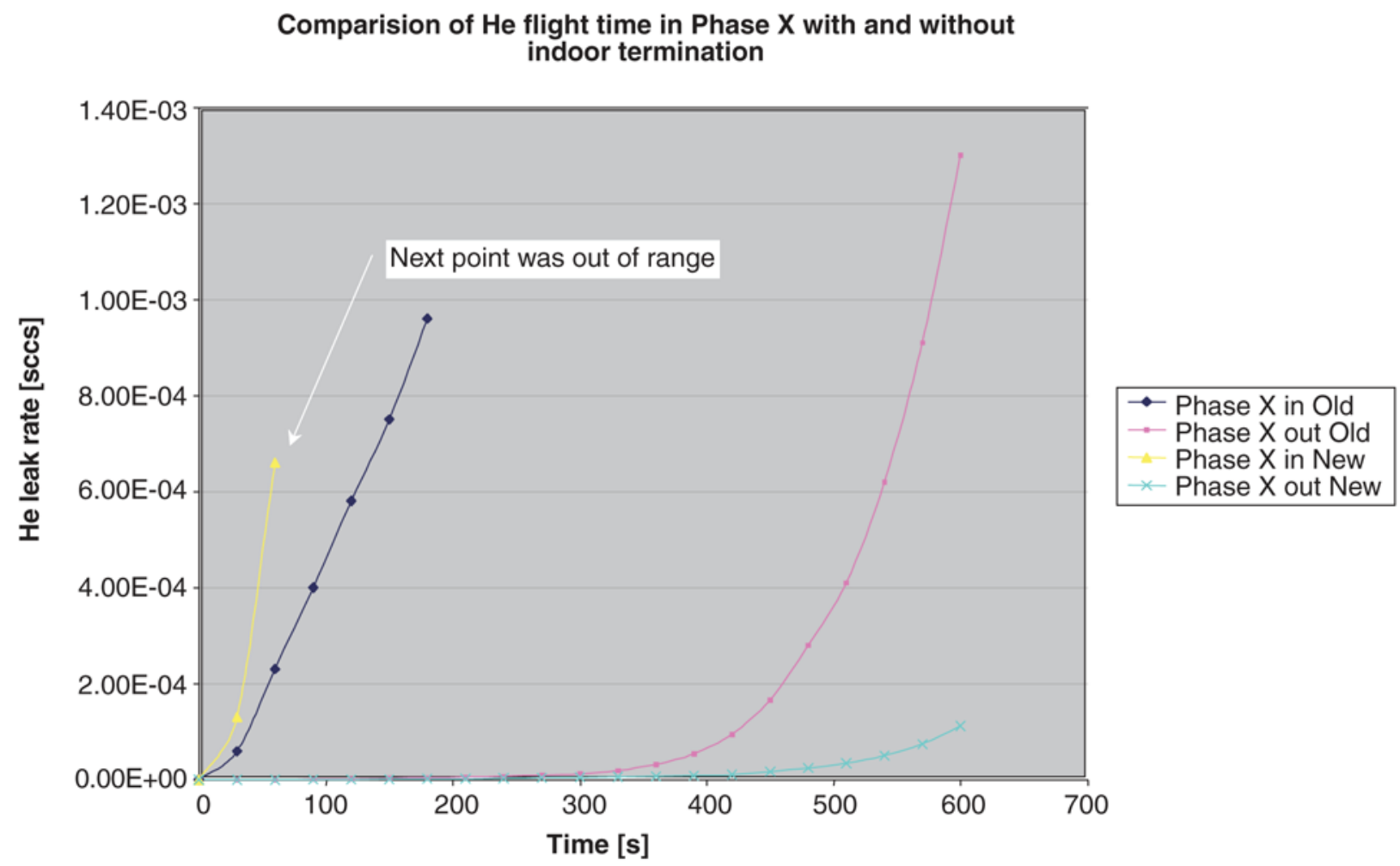

Figure 4-5

Comparison of He Flight Times in Phase X Data for Late December 2001 and Current Sample

The differences in the results are reasonable and consistent. In this test, the He does not have to diffuse through the inner termination (which results in a higher conductance, and so a shorter 
response time to the detector connected to the type $\mathrm{D}$ test chamber). Furthermore, two leak detectors were used for this test. For the tests in December, only a single detector was available. The leak detector at the indoor position causes the response time at the outdoor position to be delayed compared to the test with only a single detector. This is due to the high conductance seen by the indoor detector drawing more of the leak toward its position. So, the difference in response time between phase_X_out_new and phase_X_out_old was expected. Thus, again, this test confirmed that the leak, or at least the most significant leak, was closer to the indoor termination.

\section{Separation of Subsec c1 from Subsec $c 2$ and Sec 3}

After flushing the LN channel and the cryostat gap overnight with GN, the dielectric splice and the outer wall of the cryostat joint were removed, and temporary seals nut in place as shown in Figures 4-6 \& 4-7 below.

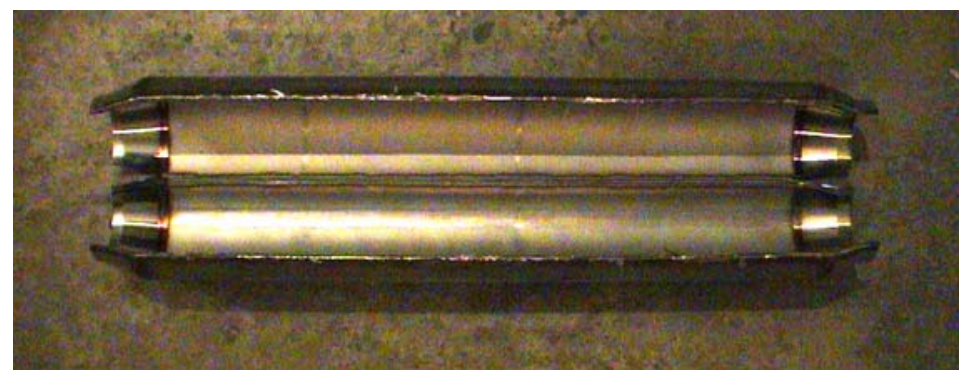

Figure 4-6

Dielectric Splice and Outer Wall of Cryostat Joint

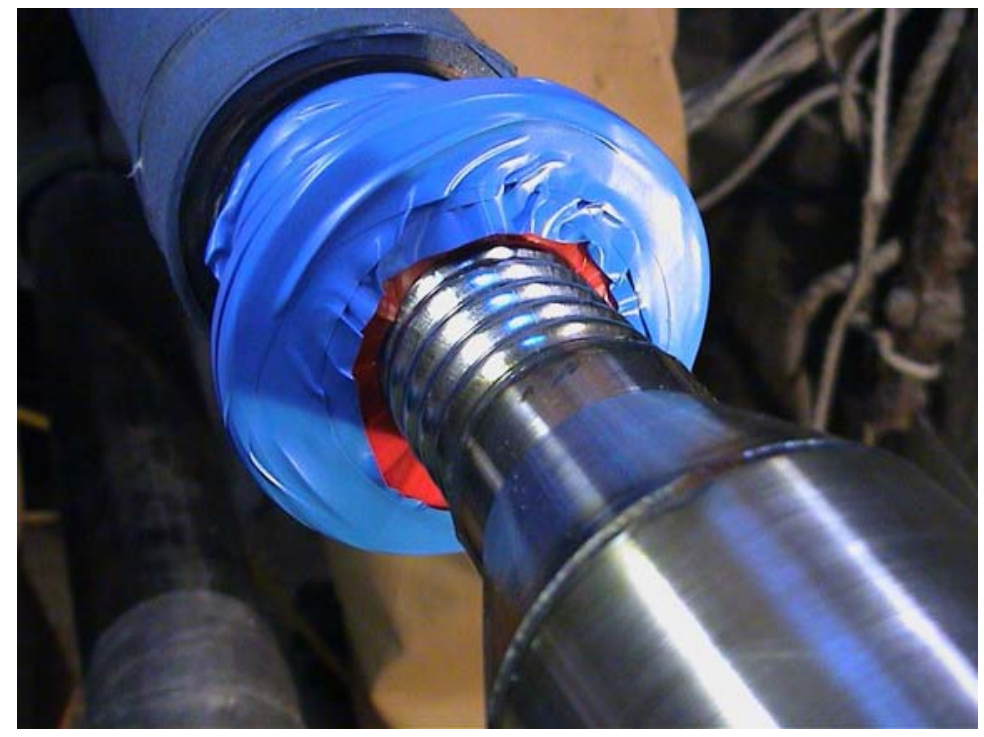

Figure 4-7

Temporary Sealed Nut 


\section{Test on Joint}

Using the temporary seals, it was possible to have the cryostat of Subsec cl, Subsec c2 and Sec. 3 under active pumping to avoid any He leak in the cryostat from affecting the sniff-test of the joint. After the LN channel was evacuated, the joint was enclosed and the sniffer put in the enclosure. Then the LN channel was filled with GHe at 15 psi. After 15 minutes with the leak detector response being steady and below $1 * 10^{-7}$ sccs, the test was considered concluded. No leaks were present from the inner sleeve of the joint cryostat.

\section{He Leak Test}

The results of the test described immediately above indicated that the leak(s) should be closer to the indoor position. After confirming that the leaks were not originating in the joint, the next tests examined the section of cable between the joint and the indoor position. This section of cable has been identified has Subsec. Cl. The temporary seal on Subsec c1 was removed and the joint test chamber installed. Then, the LN channel and the cryostat gap were flushed with GN to reduce the He background. Before and during the test, the cryostats of Subsec c2 and Sec. 3 were under active pumping. The He leak test was performed twice; the first time with the mass spectrometer connected at the type D test chamber, and the second one with the mass spectrometer connected to the joint test chamber. The LN channel was first evacuated and then filled with gaseous He at 15 psi. The results are shown in Figure 4-8. The difference in response time at $2 * 10^{-3}$ sccs has been used to calculate a rough estimation of the leak location. Under this assumption the leak could be around $25 \%$ of the Subsec c1 length away from the joint, or as it calculates to approximately $16 \mathrm{~m}$.

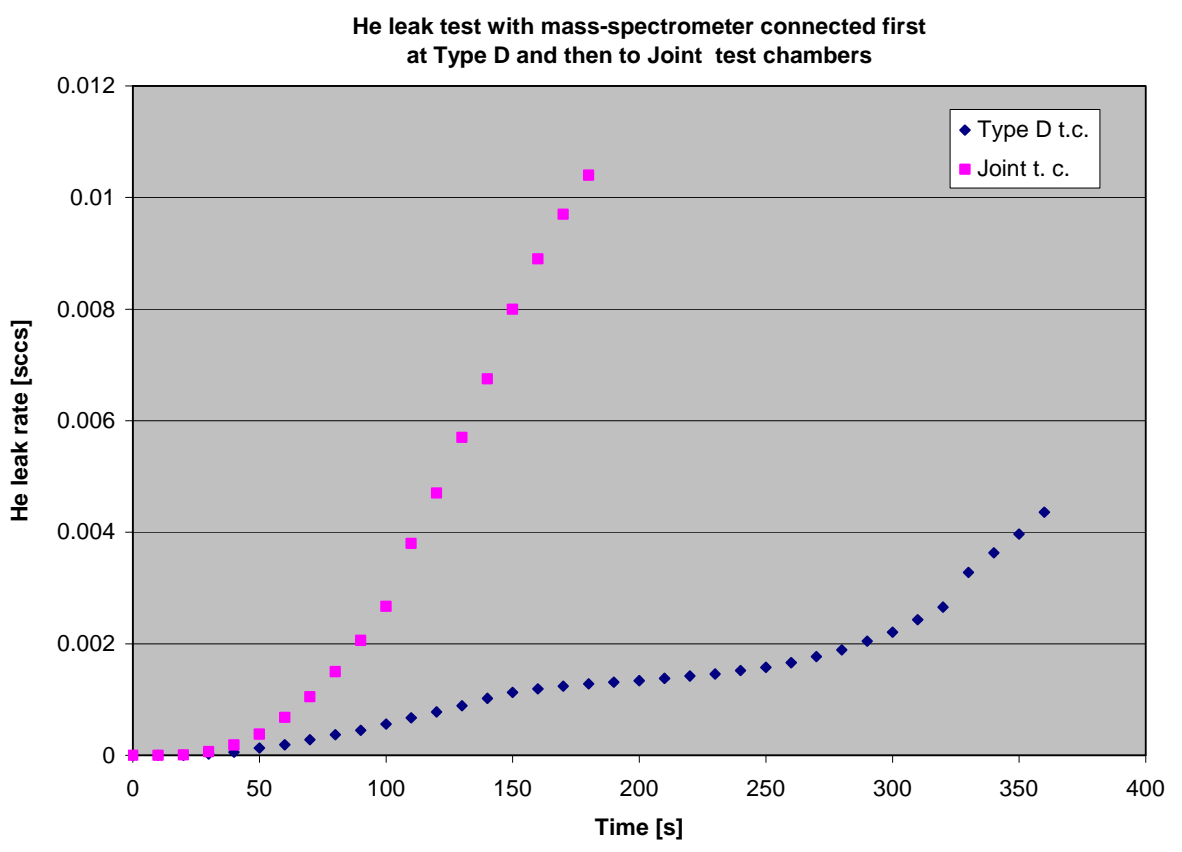

Figure 4-8

He Leak Test with Mass-Spectrometer Connected to Type D and Joint Test Chambers 


\section{Pressure Rise in the Cryostat Gap Without Active Pumping}

Next, the pressure rise in the cryostat gap without active pumping was measured. The cryostat gap and LN channel were evacuated until steady state was reached. Then, pumps were stopped and the LN channel pressurized at $1.5 \mathrm{bar}$ (22 psig) and the leak rate monitored. The test was repeated for three different values of GN pressure in the LN channel: 1.5 bar (22 psig), 3 bar (44psig) and 4.5 bar (66 psig), the results shown in Figure 4-9 below.

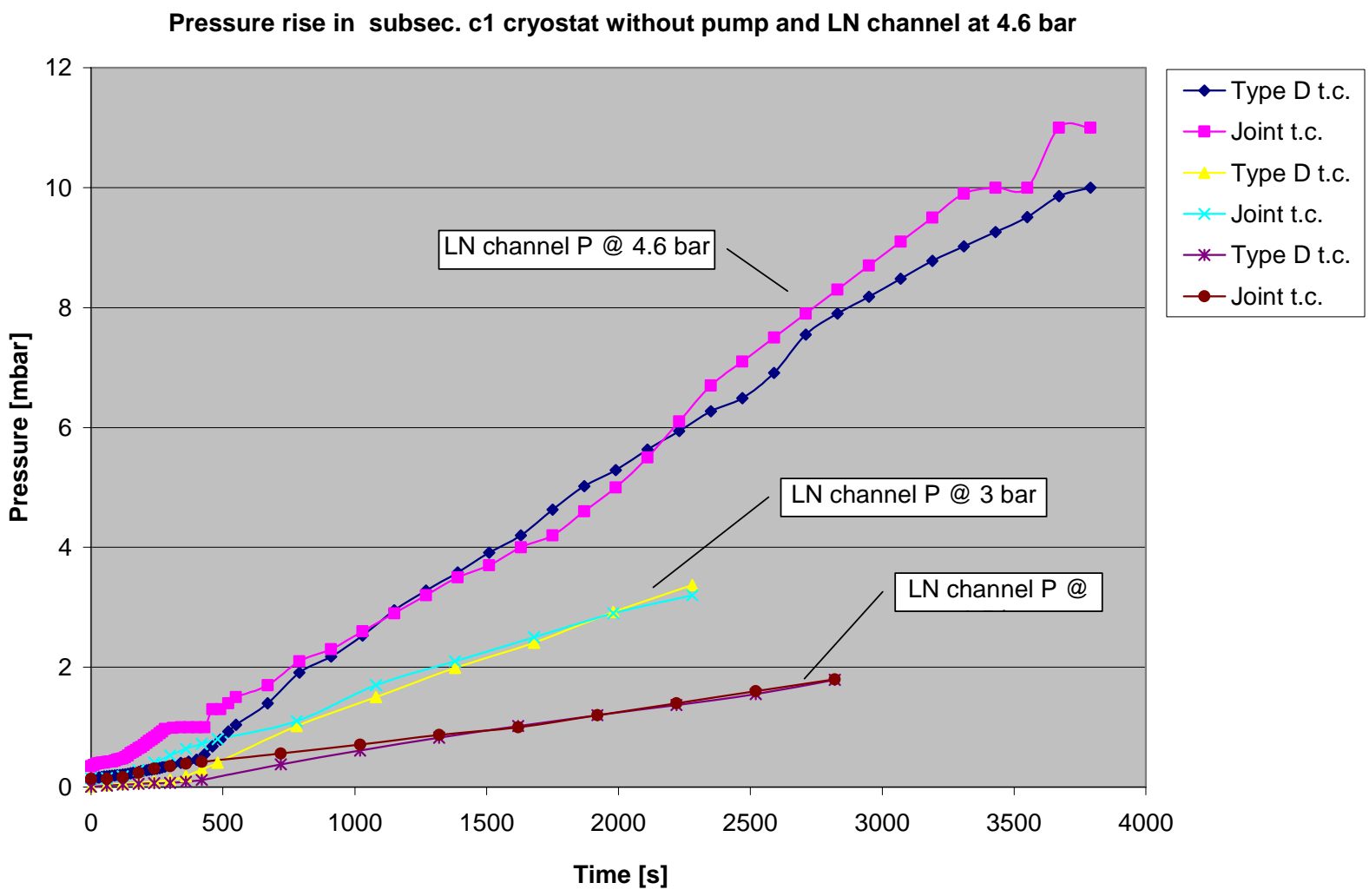

Figure 4-9

Pressure Rise in Cryostat Gap Without Active Pumping and LN Channel Pressurized

The GN leak rate into the cryostat gap when the LN channel is pressurized is: 0.049 sccs (@ 1.5 bar), 0.112 sccs (@ 3 bar) and 0.196 sccs (@ 4.5 bar). Leak rate correlation with GN pressure suggests at 4.5 bar leak is still below the critical mass flow rate.

\section{Pressure Rise in Cryostat Gap with Active Pumping on Type D Test Chamber}

Following this, the pressure rise in the cryostat gap with active pumping on type $\mathrm{D}$ test chamber was measured. The cryostat gap and LN channel were evacuated until steady state was reached. Then, the LN channel was pressurized at 1.5 bar (22 psig), 3 bar (44 psig), and 4.6 (67 psig) bar, and the pressure in the test chambers monitored. The steady state pressure in the Joint test 
chamber was 0.68 mbar (@1.5 bar),1 mbar (@ 3 bar) and 1.5 mbar (@ 4.6 bar). The results of this are shown in Figure 4-10.

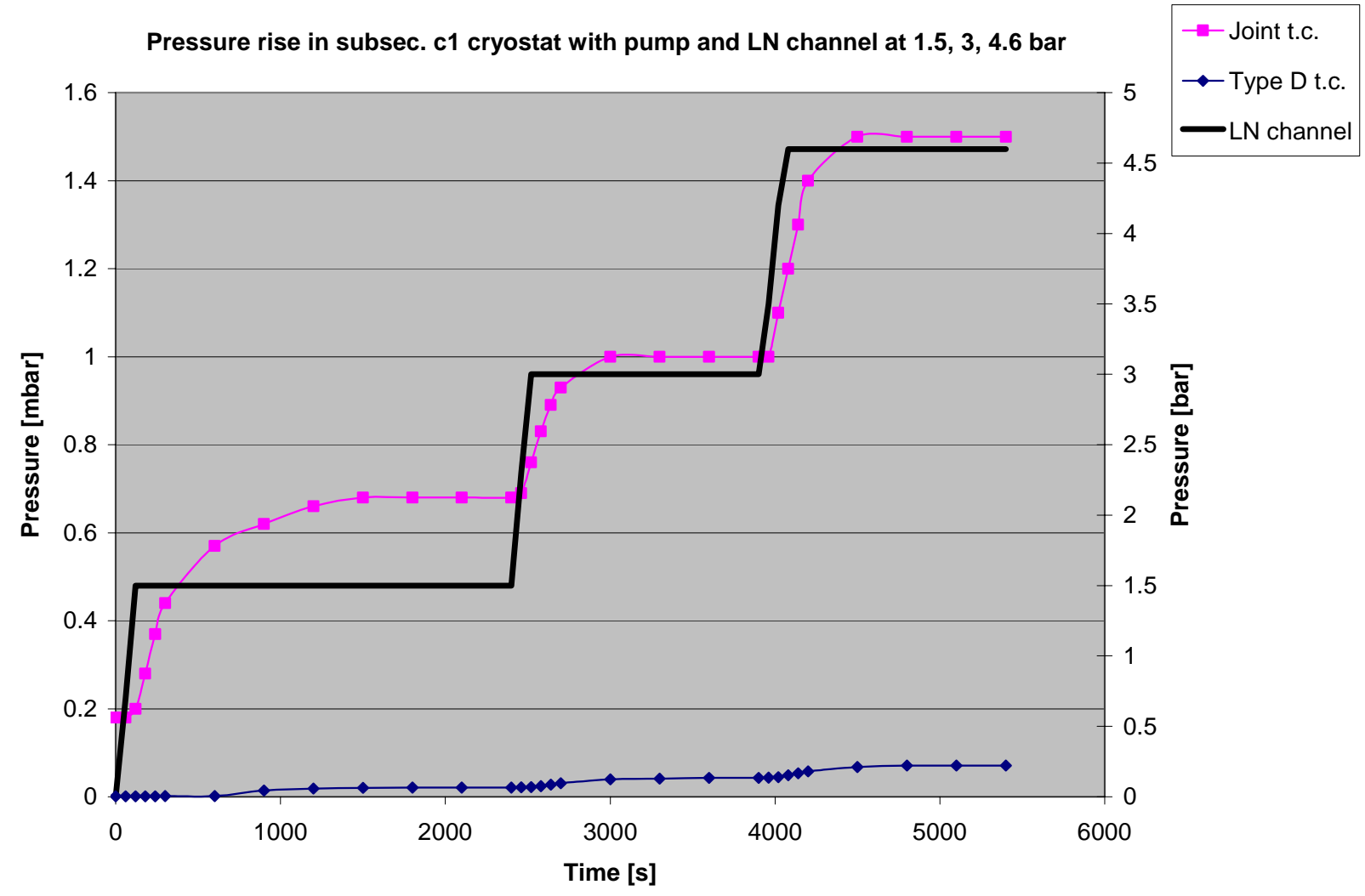

Figure 4-10

Pressure Rise in Cryostat Gap With Active Pumping and LN Channel Pressurized

\section{Nitrogen Flight Time in Cryostat Gap With LN Channel Pressurized at 4.6bar}

The LN channel and cryostat gap were evacuated. Then, with a pump connected to the Type D test chamber and a vacuum gauge one the Joint chamber, the LN channel was pressurized up to 4.6 bar and the diffusion time of LN recorded. The test pressure was maintained until steady state was reached at the vacuum gauge. The test was also performed by placing the pump at the Joint test chamber and the vacuum gauge at the Type $\mathrm{D}$ test chamber. The results of these tests are shown in the following Figure 4-11. 


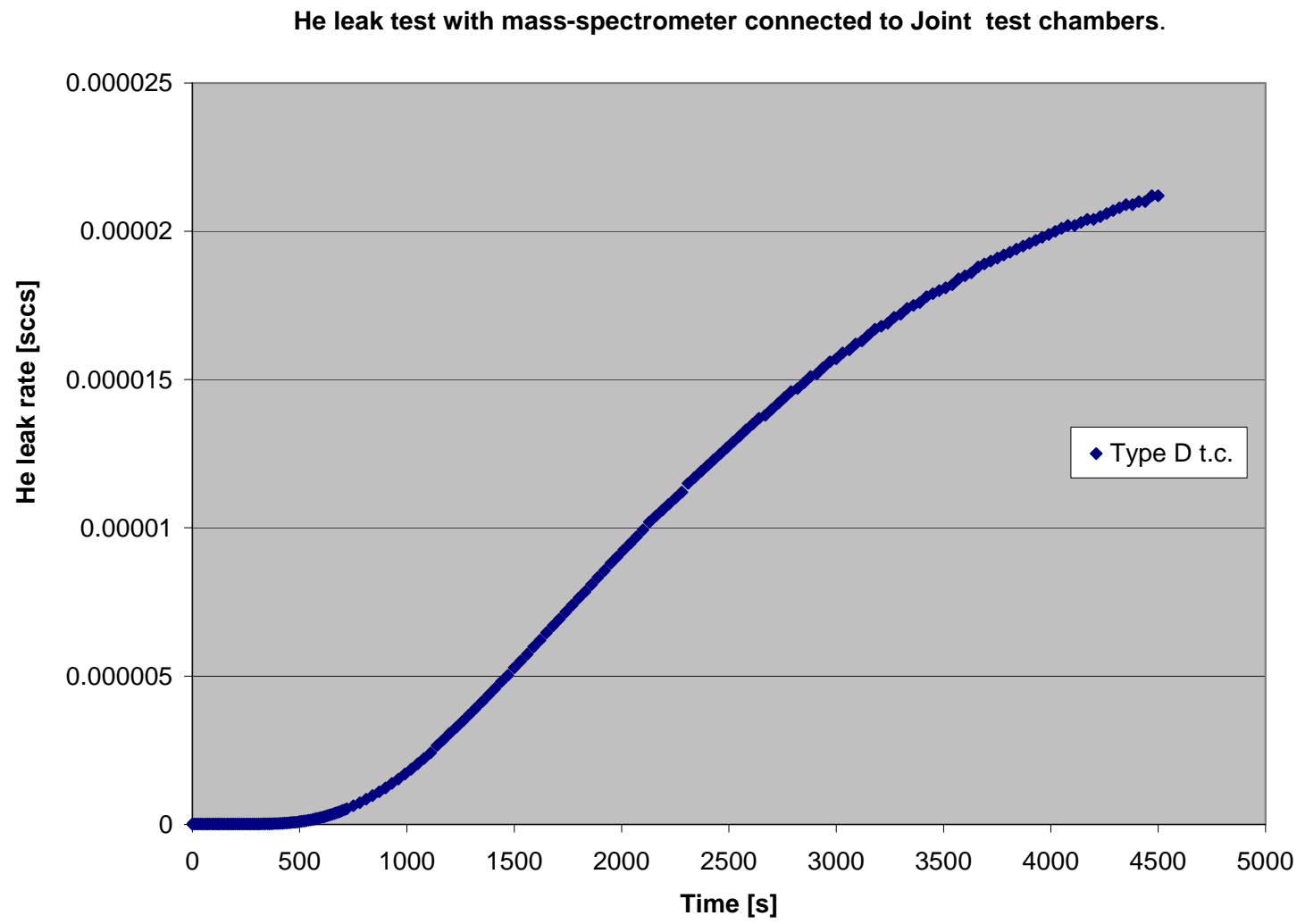

Figure 4-11

Nitrogen Flight Time in Cryostat With Pump and 4.6 bar Pressurized LN Channel

Based on estimates of the cryostat conductance, this test indicates that leak could be located between 16 and $22 \mathrm{~m}$ from the joint, towards the indoor termination.

\section{Test on Subsec. $c 2$ \& Sec 3}

The temporary seal on Subsec. c2 was removed and the joint test chamber applied. Then, the LN channel and cryostat gap were flushed with GN to reduce He background. Before and during the test, the cryostat of Subsec. cl was under active pumping. The mass-spectrometer was then connected to the Joint test chamber. The LN channel was first evacuated and then filled with gaseous He at 15 psi. Figure 4-12 shows the results of this test. 
Nitrogen Flight Time in subsec. c1 cryostat With Pump and LN channel at 4.6 bar

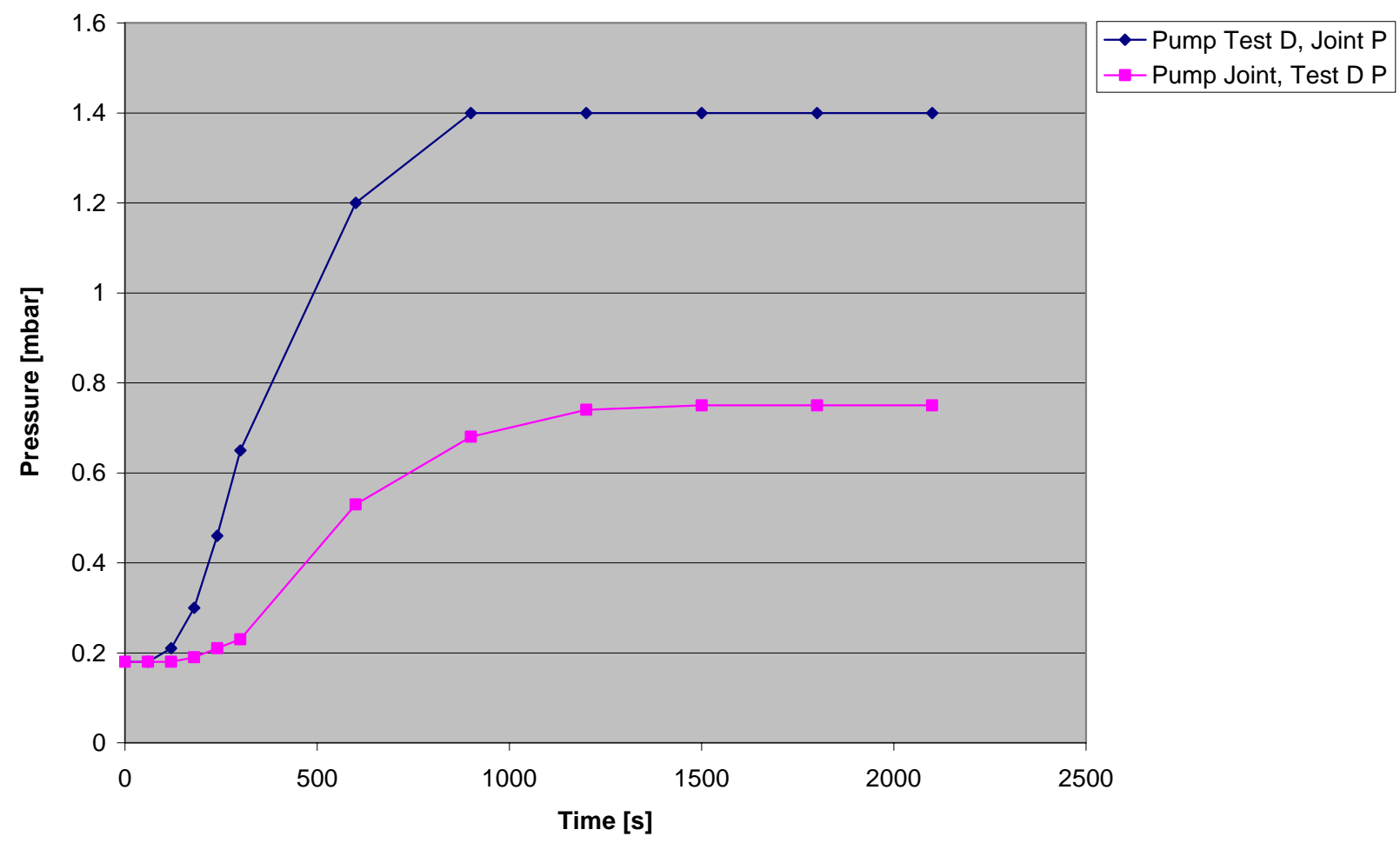

Figure 4-12

He Leak Test With Mass-Spectrometer Connected to Joint Test Chambers

\section{Pressure Rise in Cryostat Gap Without Active Pumping}

The cryostat gap and LN channel were evacuated until steady state was reached. Then, the pumps were stopped and the LN channel pressurized at 70 psi. Figure 4-13 shows that the pressure rise in this section cannot be related to a leak. 


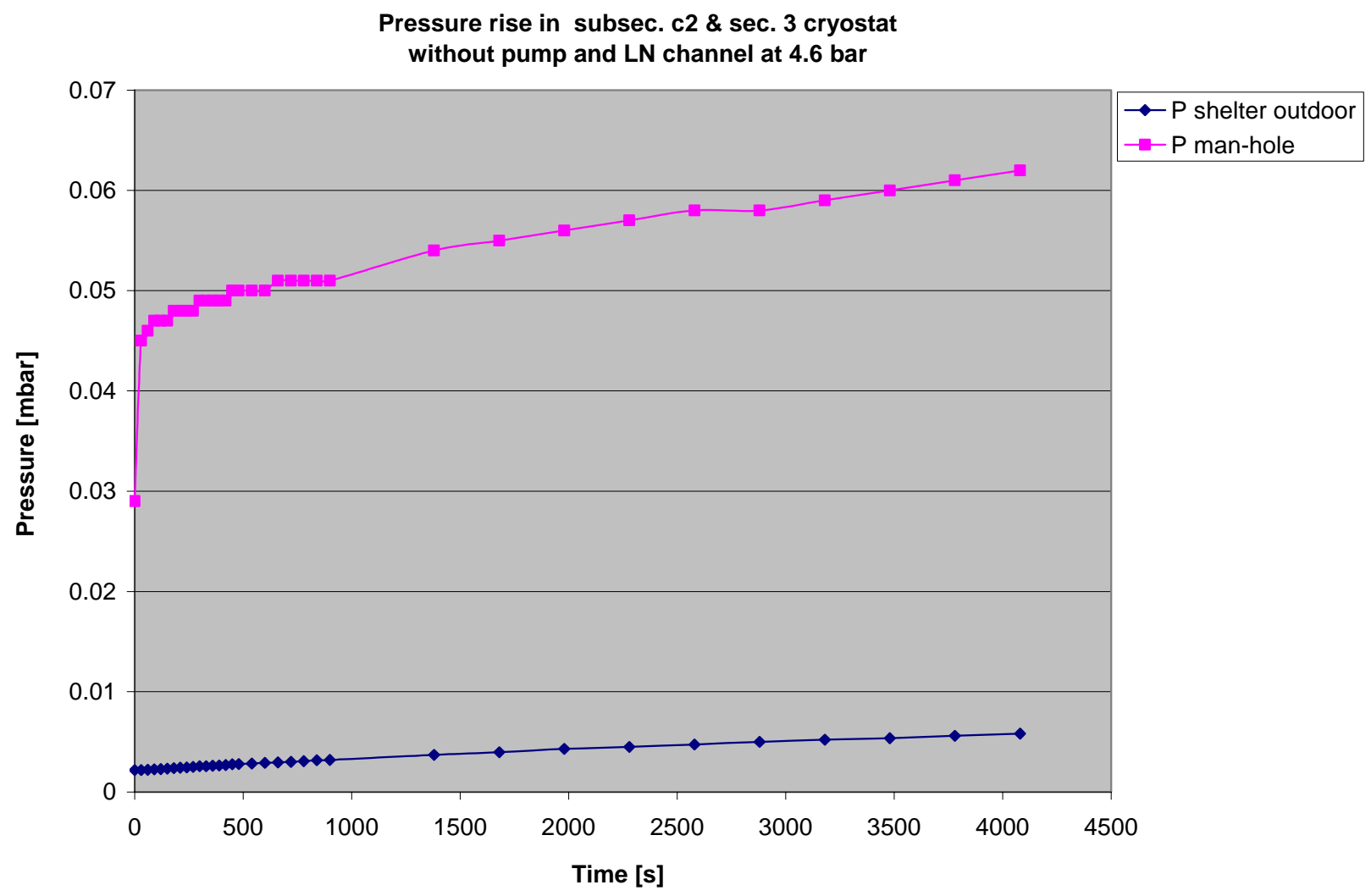

Figure 4-13

Pressure Rise Without Pumps and 5.0 bar Pressurized LN Channel

\section{Pressure Rise in Cryostat Gap With Active Pumping}

The cryostat gap and LN channel were evacuated until steady state was reached. Then, the LN channel was pressurized at 70 psi. No change in cryostat gap pressure was recorded. Because no change in pressure is noticed, this should confirm the absence of a leak (or at least the leak's insensitivity to LN channel pressure). The steady state pump pressure is determined from the overall gas removal rate. So, no change is noticed in the amount of gas being pumped out in Figure 4-14.

\section{Estimation of Conductance and Size of the Leak}

The conductance test confirmed an extremely low conductance value below $1 \mathrm{~m}^{3} / \mathrm{h}$ and a leak size of about 0.1 sccs. The conductance tests coupled with the data presented in above 2.6 have been used to estimate the leak size on Subsec c1. Based on a conductance value below $1 \mathrm{~m}^{3} / \mathrm{h}$, the leak size is approximately 0.1 sccs. 


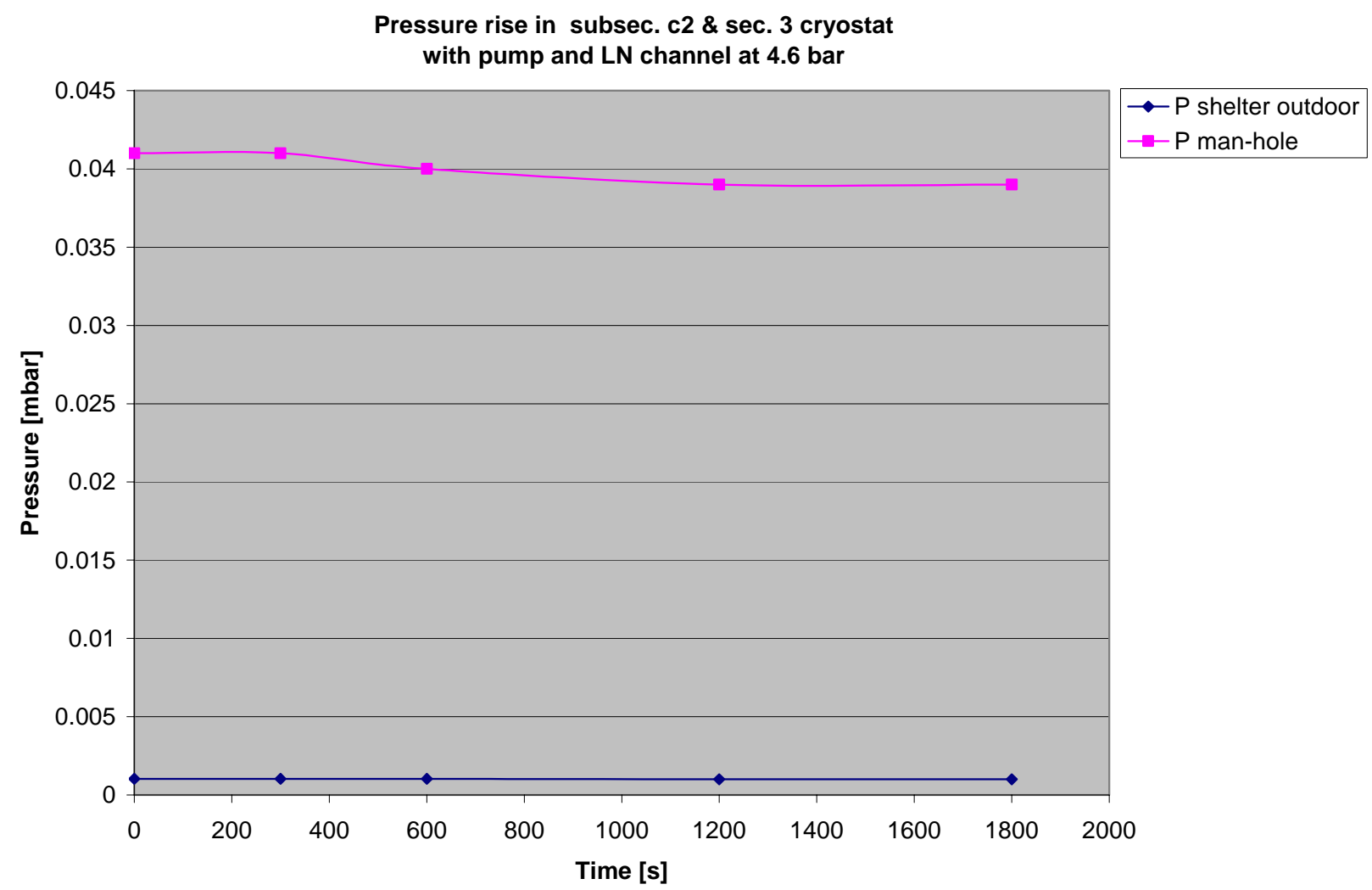

Figure 4-14

Pressure Rise With Pumps and 5.0 bar Pressurized LN Channel

A summary of the leak detection tests described above for Phase X are shown in the Table 4-1 below. (Refer to Figure 2-4 for section locations.)

Table 4-1

Leak Detection Test Summary for Phase $\mathrm{X}$

\begin{tabular}{|c|c|c|}
\hline Test Section & Subsec. & He Leak Results \\
\hline 1 & L1 & Passed \\
\hline & T1 & Passed \\
\hline 2 & C1 & Failed \\
\hline & Joint & Passed \\
\hline & C2 & Passed \\
\hline 3 & & Passed \\
\hline & L2 & Passed \\
\hline
\end{tabular}


In conclusion, the tests indicate that the leak(s) should be located approximately 16-22 meters from the splice, or 42-48 meters from the indoor termination, as illustrated on site diagrams (Figures 4-15 \& 4-16).

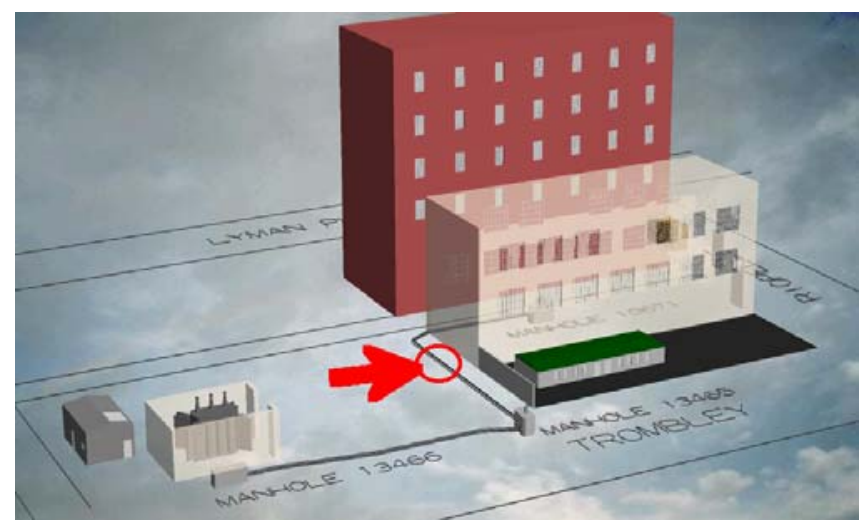

Figure 4-15 Illustration of Estimated Leak Position Near Splice

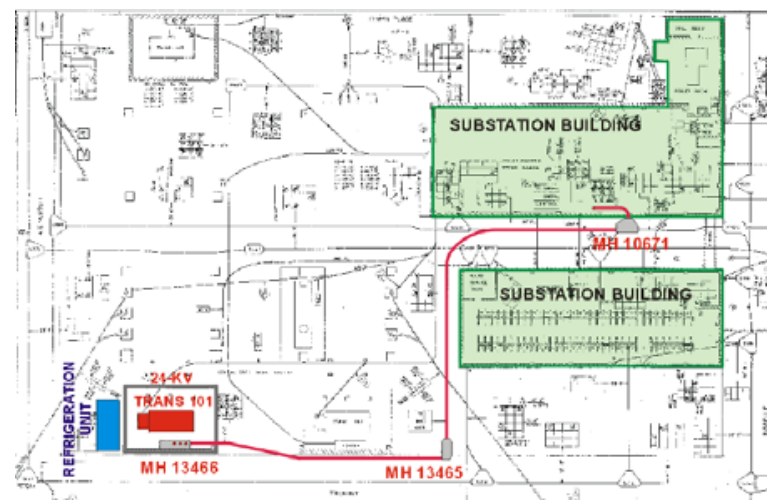

Figure 4-16

Illustration of Estimated Leak Position Near Indoor Termination

In addition to the qualitative results on leak existence, tests were conducted to establish:

1. Vacuum response in cryostat to pressurization of LN channel with GN; and

2. He flight time on section and subsection of cable.

This data was used to estimate the position of the leak(s).

Further, these test showed:

1. The estimated conductance from the leak position to LI is below $2 \mathrm{~m}^{3} / \mathrm{h}$, reducing the pump efficiency from the leak from $40 \mathrm{~m}^{3} / \mathrm{h}$ down to $2 \mathrm{~m}^{3} / \mathrm{h}$; and

2. Minimum reachable pressure in the joint chamber with LN channel pressurized @ 4.6 bar with GN is 1.5 mbar with a leak rate of 0.196 sccs. 


\section{Test on Cold Dielectric Insulation}

In addition to the leak detection activity at Frisbie substation, tests were conducted in Milan to determine if EPR insulation can endure extremely low temperatures (i.e. LN) and rapid thermal cycling between ambient and LN temperatures and still withstand severe electrical tests.

Poor cryostat performance would cause the EPR dielectric insulation to become extremely cold if the cable is cooled down to LN temperatures. Tests were performed on sections of spare cables to verify whether extremely low temperatures would damage the dielectric insulation. These tests were conducted at Pirelli's High Voltage Lab in Milan.

A 5-meter sample of the outer corrugated tube was taken from a cable sample (so that it was covered with the dielectric insulation), bent into a "u" shape (1.6 m diameter), kept in that position and filled with LN to determine if any macroscopic damage would occur.

After the test, the EPR was visually inspected and no damage detected. Then, the cable was cooled down again and kept at 60 kV a.c. for 8 hours (7 hours @ LN temperature, 1 hour warming up). After warming to room temperature, the cable was cooled down again and kept at $60 \mathrm{kV}$ a.c. for an additional 4 hours. No discharge occurred in the cable during these tests.

These tests demonstrate that EPR, with a limited amount of residual stress can endure extremely low temperatures, rapid thermal cycling between ambient and LN temperatures, and still withstand severe electrical tests.

It was determined at this point that Phases $\mathrm{X}$ and $\mathrm{Z}$, which had the large leaks, would be removed and shipped to Milan for dissection and analysis in the lab to confirm location and determine the root cause of the leak mechanism. While the tests reported above indicated that the EPR insulation would have suitable dielectric performance even at low temperatures, vacuum and safety issues precluded cooling down and energizing these two phases, leaks notwithstanding. Phases $\mathrm{X}$ and $\mathrm{Z}$ were removed and shipped to Milan where at the time of this writing dissection and analysis is ongoing.

Thus the plan was to replace Phases $\mathrm{X}$ and $\mathrm{Z}$ with conventional cables, install return LN piping and operate the system with one HTS phase (Phase Y) and two conventional phases. However, before implementing this plan, it was decided to conduct some further tests on Phase Y to ensure the leak was stable.

\subsection{Phase Y Leak Tests}

Test activity at the Frisbie substation on Phase Y consisted of thermal and mechanical cycles: cool down; pressurization; leak test; warm up; leak test.

An ordered list of leak tests performed followed by brief descriptions and results of these tests are below.

1. He leak test @ Room Temperature (Warm He Test) 
2. Cable Cool down

3. He leak test @ almost LN Temperature (Cold He Test)

4. Cable warm up

5. Warm He Test

6. Cable Cool down

7. Pressurization cycles with LN: ambient pressure - 159 psi - ambient pressure - 159 psi ambient pressure

8. Cold He Test

9. Cable warm up

10. Warm He Test

11. Cable Cool down

12. Pressurization cycles with LN: ambient pressure - 159 psi - ambient pressure - 159 psi ambient pressure

13. Cold He Test

14. \#2 Warm He Test

After each He test, the cryostat and inner corrugated tube have been purged for 30 minutes with GN to remove residual He.

\section{Warm He Test (Tests 1, 5, 10, 14)}

These tests were performed in accordance with the procedures adopted during the previous test sessions reported previously. The inner corrugated tube was evacuated and then pressurized with GHe at 15 psi, and a mass spectrometer connected to the vacuum chamber of the cryostat monitored the change of He background in it. Test 1 gave the reference values for all of the He leak tests; Tests 5, 10 and 14 gave indications on leak rate variation after thermal cycles.

\section{Cooling Down}

Cable was cooled down with a controlled manual process. The process started with GN at room temperature obtained vaporizing and heating LN from the LN tank and periodically mixing the warm gas with different quantity of LN directly coming from the LN tank. The average cool down time for the conductor was about 4.5 hours with an average gradient of $1 \mathrm{~K} / \mathrm{min}$ measured by the RTDs on the conductor.

\section{Pressurization (Tests 7, 12)}

Once the cable was cold and LN was flowing, the vent valve on the indoor termination was closed and the pressure in the cable increased up to the equilibrium pressure of the LN thank. 
Residual pressure in vacuum chamber was monitored during pressurization to monitor any change. The vent valve was then opened to relieve pressure. The first pressurization tests (Test \#7) resulted in no noticeable change in vacuum level. During the second pressurization of tests (Test \#12) the vacuum gauge on the indoor termination measured a higher residual pressure: $3.3 * 10^{-4}$ mbar vs. $2.2 * 10^{-5}$ mbar of the previous tests.

\section{Cold He Test (Tests 3, 8, 13)}

These tests were performed to verify the existence of cold leaks, i.e. leaks with detectable value only at low temperatures that disappear at ambient temperature. The cable was cooled down to LN temperatures, and for few minutes LN was relieved from the LN tank, through the cable and then through the vent valve. Then the LN channel was purged with GHe for about five minutes, and finally the inner corrugated tube was pressurized up to 22 psi with GHe. For the comparable leak sizes this test usually indicates larger leaks than the warm test because of pressure and temperature factors. Test \#3 was not meaningful because of extremely high GHe consumption during a venting phase, so that the remaining He was not enough to perform a complete He leak rate test. Test \#13 has shown degradation versus test \#10: $5.38 * 10^{-4}$ sccs vs. $4.67 * 10^{-4}$ sccs.

\section{Results}

The overall result is a small degradation of the leak after three thermal cycles and 4 pressurization cycles; the final He leak rate was about $4.5^{*} 10^{-4}$ sccs, $30 \%$ higher than the previous rate: the absolute value of the degradation is about $1.4 * 10^{-4}$ sccs.

Before the first cooling down a leak test was performed to verify the initial state of the HTS cable. The value obtained through this test was consistent with the leak levels measured during previous testing activities.

There was no evident change in the test results after the first and the second cycle, but after the third and last cycle tests the cable has shown a leak rate increase up to about $4.5^{*} 10^{-4}$ sccs (about $30 \%$ more than initial value $3.4 * 10^{-4}$ sccs).

Detailed data for these results appear below.

\section{Warm He Tests}

Figure 4-17 shows the plots of the 5 different tests (Note $1^{\text {st }}$ test data is test previous to this period.) 


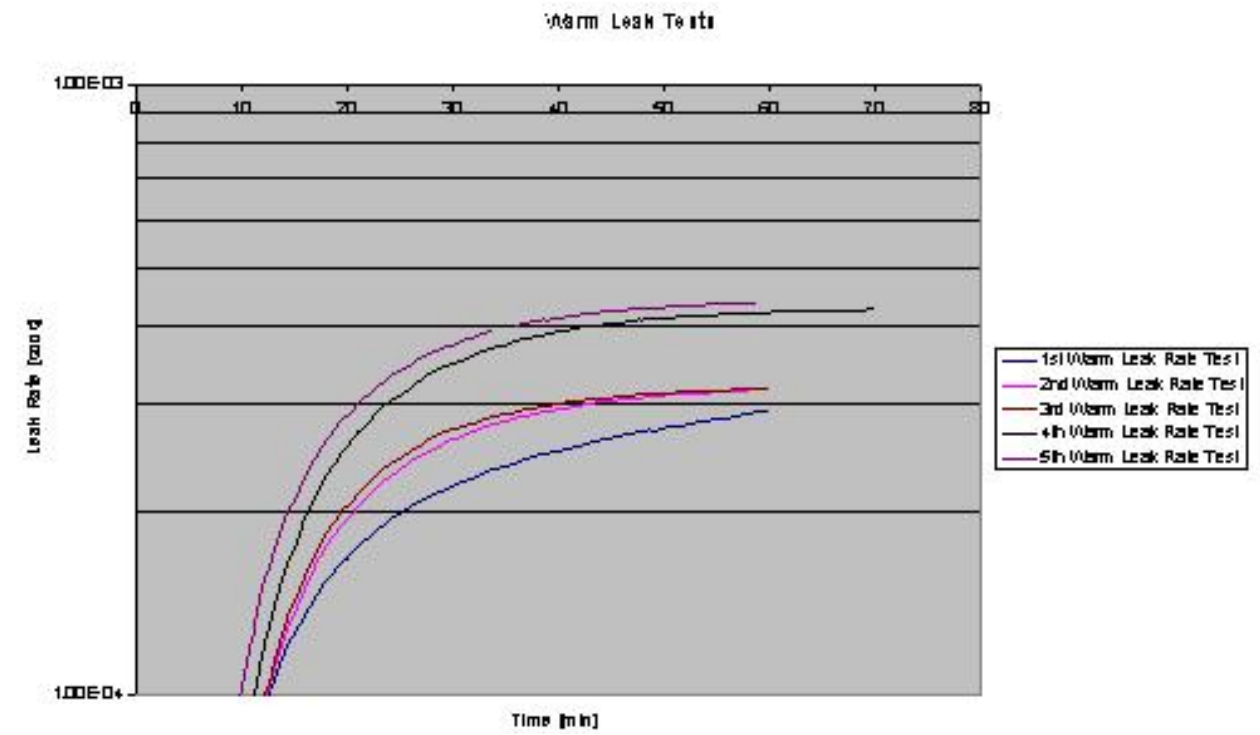

Figure 4-17

He Leak Rate Versus Thermal and Pressure Cycles

After the first and the second cool down cycles, and first pressurization cycle there was no detectable leak degradation (between tests \#1 and \#10). After cooling time for the third time a leak was observed. The He leak rate at steady state was about $4.5^{*} 10^{-4}$ sccs, almost $30 \%$ higher than former value at the same testing conditions. Test \#15 was conducted to verify the increase in He leak rate observed in tests \#12 through \#14. Between test \#14 and \#15 there was no thermal cycle. These results give indication of unpredictable/random behavior that could be expected due to cable cycling.

\section{Pressurization}

During the first two thermal cycles and the first two pressurization cycles no change in residual pressure has been detected. After the third thermal cycle and the third-forth pressurization cycle an increased residual pressure in the cryostat has been measured. The lower vacuum level at the indoor position vs. the outdoor position indicates that the leak is located closer to the indoor terminations than the outdoor terminations.

The higher value in residual pressure means the leak is larger than before, but the actual leak rate allows the system energization. 


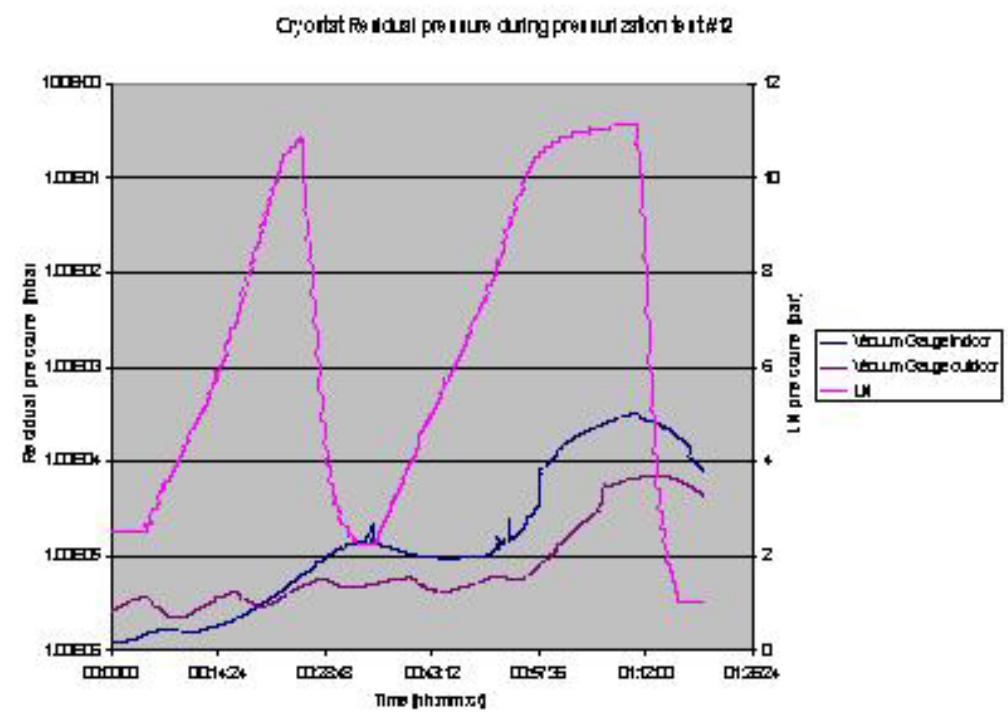

\section{Figure 4-18}

Cryostat Residual Pressure During Last Two Pressurization Cycles

\section{Cold He Tests}

Cold He leak tests, performed after every two pressurization cycles measured reasonable higher leak rates in comparison with those measured with the warm He leak tests. Furthermore the $3^{\text {rd }}$ cold test (Test \#13) confirmed the results observed in the warm He leak test and the LN pressurization tests that the leak rate had increased.

Comparing the cold leak rate between the warm and the cold He leak tests (Test \#7 and Test \#10) shows the influence of temperature on He leak rate, changing the value from $5.38 * 10^{-4}$ sccs to $4.67 * 10^{-4}$ sccs. (Figure 4-19).

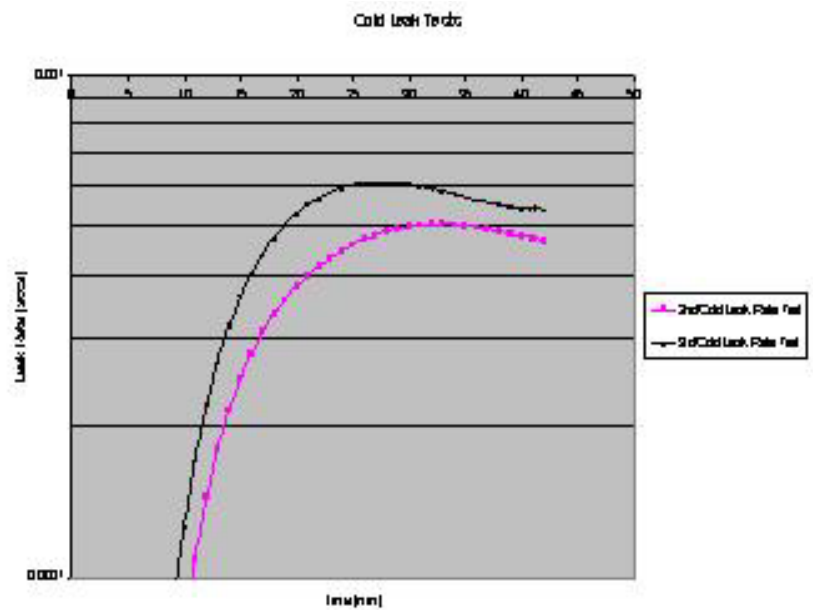

Figure 4-19

Leak Rate at About LN Temperature 


\section{Summary of Results and Conclusions}

The remaining middle HTS phase (Phase Y) was cold tested. It withstood two thermal and mechanical cycles without showing any increase in He leak rate, but during the third and last cycle an increase in leak rate occurred.

It was concluded that theoretically with this leak rate, it may still be possible to operate the cable, however, because there was some degradation of the leak rate after cycling and because the vacuum leak evolution could not be accurately predicted, some minor modifications to the vacuum connection and a further tests would have to be performed before making any final decisions about operating Phase Y.

The goal of further testing on Phase Y during this period was to have an estimation of leak evolution and an estimation of the increased safety margin in vacuum level thanks to the added pump capacity of pumping groups previously dedicated to Phase $\mathrm{X}$ and $\mathrm{Z}$. In fact because of Phase $\mathrm{X}$ and $\mathrm{Z}$ removal more pump capacity was available; moreover the turbos were placed closer to the ceramic insulator, providing greater safety margin. Furthermore a vacuum gauge was located very close to the ceramic insulator, reducing uncertainty on vacuum level between the coaxial ceramic insulators.

While the longer term test for Phase Y was being prepared, modifications to the circuit to prepare for energization with the single HTS phase was begun. This entailed delivery and installation of conventional cables to replace Phases $\mathrm{X}$ and $\mathrm{Z}$, and delivery and installation of the LN return line.

In this period, minor modifications on remaining HTS termination were completed. The modifications included connecting the vacuum gauges and turbo pumps just below the ceramic insulator in order to have the highest pumping efficiency and most precise vacuum level indication in the critical voltage transition region. Changes were accomplished for both the indoor and outdoor termination; but at the outdoor position only the vacuum gauge was moved. The pumping groups originally designated for Phase $\mathrm{X}$ and $\mathrm{Z}$ were modified to connect them in parallel to increase total pump capacity.

The decision to operate with two different pumping groups configuration was made to afford the possibility of having results comparable with the previous campaign first and then to have real indication of residual pressure value in the final configuration. This option is intended to maximize the information minimizing stress on the cable.

Phase Y was submitted to a longer-term pressurization cycle, 120 psig for 24 hours at cryogenic temperatures. During this pressurization, a stable vacuum level was obtained with no increase in leak rates. Phase Y was then warmed-up and submitted to a He leak check. The data from the He leak check showed the leak rate had changed, showing continued instability in the leak. 


\section{Results and Conclusions from These Tests}

A. The results of the longer-term tests to Phase Y showed that the warm leak rate is not stable confirming the leak has the potential for increase. The nature of a leak is that it is unstable. Therefore it is unpredictable how the leak would evolve under operation.

B. The leak requires vacuum systems to be running continuously. The vacuum systems were designed as a secondary system providing back up service. They were not designed using N1 failure criteria, as now is required. Thus, these secondary systems would be required to run continuously as a critical component.

C. If there would be a vacuum failure, even if the control system operated properly, it is necessary to de-energize a transmission feeder to isolate the test cable from system voltage. While this operation can be automated, the process could be intrusive on network operations.

D. Based on the above, it was Pirelli's recommendation, and confirmed by the team that Phase $\mathrm{Y}$ would not be put into operation in the electrical grid. 



\section{5 \\ DISSECTION AND ANALYSIS OF PHASES X AND Z LEAKS}

After removing the two superconducting cables comprising Phase $\mathrm{X}$ and Phase $\mathrm{Z}$ of the three phase circuit, a number of sections were taken from the cryostat's inner tube for metallurgical analysis. The individual sections removed were identified as having leaks identified using mass spectrometry.

\subsection{Microscopic Methodologies}

Using He mass spectrometry, leaks in the inner cryostat tubes were located. Four sections of the cryostat, each approximately $0.4 \mathrm{~m}$ in length, around leak locations were removed and taken to the laboratory for microscopic analysis. The position of each of the four sampled sections, as they would have been located at Frisbie is noted in Figure 5-1.

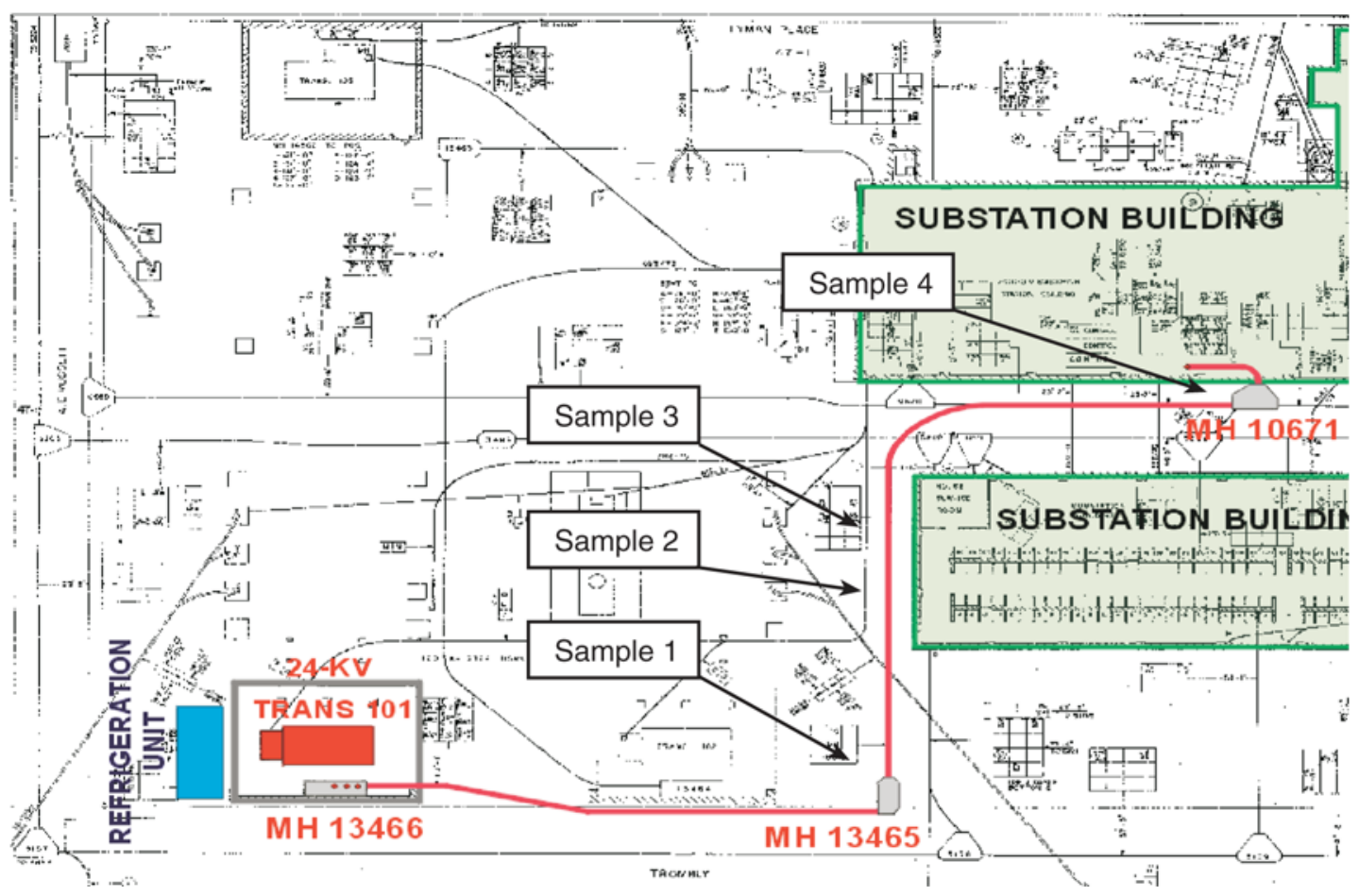

Figure 5-1

Sample Locations 
The samples were examined as received using an optical stereomicroscope. Cracks located by this method were prepared and examined using both optical and scanning electron microscopes.

Metal morphology inside and outside the weld region and the characteristics of individual defects have been analyzed to provide clues regarding the root cause of the cryostat failures.

\section{Macroscopic Inspection}

The samples were initially given a preliminary inspection, as they were received, using an optical stereomicroscope.

\section{Optical Microscopic Inspection}

Most of the optical observations were carried out after micrographic preparation (cutting and polishing) and chemical etching, to better analyze the crystalline features of the steel tube. In the following, the different samples will be identified according to the number of the tube from which they were taken.

\section{SEM Inspection}

The outer and inner surfaces of the tube samples were observed at different magnifications using SEM. Details of the cracks and other small defects were also observed at high magnification after optical preparation.

\subsection{Results}

\section{Macroscopic Location of Cracks}

By this method, a few microcracks were identified on the outer surface of the tube. These cracks were examined in deeper detail by optical and SEM microscopy. All the observed microcracks were found to be oriented parallel to the axis of the tube and to be localized inside a corrugation groove along the welding line.

\section{Morphology of the Cracks}

The appearance of the defective spots is best documented by the pictures taken using the

SEM. As can be seen in the example Figure 5-2 - 5-7, the largest cracks were all found to extend parallel to the axis of the tube, and to be typically visible on the outside surface. 


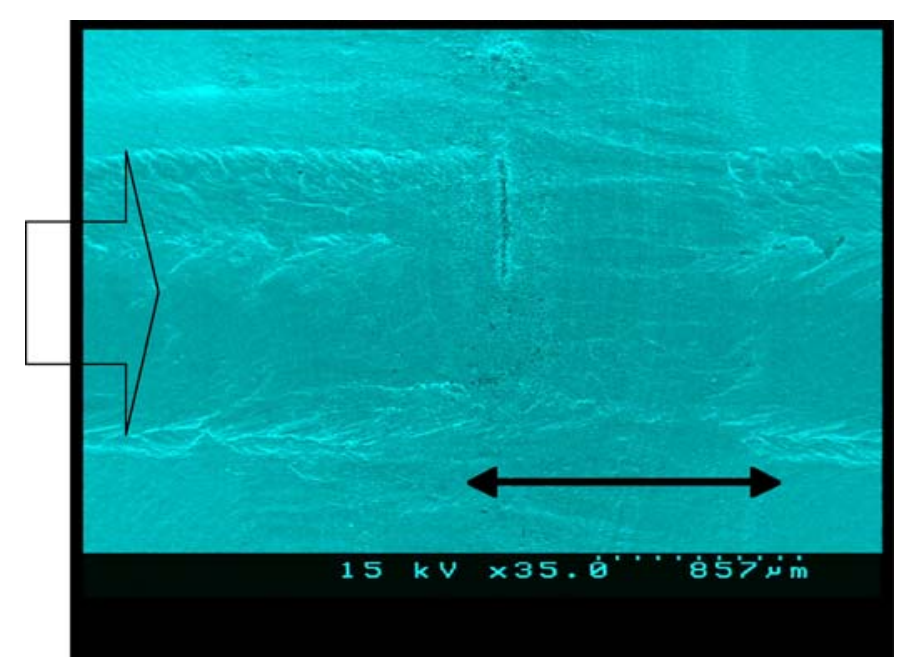

Figure 5-2

Tube Sample 4, Crack Along the Welding

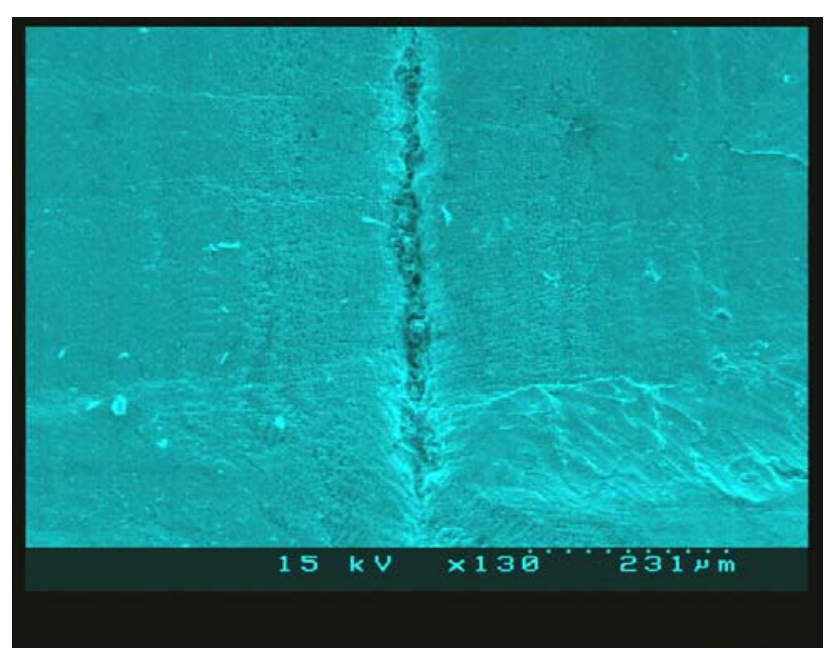

Figure 5-3

Tube 4, Detail of the Crack 


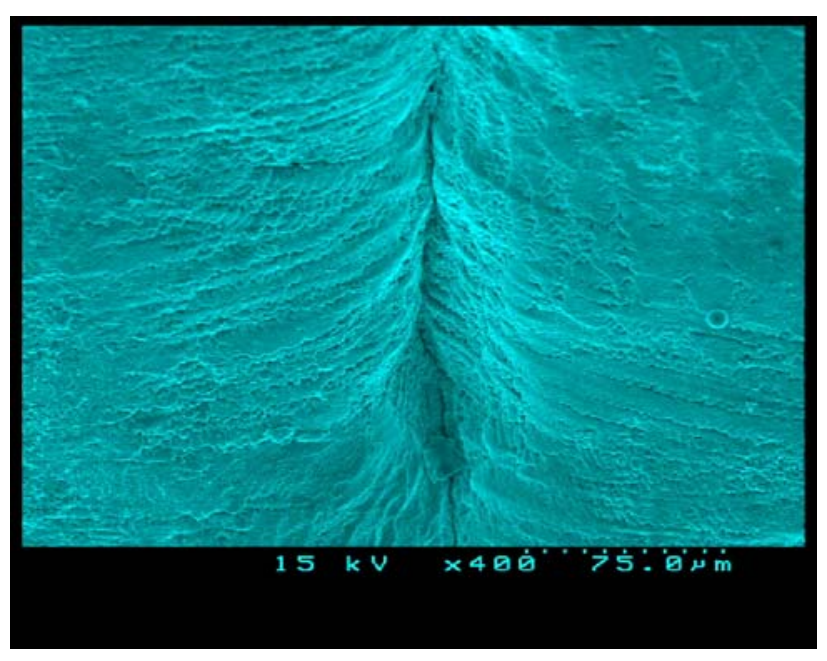

Figure 5-4

Crack in Tube 1

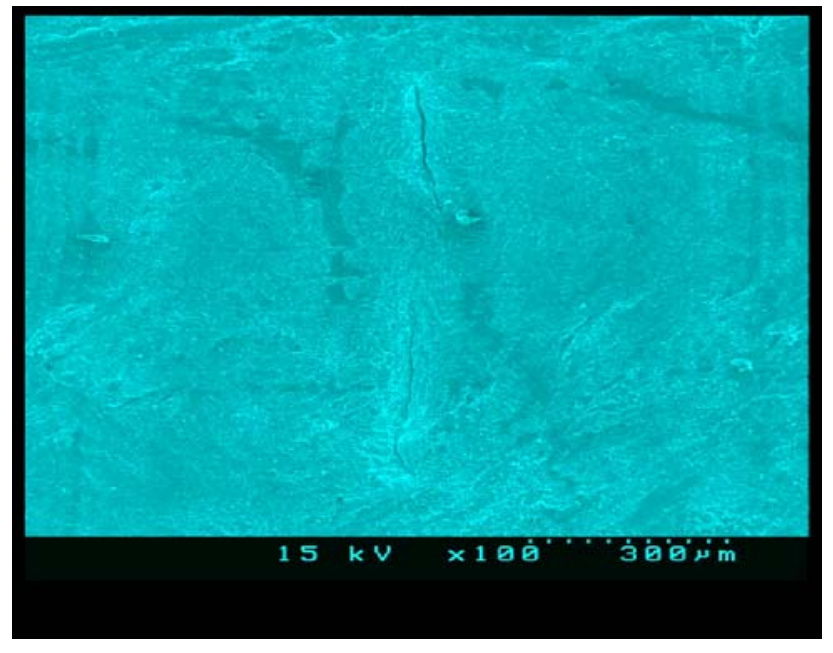

Figure 5-5

Crack in Tube 2 


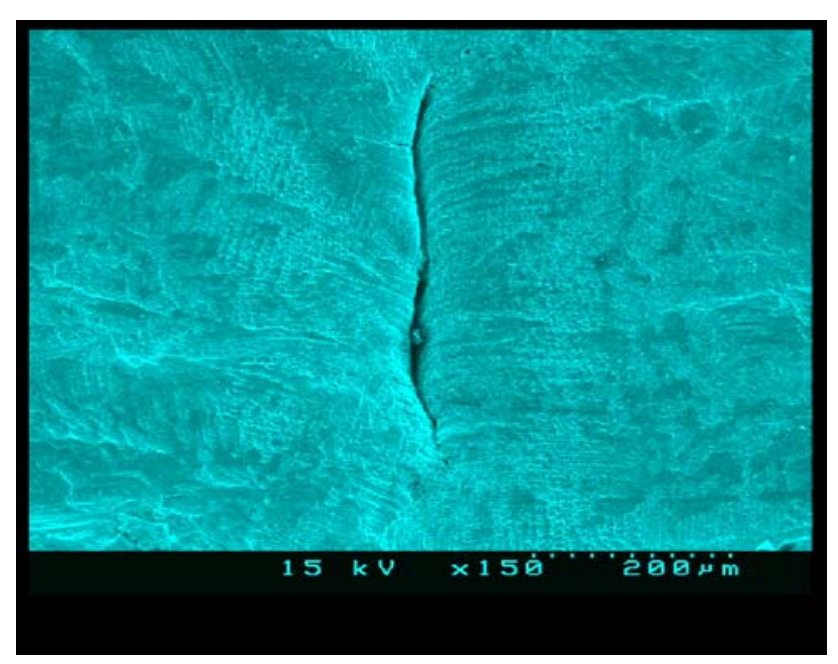

Figure 5-6

Crack 3-1 in Tube 3, Outer Surface

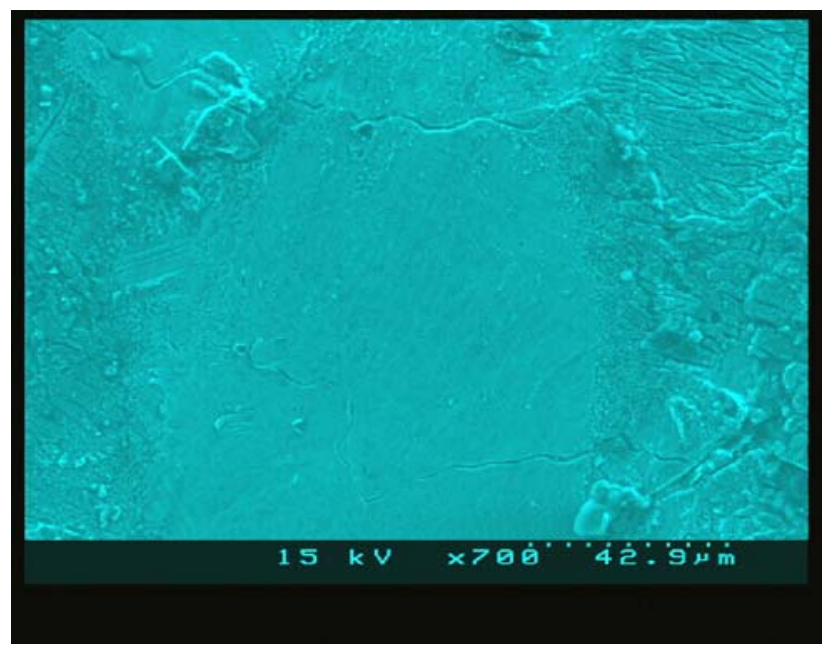

\section{Figure 5-7}

Crack 3-1 in Tube, Inner Surface (Right)

In all the above documented cases, the cracks seem to have initiated from the outer surface, where there appears to be a small and smooth V-shaped groove. Such a feature, which is better evident from the micrographic optical observation was searched for in other parts of the welding along the tube, inside other corrugation grooves adjacent to the crack location, and found to be generally absent.

A weld line, due to the complex flow of the material during cooling, is not in itself a totally uncommon feature in some metal systems and under some conditions, in this particular case this is only found occasionally, and seems to be a local indicator of a defective spot. 


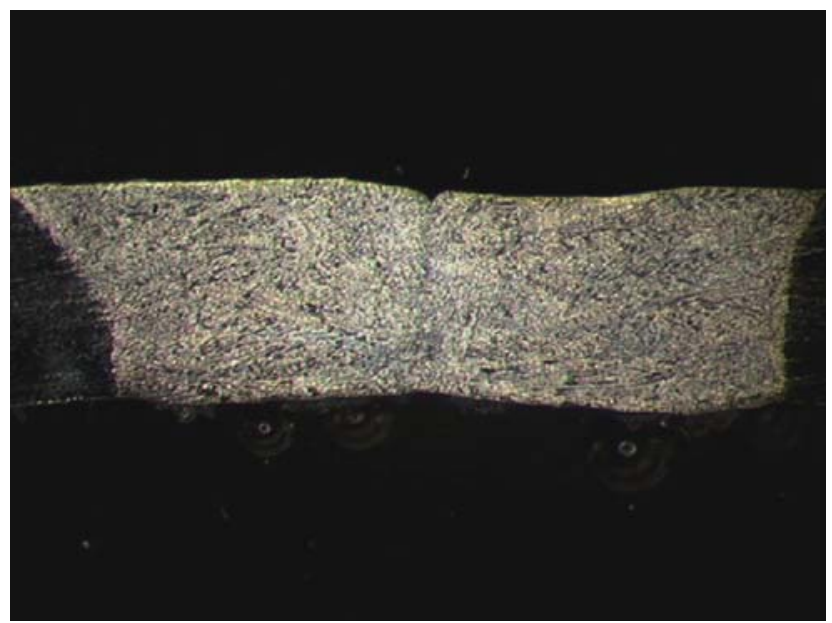

Figure 5-8

Tube 3 - Crack Location

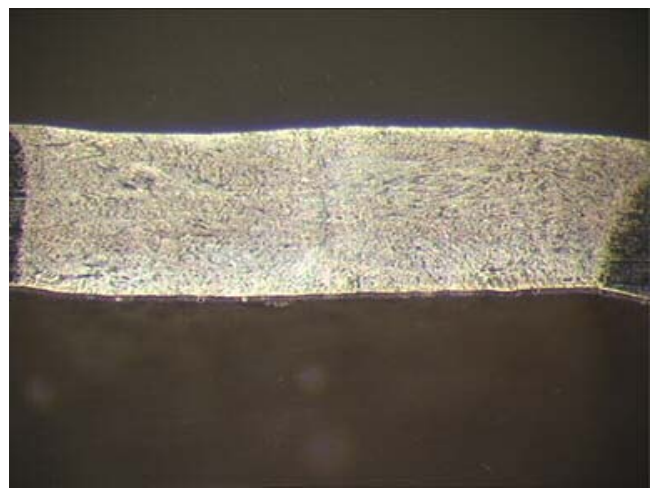

Figure 5-9

Tube 3 - Few Millimeters from Crack

\section{Metallographic and SEM Observation}

A number of samples taken to include the largest surface cracks, as well as a sample taken from a "good" part, were given a standard metallographic preparation to expose a normal cross-section including the crack. The polished and chemically etched samples were then observed at different magnifications.

Figures 5-10 - 5-12 show the only sample where the crack is actually visible in its complete extension. As can be observed, the fracture line, which is located quite in the center of the weld (the anvil-shaped, lighter region in Figure 5-10), is rather "broken," and seems to suggest that the fracture might have occurred in two steps. The crystalline structure that is well visible at higher magnification (shown in Figures 5-11, 5-12) does not show particular anomalies, and is quite similar to the one found in other samples taken from a non-defective welding region. 


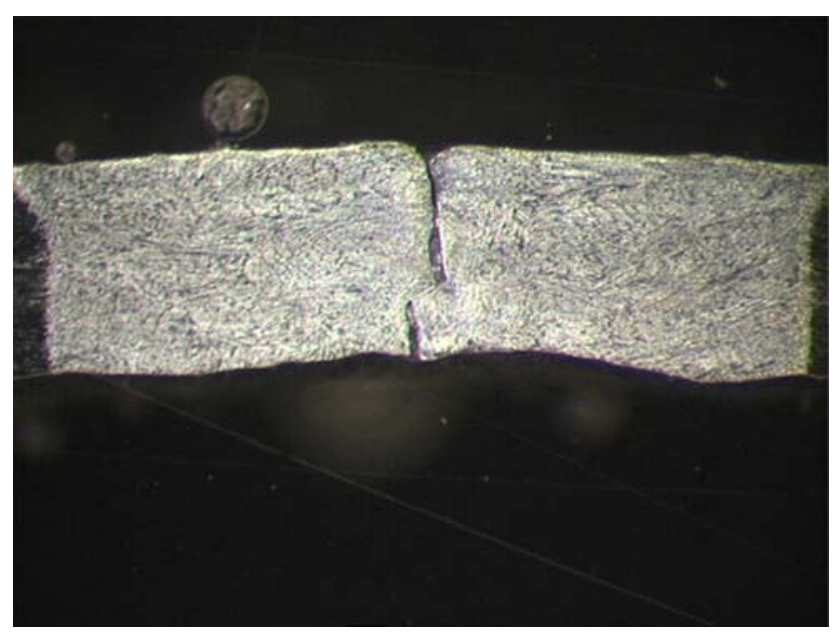

Figure 5-10

Crack in Tube 1

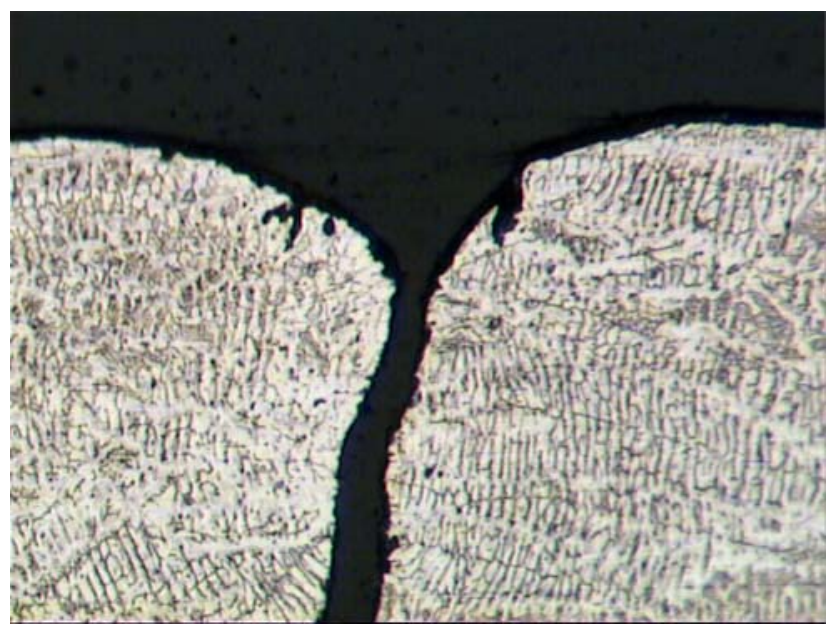

Figure 5-11

Tube 1- Detail of Crack on Outer Surface 


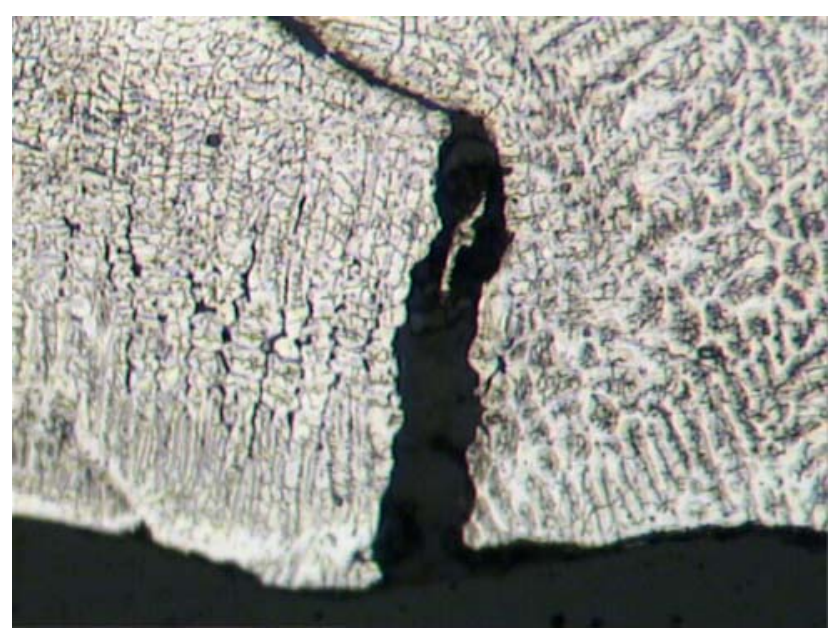

\section{Figure 5-12}

Tube 1 - Detail of Crack on Inner Surface

The metallographic structure in the welding zone is a two-phase dendritic, while the tube at the weld boundary has a single-phase structure. The two-phase structure is due to ferrite formation along with the original austenite, confirmed by observing a slight magnetic attraction at the weld while the rest of the tube is definitely non-magnetic.

All the observed cracks strictly follow the interphase boundaries. This is supported by SEM observations of cracks opening at the outer surface (see Figures 5-13 and 5-14) showing interphase boundaries (dendrite nodules in Figure 5-15). This indicates that these defects were formed during the solidification process.

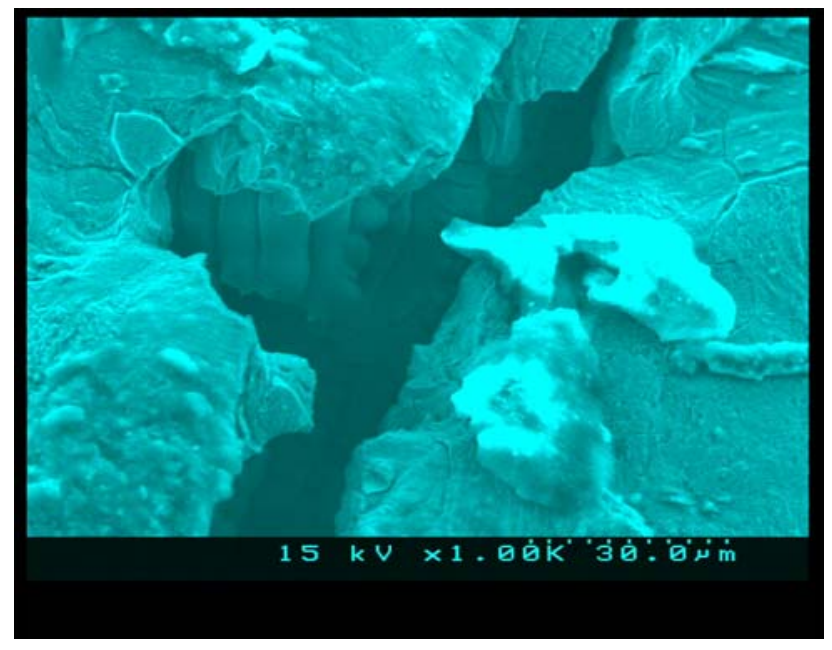

Figure 5-13

Tube 1 - Detail of Crack on Inner Surface 


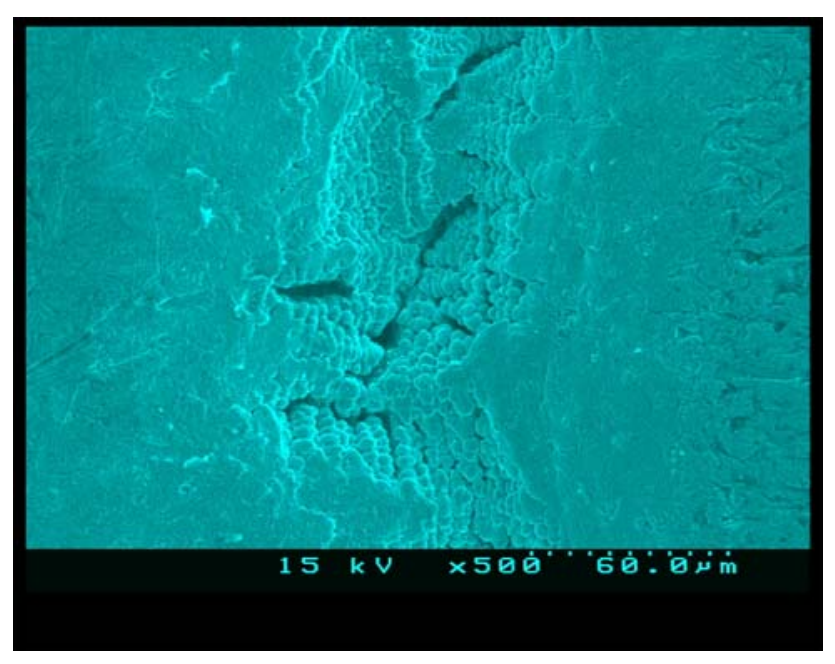

Figure 5-14

Tube 1 - Outer Surface

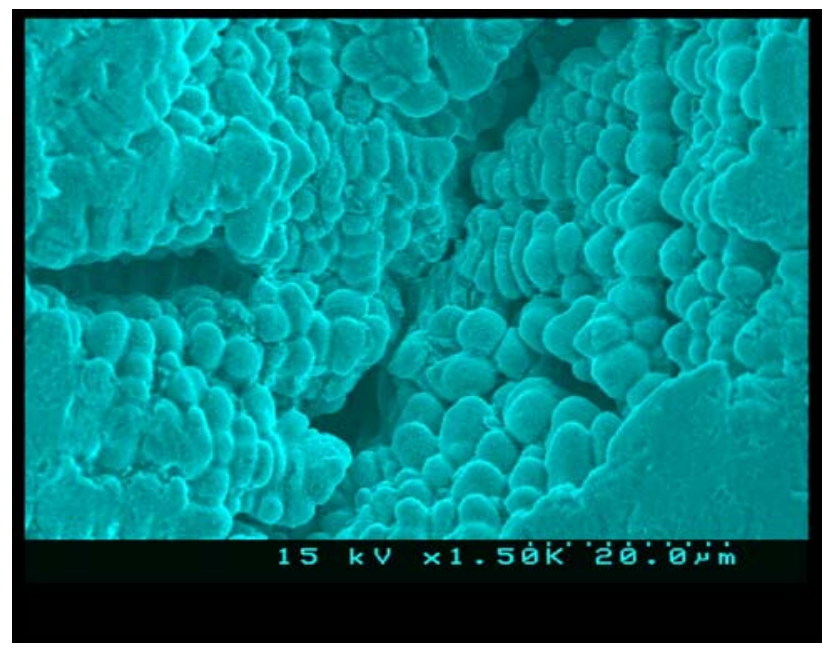

\section{Figure 5-15}

Tube 1 - Detail of Crack Shown in Figure 5-12

The actual cause for these defects is not completely clear. The distribution (defects were never found in adjacent sections) of these defects shows, on the contrary, a very localized pattern. This is evidence in favor of an origin due to material characteristics rather than welding process anomalies.

In particular, the hypothesis of excessive gaseous content is worth evaluating.

In fact it could explain some peculiar aspects like inner bulk location of incipient defects, their interphase boundary contour and their association to "macroscopic" shrinkage. Another point worth to be considered is the systematic location of the defects in correspondence to the corrugation grooves. Corrugation is the result of cold working after welding, which by no means could "attract" the defects formed by solidification shrinkage and cause them to localize. 
In fact a perhaps more likely, alternative picture to that of a "pure" solidification shrinkage effect, comes by considering a hydrogen embrittlement mechanism. Under this theory, defects would have developed under the action of the corrugation stresses at random locations rich in hydrogen (it is known for instance that martensitic stainless steels show marked brittleness at room temperature with 3-5 ppm H2). In this hypothesis the damage is interpreted as a mechanical-stress-driven brittle propagation of cracks along hydrogen polluted interphase boundaries generated during welding. These fractures must be supposed to have been originally incomplete, having not been detected during manufacturing. They would eventually develop to the full thickness of the tube when further stress was applied.

Partial support to the above came from the additional observations that were carried out on a sample taken from a non-defective region of tube 1, from outside the welding and outside the corrugation groove. Careful metallographic observation showed also in this sample the presence of tiny defects like the ones shown in the Figure 5-16 - 5-19.

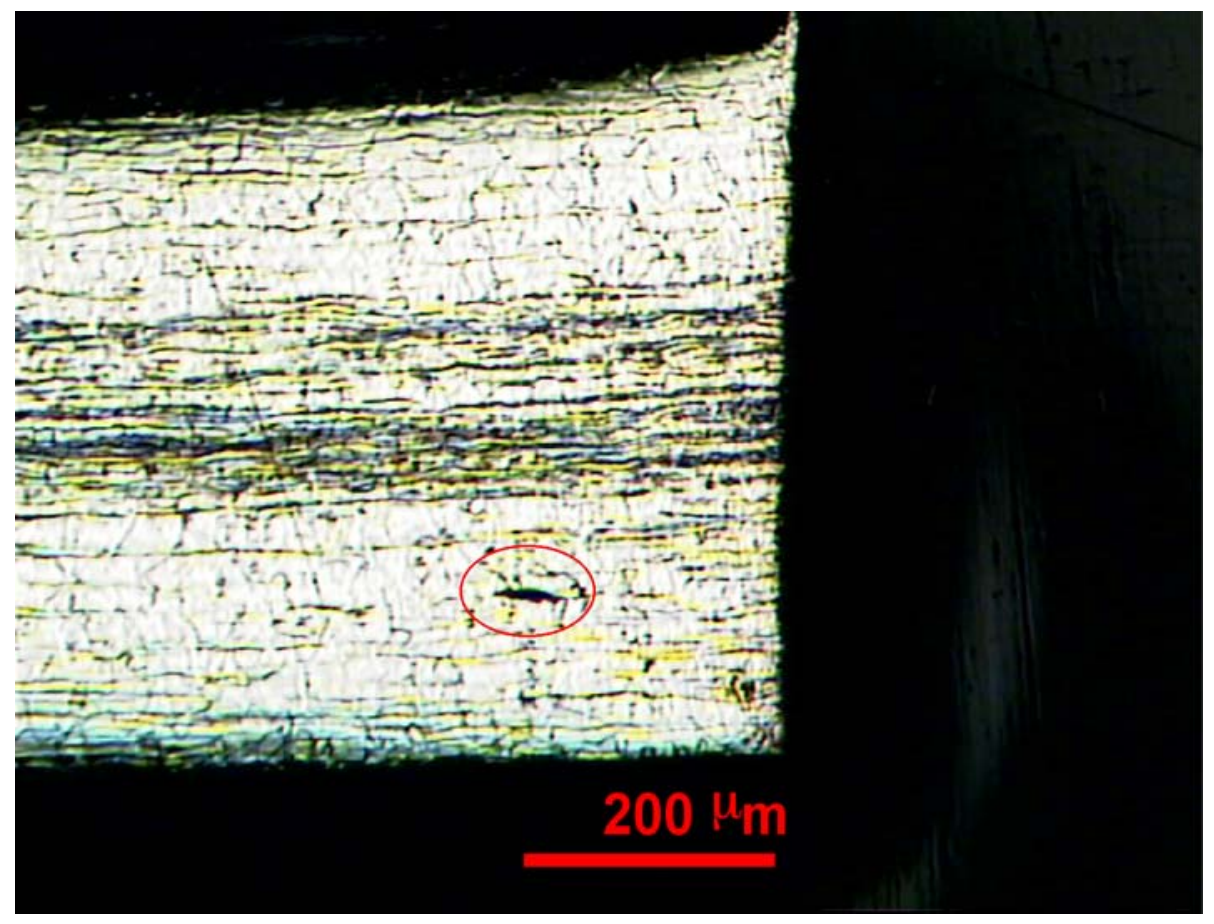

Figure 5-16

Tube 1 - Outside the Welding 


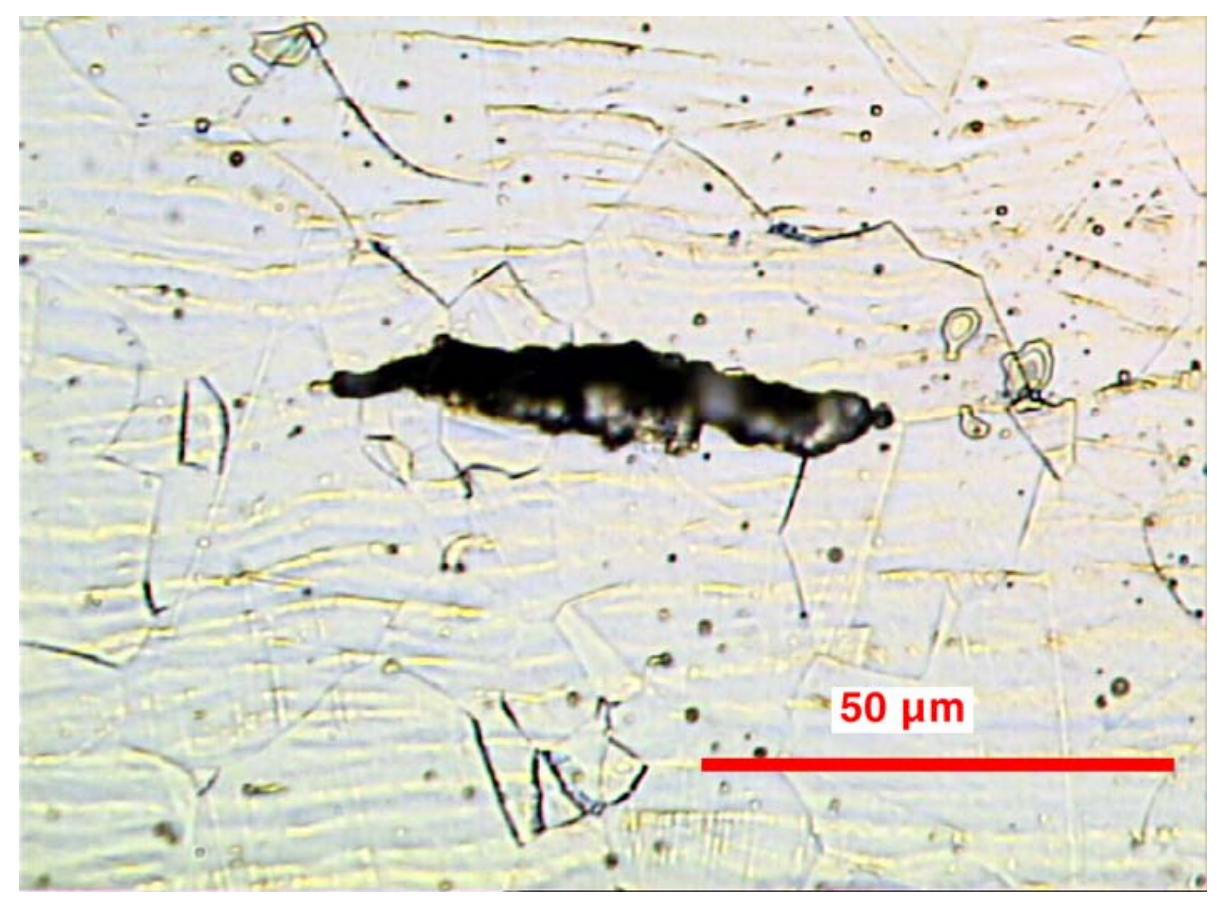

Figure 5-17

Tube 1 - Detail of the Defect in Figure 60

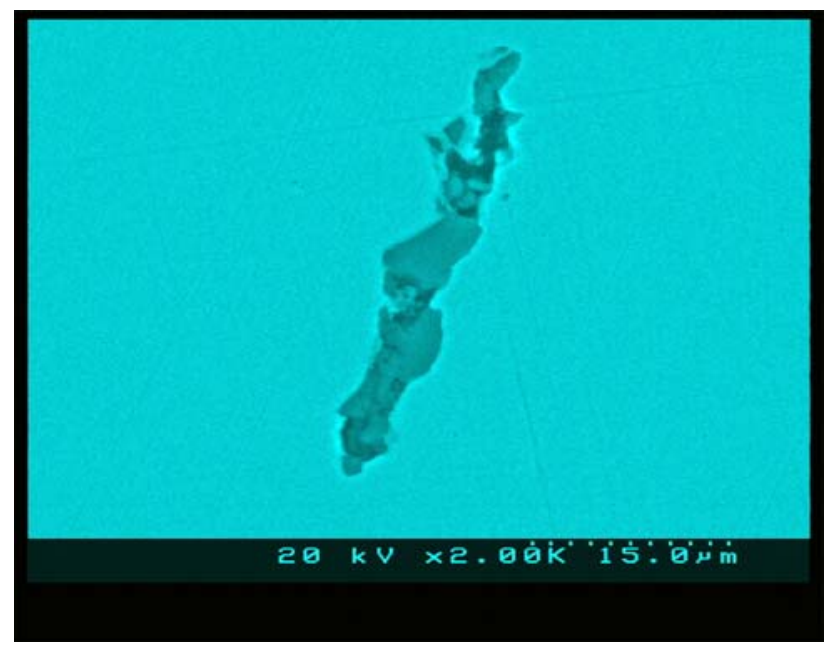

Figure 5-18

SEM Pictures of Defects in tube 1 - Outside the Welding 


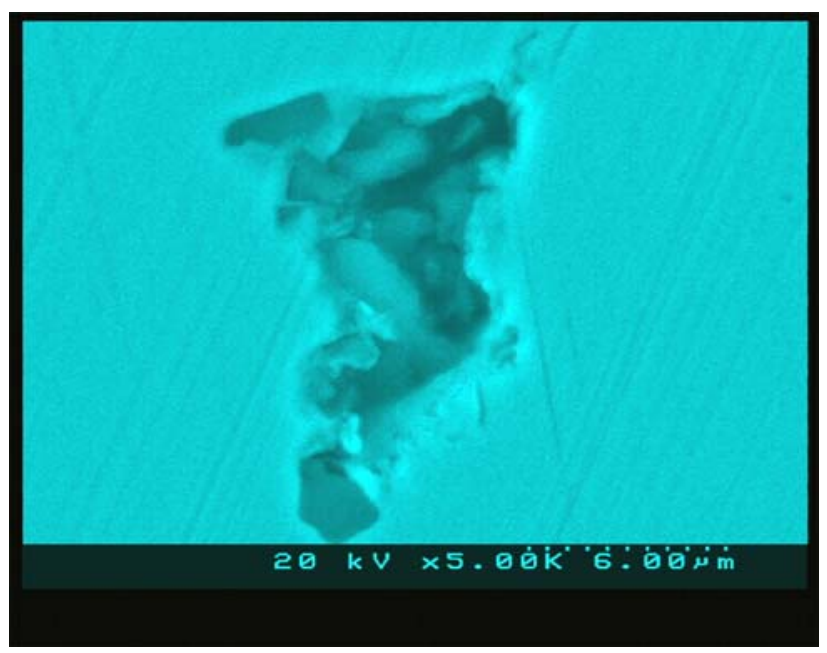

Figure 5-19

SEM Pictures of Defects in tube 1 - Outside the Corrugation Groove

\subsection{Summary and Conclusions for Leak Analysis}

Microscopic analysis of the leak locations revealed that nearly all of the leaks occur near the middle of the weld seam in the cryostat corrugations, at microcracks that were oriented parallel to the weld direction. The weld seam in correspondence to the defects has a slight depression in the middle along the weld direction probably caused by the complex flow of metal during the welding process.

In one case it was possible to prepare a metallographic sample that included a crack in its full extension. The fracture path followed a broken line, strongly indicative that the crack was formed in two steps. This suggests that the fracture may be due to the combination of a mechanical stress and a defective, weaker point in the welding region.

Some data suggests that the material might have been originally affected by anomalous hydrogen content, which would have in turn given rise to hydrogen-rich, brittle interphase boundaries during welding solidification. Incomplete fractures would then have been formed due to the mechanical stress of the corrugating process, and would eventually develop to the full thickness of the tube when further stress was applied. 


\section{6}

\section{AC LOSS TESTING}

In order to test the characteristics of the superconductor element of the cable it was decided to arrange for phase 2 to be energized at low voltage, out of the grid. Phase 1 and 3 were removed from the underground ducting and 6 copper cables installed. In the original Detroit Edison project test program it was not included an ac loss test carried out using an independent current supply. The cooling system was simplified in that saturated (boiling) liquid nitrogen was passed along phase 2 in one direction and then vented to atmosphere.

\subsection{August 2003 Tests}

The HTS cable system was to be available for 5 days for testing in the period August 4th- 8th 2003. Planned activities were as follows:

\begin{tabular}{|c|c|}
\hline Day & Planned Activity \\
\hline 1 & $\begin{array}{c}\text { 1 Cryo check out } \\
\text { DC power supply connection } \\
\text { Instrument connection }\end{array}$ \\
\hline 2 & $\begin{array}{c}\text { Cool down } \\
\text { Dc check out } \\
\text { Computer control check out }\end{array}$ \\
\hline 3 & $\begin{array}{r}\text { DC Ic measurements } \\
\text { Rewire for ac } \\
\text { Ac supply check out } \\
\text { Ac loss instrument connection }\end{array}$ \\
\hline 4 & Ac Loss measurement \\
\hline 5 & Ac Loss measurement \\
\hline
\end{tabular}

\section{Cooling}

The cable was cooled on Day \#2 of the tests without any problems. The vacuum jacket had been pumped continuously for at least a week prior to this and was pumped during test period. The cable achieved a stable temperature with an inlet pressure of 2.8bar and temperature of 86K. The saturated two phase liquid nitrogen flow, along with the high heat leak of the cryostat due to poor vacuum, conspires to produce a very complicated cryogenic system. Thermometry on the cable showed that the temperature decreased between the nitrogen inlet and outlet. At the $110 \mathrm{~m}$ point the temperature was approximately $82 \mathrm{~K}, 4 \mathrm{~K}$ lower than the inlet. This was due to the pressure gradient along the cable. As the pressure reduced towards the exit (at the 'inside' end) the 
saturation temperature decreased, liquid nitrogen would then vaporize to keep the two phase flow on the saturation line.

\section{Energization}

In order to energize the cable with dc current six 875A, 5V dc power supplies were shipped from Pirelli, Milan for connection in parallel. The dc current was to be passed along the cooled HTS cable and returned via the 6 copper cables connected in parallel. In this circuit the maximum system voltage available was 5V and maximum possible current 5250A dc

The experimental set-up is shown in Figure 6-1.

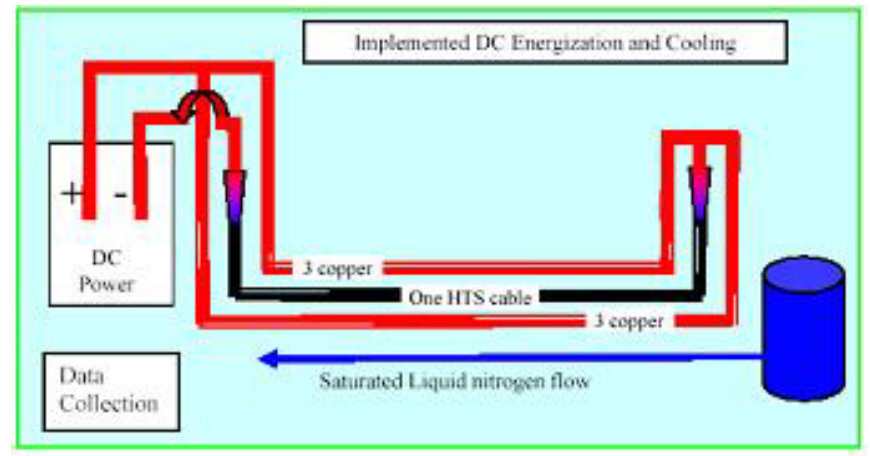

\section{Figure 6-1}

Tube 1: Outside the Welding

\section{Instrumentation}

Voltage taps were available along the cable at the $0 \mathrm{~m}, 10 \mathrm{~m}, 40 \mathrm{~m}, 70 \mathrm{~m}$ and $110 \mathrm{~m}$ points in order to pick up the generated voltage. At each point there was a pair of wires to provide redundancy in case of failure. These taps were placed during cable construction and could not be changed or adjusted in any way during the tests. The eight voltages were to be recorded using a computer controlled scanning nano-voltmeter that also was to control the six dc power supplies. Four pairs of thermometers were also placed at intervals along the cable.

\section{Tests}

Progressive failures of thermometry reduced the number of temperature data points available.

\section{Results}

Figure 6-2 shows the DC voltage cable measured at various points along the cable, all measurements are referenced to the voltage taps at ' $0 \mathrm{~m}$ '. Note that the data is taken at slightly different temperatures due to the temperature variation along the cable. Also it should be noted that all these data are the voltage difference between that point and the ' $0 \mathrm{~m}$ ' point of the cable. For example, the ' $110 \mathrm{~m}$ ' voltage includes the ‘ $70 \mathrm{~m}$ ' voltage values. The noise on these 
measurements is significant, mainly due to the electrical environment in the Frisbie substation. Given more time it would probably have been possible to collect better data. The $10 \mathrm{~m}$ and $40 \mathrm{~m}$ data seems particularly noisy.

On a $100 \mathrm{~m}$ cable the critical current level of 1 micro-volt per cm would yield $10 \mathrm{mV}$. Please note than in Figure 6-2 are plotted curves related to several tap-to-tap distance and the $10 \mathrm{mV}$ is only for the $100 \mathrm{~m}$ tap-to-tap distance.

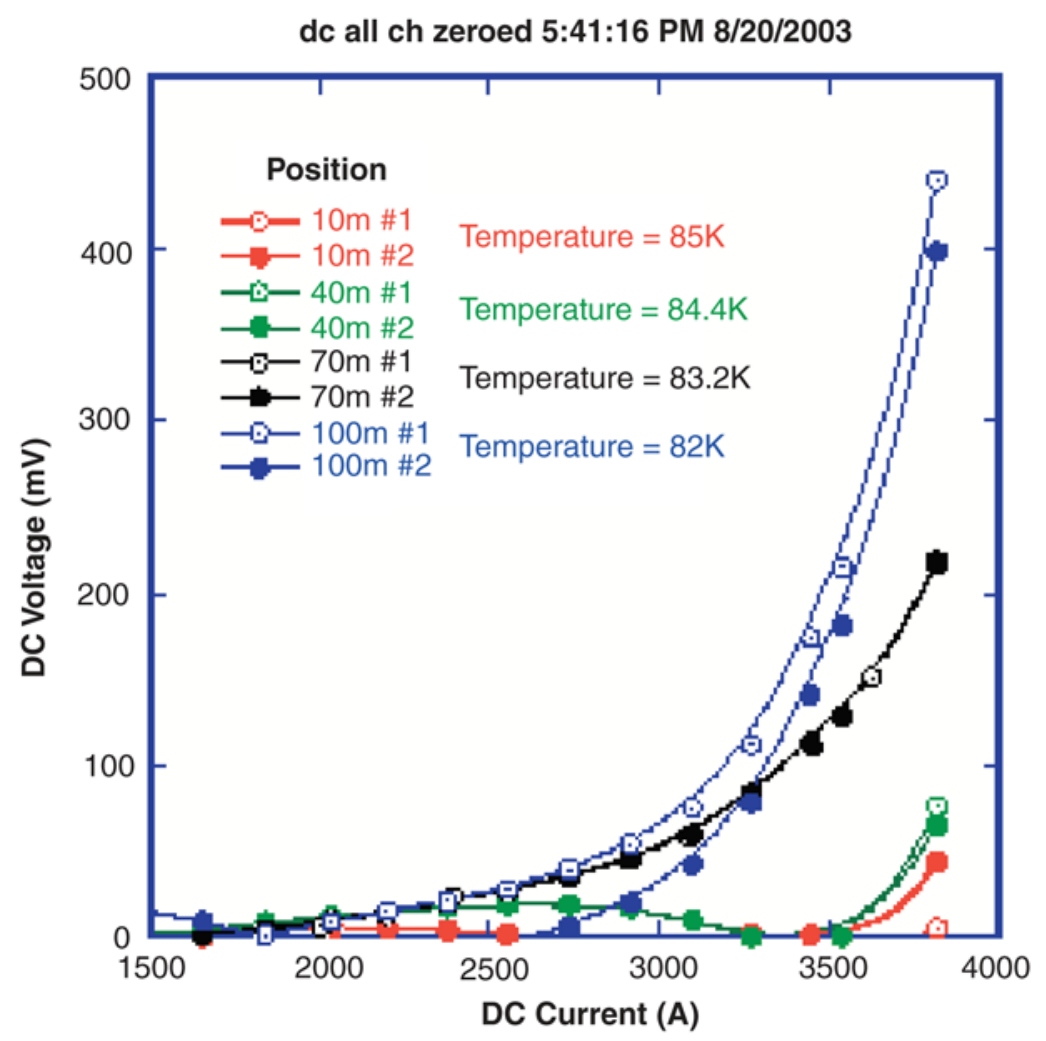

\section{Figure 6-2}

Tube 1: Detail of the Defect in Figure 6-1

Closer examination of the data presented above indicates that the critical current of the cable was approximately 2000A at this temperature range. If we scale this to $77 \mathrm{~K}$ we might expect a critical current of 2800A. There is some indication that a lower Ic region exists in the section between $40 \mathrm{~m}$ and $70 \mathrm{~m}$ (the $100 \mathrm{~m}$ and $70 \mathrm{~m}$ data show very similar behavior at currents below $2500 \mathrm{~A}$, whilst the Ic up to the 40m seems significantly smaller), but the noise in the measurement make this a tentative conclusion. Furthermore, the critical cooling condition and unfavorable LN flow surely induced inhomogeneous cable temperature distribution causing ohmic behavior also at current below the IC one, where they usually are not expected to be. During these measurements no significant change in the cable temperature was noted. 


\section{AC Energization}

The cable was energized in 3-phase configuration using the two installed "copper" phases in place of the non-operational HTS phases. The three phase conductors were connected to the low voltage side of a delta-wye transformer located at the 'outside' end of the cable. This transformer had a turns ratio of 8:1. The 'inside' ends of the three phase conductors were shorted together using a copper bus bar. This common point was linked to the neutral of the 'delta' winding of the transformer using a copper cable. This allowed the return of any imbalance current due to the non-symmetric cables configuration. The HTS cable shield was grounded at the 'outside' terminal, this was the only ground point in the circuit.

Implemented AC Energization and Cooling Scheme

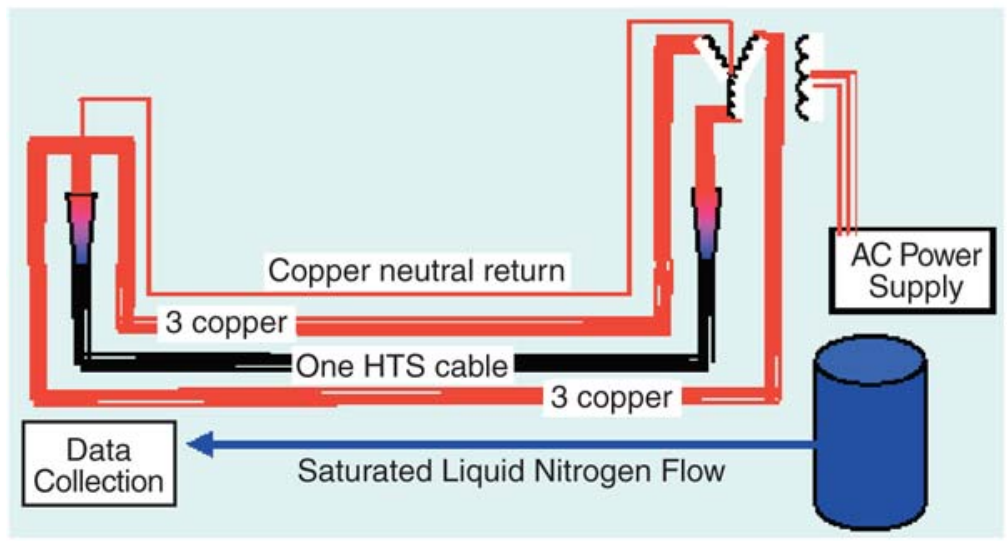

Figure 6-3

SEM Picture of Defect in Tube 1; Outside the Welding

The 'wye' side of the transformer was connected to an inverter based power supply provided by American Superconductor Corporation. This was powered by 480V, 3 phase line supply. Although the 'resistance' of the circuit is low, about $60 \mathrm{~V}$ ac was required to drive the required currents due to the inductance of the system. The outputs of this power supply were floating from ground.

\section{Instrumentation}

In order to measure the ac losses of an HTS cable it is necessary to make a 'phase sensitive' voltage measurement. This is done using a lock-in amplifier. (LIA). A LIA depends on a reference signal to provide frequency and phase information, we attempted to obtain a reference signal from a transformer placed on the HTS phase and alternatively from the resistive signal generated on the copper phases.

This reference must be a very 'clean' sine wave in order for the LIA to “lock”. The waveform from the AC power supply was highly distorted, with numerous high frequency components. Visually, the current "sine wave” had $3.5 \mathrm{kHz}$ 'spikes” superimposed (this was breakthrough from the switching frequency of the supply) and was more akin to a square wave at the $60 \mathrm{~Hz}$ frequency. Main reason of spikes was the absence of filter after the AC power supply. 
We were unable to force the LIA to lock to $60 \mathrm{~Hz}$ in the presence of so much $3.5 \mathrm{kHz}$ on the reference signal, except at the highest amplitudes. In addition the voltage returned by the LIA only makes sense as a "loss voltage" if the current waveform is a 'clean' sine wave. After considerable effort we abandoned all attempts to measure the losses electrically. It may be possible to make this measurement, but possibly a much 'cleaner' power supply would be needed.

As an alternate method to measure losses, LANL had developed a calorimetric technique. This utilized the difference in the electrical permittivity between liquid and vapor nitrogen to measure the vapor/liquid ratio in the coolant flow. In principle the energy losses could then be calculated from knowledge of the temperature and specific and latent heats of liquid nitrogen. This technique had worked well in the lab but failed in the field. The reasons for failure were twofold:

1. the extremely high background losses due to the poor thermal insulation on this cable (they were estimated to be about 2 orders of magnitude higher than the ac losses we were attempting to measure); and

2. a liquid flow impedance near to the exit of the cable, this essentially vaporized much more liquid than the ac losses and swamped and measurement.

\section{Results}

Neither of the intended ac loss measurement techniques yielded any data. During the attempts to make these methods work though, it was noticed that the cable temperature did change slightly when the ac current was applied, this was not seen during the dc tests. In Figure 69 we show the cable temperature rise at the $100 \mathrm{~m}$ point along the cable (i.e. $100 \mathrm{~m}$ from liquid nitrogen inlet).

The reason for the increase in temperature is not straightforward. The liquid nitrogen is boiling at all points along the cable, consequently an increase in temperature indicates an increase in pressure at that point. A higher pressure in the cable indicates higher viscosity in the two phase liquid flow downstream, caused presumably by a greater percentage of vapor in the flow compared to liquid - due to the higher heat input from the ac losses. In principal some estimate of the ac losses could made from this data although it is not thought to be worthwhile though as:

a. It would be very approximate; and

b. Given the distorted waveform of the current the results would not be meaningful (there are many frequency components present, most particularly the $3.5 \mathrm{kHz}$ ). We can give some minimum value for the losses. If we assume all the ac loss energy is used to raise the temperature of the two phase liquid nitrogen flow, and not to vaporize more liquid, we find losses of approximately 35W for the whole cable length at a transport current of 2500A. 


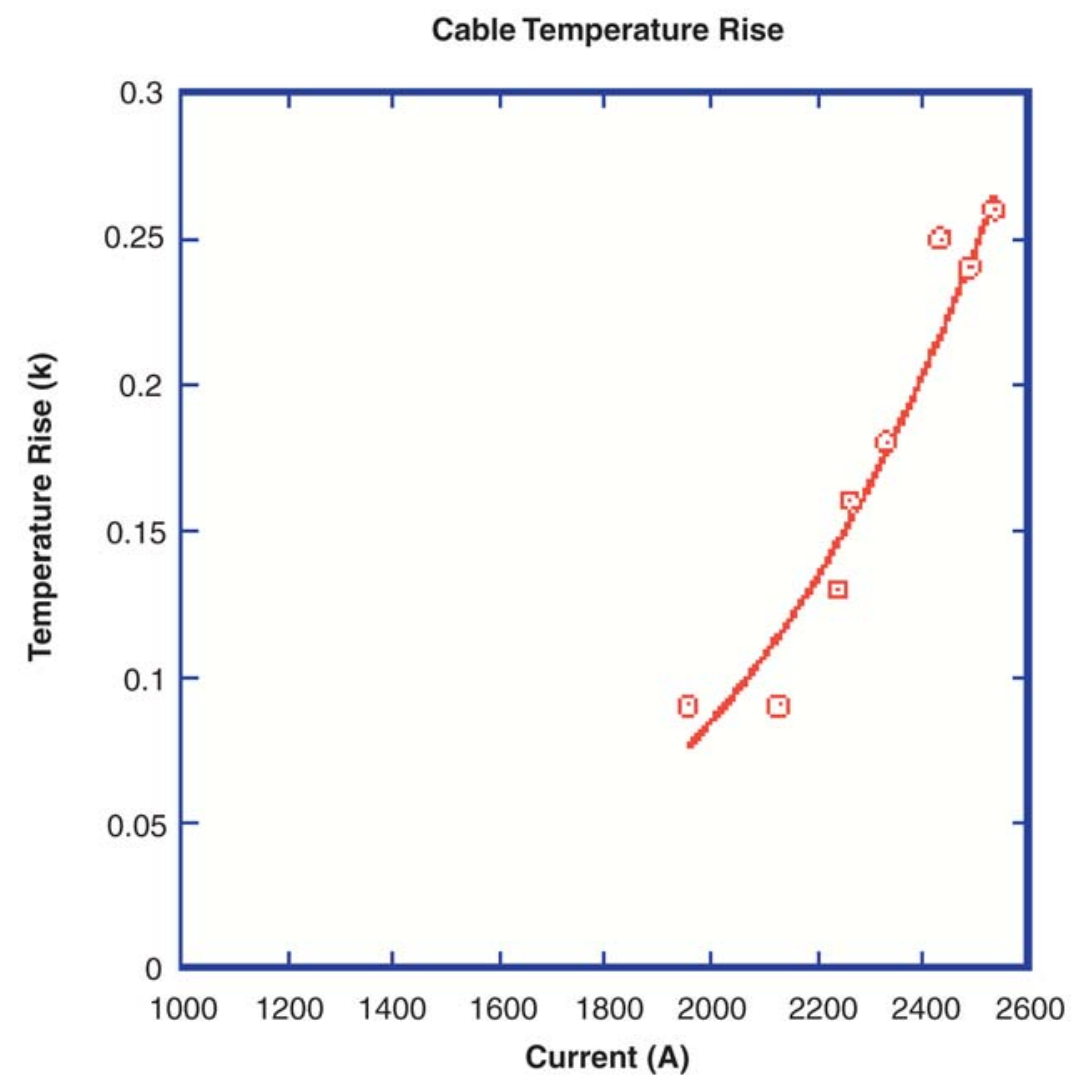

Figure 6-4 SEM Picture of Defect in Tube 1; Outside the Corrugation Groove 


\section{CONCLUSIONS FROM THE HTS CABLE DEMONSTRATION PROJECT}

Many advances were achieved during the execution of the project that have broad application to the design, manufacturing, and operation of HTS power cables. While the $24 \mathrm{kV} / 100 \mathrm{MVA}$ cable system wasn't eventually put in continuous operation on the utility network, the lessons experienced and described in this report represent a significant step forward for the understanding of many complex issues related to this subject involved and will directly impact future development efforts. The following paragraphs summarize the key advancements from this program.

\subsection{HTS Conductor}

29,000 meters of high strength, balloon-proof BSCCO tape were manufactured and tested. The mechanical characteristics of the balloon-proof BSCCO tape withstood the rigors of cable manufacturing and installation. Robust tape enables optimized cable conductor designs and tight cable bending radii and is vital to practical application of HTS power cables.

A conductor was designed employing current-sharing designs to minimize ac losses on the cable. The robust conductors allowed very shallow wire pitch angles, necessary for current-optimized designs. The low ac losses were verified in a calorimeter with three-phase magnetic interaction.

\subsection{HTS Cable}

A process was developed and demonstrated for the manufacture of long-length WD HTS power cables. The long conductor assembly demonstrated the fabrication techniques that could eventually be used for manufacturing of commercial lengths of cable. All subsequent manufacturing operations were conducted on the whole length.

An extrusion was performed over a corrugated stainless steel tube without damaging the HTS conductor. The extrusion introduced an additional technical element into the fabrication of the system, as no long length HTS cable had been previously fabricated in this manner. Factory tests to applicable cable standards confirmed that the dielectric insulation had been properly extruded extruded and that the underlying layers had kept their integrity.

\subsection{HTS Accessories}

Pre-molded accessories were designed, tested and installed for WD HTS cables. 
The demonstration system includes three outdoor terminations, three indoor terminations, an installation joint on one phase, and a repair joint on another phase. The terminations were fabricated using pre-molded silicon dielectric control sleeves. The installation joint used the same premolded silicone body as the terminations. A repair joint was installed and demonstrates a repair jointing procedure.

Among the lessons learned, it was found that vacuum bushings are not adequate in this design, to provide reliable long-term operation of the cable system. In a WD cable design, the thermal control, $\mathrm{LN}_{2}$ transfer, and vacuum transfer must all be conducted at high voltage. The technique of using vacuum bushings to meet this requirement was not adequately robust to enable commercial use.

\subsection{Installation}

The cable and associated systems were installed, as much as possible, using standard Detroit Edison personnel. The cable was installed into a rigorous route, including multiple very tight bends. While the conductor retained a very high level of its original critical current, the installation route may have contributed to the vacuum failures.

Installation plays a critical role in the final performance of the cable system and further work on this field needs to be performed to allow a commercial utilization of HTS technology for cable systems.

\subsection{Refrigeration System}

A fully-engineered refrigeration system was designed, fabricated, and commissioned. The refrigeration plant included redundant measures to ensure its reliability. The refrigerator included SCADA communication and alarming capability, hydraulic buffering systems, and could be scaled upward to meet commercial length installations of HTS cables.

\subsection{Conclusion}

The technological advances in HTS tape, conductor, accessories and cable manufacturing made during this demonstration project have represent a big step forward for HTS cable technology and will be a valuable basis for subsequent efforts to be conducted in the future. 


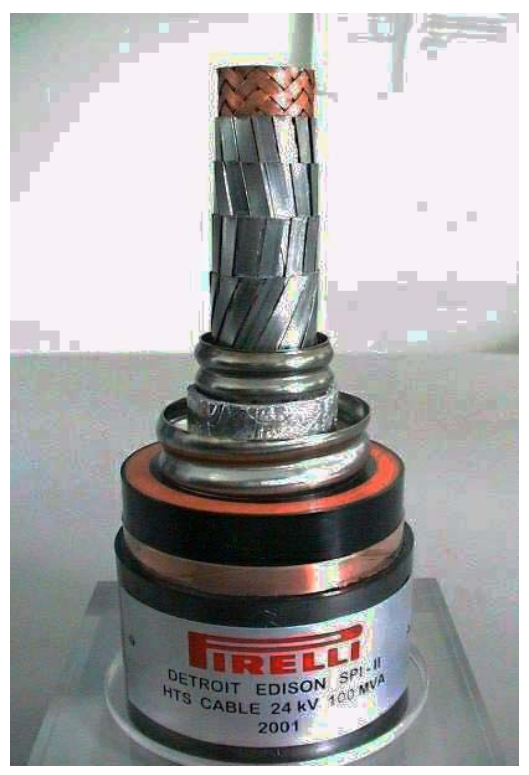

Figure 7-1

Sample of Frisbee Station HTS Cable - 24 kV

The installation of the whole system (cables, accessories, refrigeration system and control) inside a utility substation, highlighted important issues related to robustness of the full system and specific requirements of HTS technology that will be a fundamental starting point for future projects of this kind.

In particular, the experience gained on the ground regarding installation techniques and the experience gained on the ground by HTS cable system designers and by utility personnel will prove invaluable to forthcoming installations. 

